\title{
ARTICLES
}

\section{New Tax Issues Arising From the Dodd- Frank Act and Related Changes to Market Practice for Derivatives}

\author{
Erika W. Nijenhuis*
}

I. OVERVIEW OF PRODUCTS AND TAX RULES 6

A. Description of Certain Common Derivative Financial Instruments....................6

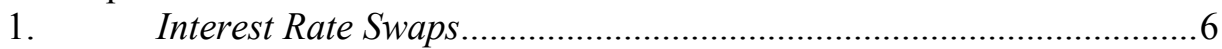

2. Options, Including Swaptions ..................................................

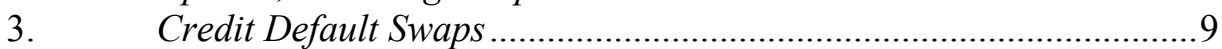

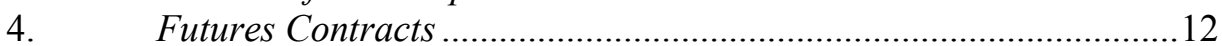

B. Overview of Taxation of Common OTC Derivatives ......................................12

1. Notional Principal Contracts ........................................................12

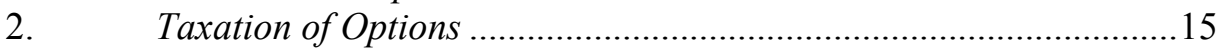

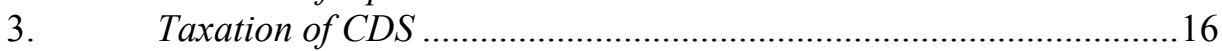

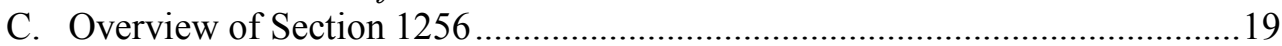

D. Overview of Other Special Tax Rules for Derivatives....................................21

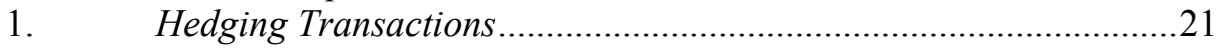

2. Mark-to-Market Rules …..........................................................23

II. DEVELOPMENTS IN THE MARKETS AND THE LAW .........................23

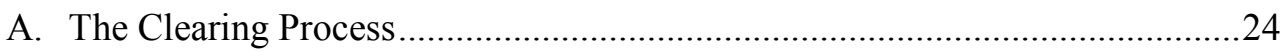

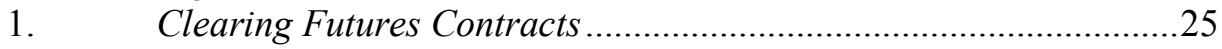

* By Erika W. Nijenhuis, a partner in the New York office of Cleary Gottlieb Steen \& Hamilton LLP. A prior version of this article, written before the amendment to $\S$ 1256 described herein, was published at 127 TAX NOTES 1235 (June 14, 2010), based on a version presented at the Tax Forum on April 5, 2010 (Paper No. 623), and will be republished in The Corporate TAx Practice Series (Practising Law Institute 2010). C Erika W. Nijenhuis. All rights reserved.

Many thanks to Biswarup Chatterjee for his assistance with Section II.C of the article, and to Donald Bendernagel, Adrienne Browning, Michael Farber, Silas J. Findley, Viva Hammer, Laura Klimpel, Andrea S. Kramer, Jeffrey Maddrey, William Paul, Larry Salva, David H. Shapiro, Diane G. Simons, Jonathan Silver and Michael Yaghmour for their comments on earlier drafts of the article.

The author advised one of the U.S. CDS clearinghouses described below on tax issues in connection with clearing CDS, and has represented the Securities Industry and Financial Markets Association and members thereof regarding the tax issues discussed in this article.

The manner in which the derivatives markets operate is complex and evolving. Every effort has been made to describe them correctly as of December 2010 by consulting with experts, but it is possible that some aspect of either market practice or the legal rules governing those instruments described herein is inaccurate, as the author is a not a banker or an expert in the non-tax rules governing these markets and instruments. Any errors are those of the author. 
2. Clearing CDS

3. Clearing Interest Rate Swaps ..........................................................

B. Summary of Dodd-Frank's Provisions Relating to Derivatives.........................33

1. Definition of "Swap" "....................................................................33

2. $\quad$ Clearing and Exchange-Trading Requirements ………....................35

3. Swap Dealers, Major Swap Participants and End-Users...................36

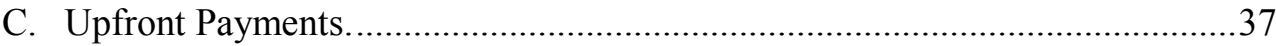

1. Standardization of Coupons - In General .......................................37

2. Standardization of CDS Coupons ……………………………............

3. Other Types of Upfront Payments ……………………………........45

III. THE DODD-FRANK AMENDMENT TO SECTION 1256 .............................46

A. Effect of Section 1256 Treatment for OTC Derivatives....................................51

1. Interest Rate Swaps and Swap Futures Contracts.............................51

2. Interest Rate Swaps and Hedges Thereof .........................................55

3. Benefits of Section 1256 Treatment ..................................................58

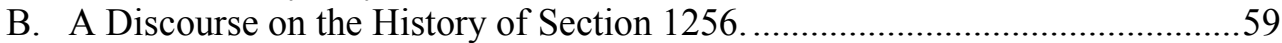

1. Construing "Regulated Futures Contract" .......................................60

2. $\quad$ The 1983 Controversy over the Scope of the RFC Definition ...........66

3. History of Foreign Currency Contracts...........................................68

4. Other Service Guidance on the Scope of the RFC Definition............71

IV. INITIAL PAYMENTS 82

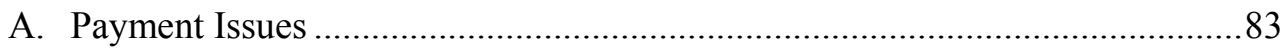

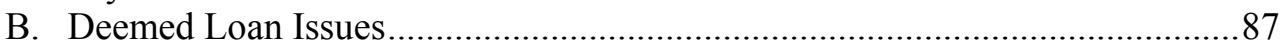

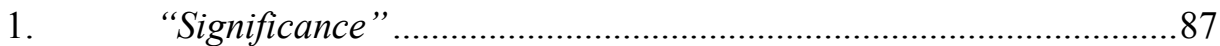

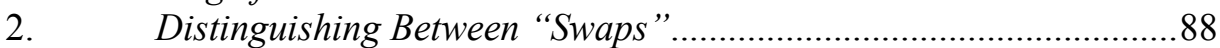

3. Special Attributes of Cleared Swaps................................................ 88

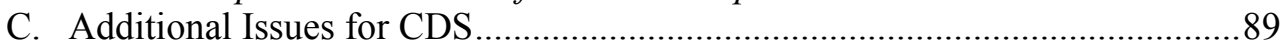

1. Do the Deemed Loan Rules Apply? ...............................................89

2. If There is a Loan, What are its Terms? .........................................91

3. What About the Proposed Swap Regulations? ………………….....93

On July 21, 2010, the Dodd-Frank Wall Street Reform and Consumer Protection Act ("Dodd-Frank") was enacted into law. ${ }^{1}$ DoddFrank mandates the most sweeping changes to the U.S. markets for derivative financial instruments in decades. This article discusses a number of U.S. federal income tax issues raised by Dodd-Frank and related changes to market practice for derivatives.

\footnotetext{
${ }^{1}$ Dodd-Frank Wall Street Reform and Consumer Protection Act of 2010, Pub. L. No. 111-203, 124 Stat. 1376. European authorities also are considering sweeping reforms of the European derivatives markets. See, e.g., Report on Derivatives Markets: Future Policy Actions, EuR. PARL. Doc. (2010), available at http://tinyurl.com/LangenReport2010; Proposal for a Regulation of the European Parliament and of the Council on OTC derivatives, central counterparties and trade repositories, EuR. COMM. Doc. (2010), available at http://tinyurl.com/OTCRegulation.

All citations to sections are to the Internal Revenue Code of 1986, as amended (the "Code"), or to the Treasury regulations promulgated thereunder, other than references to sections of Dodd-Frank or to sections of this article.
} 
As discussed in more detail in Section II.B, below, Dodd-Frank requires that most over-the-counter ("OTC") derivatives, colloquially referred to as swaps, be cleared through a regulated central counterparty (a "clearinghouse") and traded on a regulated exchange. Historically, OTC derivatives generally have been taxed under the conventional realization method of accounting used for stocks, bonds and other securities, while exchange-traded derivatives generally have been taxed under the special rules of $\S 1256$. Section 1256 generally requires that contracts within its scope be marked-to-market on an annual basis, and provides that gain or loss from such contracts is capital gain or loss with a $60 \%$ long-term and $40 \%$ short-term holding period. The most obvious tax question raised by Dodd-Frank, therefore, is whether the migration of OTC derivatives onto exchanges will cause them to become subject to $\S 1256$.

At the very last hour of Dodd-Frank's marathon progress through Congress, this issue was partially addressed through the adoption of an amendment to $\S 1256$ that clarifies that certain types of OTC swaps will not become subject to $\S 1256$. Notwithstanding this amendment, many questions remain, as the scope of the amendment is not clear. In addition, decisions still to be made by regulators and the market as to how derivatives will be traded are likely to affect the impact of the amendment. Factors that may be relevant include (i) which swaps will migrate onto exchanges when; (ii) the effect of what appears to be a forthcoming wider range of products offered by exchanges that constitute "futures contracts" that may compete with swaps; (iii) whether swaps will be traded on traditional securities and commodities exchanges or instead on "swap execution facilities," a new type of exchange created by Dodd-Frank; (iv) whether end-users will choose to clear the swaps they enter into; and (v) where the line between "bespoke" swaps not required to be centrally cleared and traded and standardized swaps subject to those requirements will be drawn. Those issues generally are outside the scope of this article, but they are briefly adverted to in connection with a discussion of possible guidance on the scope of the $\S 1256$ amendment.

This article discusses a range of possible interpretations of the Dodd-Frank amendment to $\S 1256$, and argues in favor of an interpretation that the amendment covers all notional principal contracts and possibly certain closely related contracts. The article also urges that the Treasury Department and Internal Revenue Service ("Treasury" and "the Service," respectively) provide prompt guidance on this issue, because the scope of the amendment affects not only OTC derivatives that migrate in the future to regulated clearing and trading, but potentially also certain kinds of swaps that were being cleared by a central counterparty prior to Dodd-Frank. ${ }^{2}$

\footnotetext{
${ }^{2}$ The current Treasury/IRS "business plan" for the 2010-2011 year includes an item described as "Guidance on the application of $\S 1256$ to certain derivative contracts." Department of the Treasury, Office of Tax Policy, and Internal Revenue Service, 2010-2011 Priority Guidance Plan (Dec. 7, 2010), available at http://www.irs.gov/pub/irs-utl/20102011_pgp.pdf. Comments by government officials indicate that this item relates to the Dodd-Frank amendment. See Amy Elliott, IRS May Restrict Definition of Swap to Notional Principal Contracts (Dec. 15, 2010), 2010 TNT 240-3; Diane Freda, IRS May Hold to Narrow View of Futures Under Dodd-Frank Wall Street Reform (Dec. 15, 2010), 239 DTR
} 
The article also suggests some further amendments to the Internal Revenue Code that could alleviate pressure on the guidance process.

The second set of tax issues addressed by this article are those stemming from the fact that the move towards regulated clearing and trading has and can be expected to have the effect of increasing substantially the number of swaps that are entered into, or deemed entered into, with upfront payments. In the OTC markets, most swaps were entered into at-market - that is, with payments required to be made at the thenmarket level - so that it was relatively rare for a swap to have an upfront payment. (This is not true for options, of course, or for certain specific types of swaps.) Because centralized clearing both requires and encourages standardization of terms and a ready ability to transfer contracts from one party to another, the move towards centralized clearing results in more frequent upfront payments or possible deemed upfront payments between swap parties.

There are long-standing rules governing the treatment of upfront payments on swaps that are classified as "notional principal contracts" ("NPCs"). Under those rules, such a payment can give rise to a debt obligation between the parties if the payment is "significant." This issue is of relevance because a deemed loan would give rise to deemed interest income on the debt instrument, which interest would be subject to reporting, withholding and other U.S. federal income tax rules applicable to debt instruments. The existence of a deemed loan might also raise issues under $\S 956$ for some taxpayers. ${ }^{3}$

The treatment of significant upfront payments on interest rate swaps and most other swaps as deemed loans for U.S. federal income tax purposes is a rule that has been on the books for many years, but has not in practice affected most actual OTC contracts. Thus, for most swaps, taxpayers' concerns now have to do with the substantial expansion of an existing regime. These concerns are partly legal—primarily that current law does not provide clear rules for when a deemed loan arises, and does not take into account the special characteristics of centrally cleared swapsand partly practical, because compliance in a world in which significant upfront payments may be the rule rather than the exception would require taxpayers to modify reporting and withholding practices, and to develop automated systems to distinguish between NPCs and options and other types of derivatives not subject to the deemed loan rules.

G-3, available at www.bna.com; John Herzfeld, Guidance on Section 1256 Contracts Under Study, IRS Legal Official Says (Oct. 25, 2010), 204 DTR G-2, available at www.bna.com.

${ }^{3}$ These issues are briefly discussed in a submission made by the Securities Industry and Financial Markets Association ("SIFMA") in a letter to Treasury and the Service requesting guidance on these issues, in particular the potential application of $\S 956$ to deemed loans arising from large initial premium payments on credit default swaps. See Letter from SIFMA to Steven A. Musher, Associate Chief Counsel (Int'1), IRS (May 26, 2009), reprinted in 1 Taxation of Financial Products and Transactions 2010, Ch. 1 (Practising Law Institute 2010). The author and one of her partners represented SIFMA in preparing that letter. 
For credit default swaps ("CDS"), there are very significant uncertainties as to whether these rules apply at all, and if so how they apply. The question of whether a deemed loan or deemed interest arises under current law as a result of a large initial premium on a standard coupon CDS cannot be answered without first answering the question of whether a CDS is properly characterized as an option or NPC. As that issue is unclear under current law and has been exhaustively discussed elsewhere, this article focuses instead on whether, assuming that a CDS is properly treated as an NPC, current law could deem one CDS counterparty to lend money to the other in a transaction treated for U.S. federal income tax purposes as giving rise to indebtedness.

Finally, as noted above, the application of $\S 956$, which can have career-ending consequences, could potentially be vastly expanded. This would be unfortunate, to say the least, given that the context is one in which there is no policy reason for $\S 956$ to apply because any upfront payment made under a cleared swap is immediately offset as a cash flow matter by an equivalent amount of cash collateral.

It seems fair to expect the government to clarify the rules as to when a deemed loan arises before taxpayers build the necessary systems to track them. And it seems reasonable to hope that the government would clarify that it would not choose to apply $\S 956$ in the offsetting payment case described above.

This article therefore recommends a number of areas in which the Treasury and Service should provide guidance before taxpayers make the investment to build such systems, including (i) clarifying whether and how the rules apply to centrally cleared swaps, (ii) how a deemed loan that arises when a "significant" upfront payment is made on an NPC should be taken into account for a centrally cleared swap, (iii) more detailed guidance on when an upfront payment is "significant", and (iv) whether credit default swaps are subject to these rules. In the interim, regulatory guidance could be provided in the form of a Notice stating that nonperiodic payments on swaps, including CDS, will not be treated as investments in United States property for $\S 956$ purposes to the extent that they are immediately as a contractual or legal matter offset by an equivalent amount of cash, absent abuse, and a Revenue Procedure stating that the Service will not take the position that taxpayers are obligated to treat upfront payments on CDS as deemed loans until guidance is issued to that effect or on other swaps until the meaning of the term "significant" is clarified, again absent abuse. Legislative amendments could address the $\S 956$ issue by adding a reference to cash collateral in $\S 956(\mathrm{c})(2)(\mathrm{J})$, and by stating an expectation in legislative history that the Service will act as described in the second half of the preceding sentence.

Part I of the article provides an overview of the financial products discussed herein and the tax rules currently applicable to OTC derivatives and under $\S 1256$. Readers familiar with these products and rules can skip over or skim this part of the article. Part II of the article discusses DoddFrank and other changes to the law and market practice for derivatives. Part III of the article then turns to the $\S 1256$ issue, and Part IV of the 
article discusses the issues arising from upfront payments on centrally cleared swaps.

\section{OVERVIEW OF PRODUCTS AND TAX RULES.}

As noted above, OTC derivative financial products historically have been subject to the conventional realization method of accounting. When applied to derivatives, those rules can become quite complex, as the basic rules have been overlaid with a hodgepodge of special rules intended to take into account the fact that many derivative financial products resemble, or are comprised of, other such products, the liquidity of many derivatives, and their widespread use as hedges for business risks. Part I briefly describes several derivatives that will be referred to throughout this article and the basic rules applicable to them, as well as some discussion of special hedging and mark-to-market rules affecting derivatives. Part I also provides an overview of the rules of $\S 1256$.

A. Description of Certain Common Derivative Financial Instruments.

1. Interest Rate Swaps. Probably the most common type of swap is an interest rate swap. Under the terms of a standard interest rate swap, one party agrees to pay amounts determined by reference to a fixed rate, e.g., $6 \%$, and the other party agrees to pay amounts on the same payment dates determined by reference to a floating rate, usually the London Interbank Offered Rate ("LIBOR"). Both payments are determined by multiplying the applicable rate by the same "notional principal amount," a hypothetical amount used to determine the parties' payment obligations but that is not paid or otherwise transferred between the parties. The sole payments on an at-market interest rate swap are these periodic payments, which typically are made semi-annually, and are netted so that only the difference between the fixed and floating amounts is paid.

Interest rate swaps are widely used to hedge interest rate risks, for example by an issuer that issues debt or a company with assets or non-debt liabilities that are interest rate-sensitive. Because the cost of money is so fundamental an economic factor, and because different parts of the fixed income market operate on the basis of different rate bases, the interest rate swap markets are very liquid, very competitive, and very large. According to the most recent authoritative market survey, there are over a hundred trillion dollars (notional principal amount) of U.S. dollar-denominated interest rate swaps outstanding. ${ }^{4}$

\footnotetext{
${ }^{4}$ The Bank for International Settlements reported $\$ 347.5$ trillion notional principal amount of interest rate swaps outstanding globally at the end of June 2010 . While there is no break-out of U.S. dollar-denominated interest rate swaps, if such swaps represented the same percentage of total interest rate swaps as U.S. dollar-denominated interest rate derivatives represented of all interest rate derivatives, there would be about $\$ 126$ trillion notional principal amount of U.S. dollar-denominated interest rate swaps. Karsten von Kleist \& Carlos Mallo, Bank for Int'l Settlements, Triennial and SEmiannual Surveys: Positions in Global Over-The-Counter (OTC) Derivatives Markets at End-June 2010, 16, 18 tbls. 1 \& 3 (Nov. 2010), available at www.bis.org/publ/otc_hy1011.pdf.
} 
A foreign currency swap is similar to an interest rate swap, except that one party's payments are denominated in and determined by reference to one currency and the other party's payments are denominated in and determined by reference to a second currency. The payments are both fixed rate, and the parties will exchange the principal amount at the end and sometimes at the beginning of the transaction. A swap may combine interest rate and foreign currency risk by providing for the payments in one or both currencies to be based on that currency's appropriate floating rate, e.g., Party $A$ pays 6 percent x $\$ 100$ million notional principal amount and Party $B$ pays a yen floating rate on an amount of yen equivalent at the inception of the trade to $\$ 100$ million. Another common type of foreign currency derivative used to hedge currency risk is a foreign currency forward contract, which generally is a relatively short-term instrument that provides at maturity for a payment determined by reference to the change in value of two specified currencies.

An interest rate swap entered into with at-market terms will not have an upfront payment. An interest rate swap entered into with offmarket terms, for example with a $5 \%$ rate when the market is $6 \%$, generally will have an upfront payment compensating the party receiving the belowmarket payment (or paying an above-market payment). For example, if a taxpayer wishes to hedge a $\$ 100$ million debt instrument that it has issued with a 5\% coupon into an effective floating rate instrument, it will enter into an interest rate swap with a dealer under which it receives 5\% x $\$ 100$ million and pays LIBOR x $\$ 100$ million on the interest payment dates for the debt instrument. In addition, the dealer will make an upfront amount to the taxpayer equal to the present value of the foregone stream of $1 \%$ payments $(6 \%$ minus $5 \%)$ over the life of the swap.

As with other swaps, the market for interest rate swaps historically has been the "over-the-counter" market. The OTC market is a modern version of the historic market as a place where parties come to buy and sell their wares. Unlike the historic wares offered in securities and other markets, an OTC derivative is a contract, negotiated by and entered into between two parties, typically pursuant to standard documentation made available by the International Swaps and Derivatives Association ("ISDA"). An OTC derivative remains for its life a private bilateral contract. This private aspect of OTC derivatives had considerable consequences when the credit crisis arose.

The principal information publicly available about outstanding OTC derivatives is derived from the published financial statements of swap dealers, and from reports by industry organizations, regulators and credit rating agencies. This public information reflects aggregated information at a high level. Bank regulators and other regulators of major swap participants have access to more information as part of their regulatory oversight, but no one regulator or government agency has a complete picture of the market. Moreover, some major participants in the market have been essentially unregulated or very lightly regulated, most notably AIG Financial Products ("AIG FP"), an affiliate of a major insurance company, which for many years was a very large player in the credit default swap ("CDS") market. Hedge funds, which are also major market 
participants in the swap market, are also largely outside the scope of regulatory oversight.

One other important characteristic of the historic swap market is that while customers generally are required to provide collateral to secure a dealer's credit exposure to the customer, some highly rated participants in the market such as insurance companies were not required to provide collateral to their counterparties unless their credit rating dropped below a specified level. AIG FP, for example, apparently fell into the latter category; as a result, when doubts arose as to its ability to pay and a credit downgrade appeared imminent, those doubts were reinforced by the realization that AIG FP would be required to post billions of dollars of collateral to its counterparties that it did not have.

Unfortunately, AIG FP was also a hugely significant player in the CDS market, so that the potentially disruptive consequences of its demise led to the universal conclusion, at least by governments, that CDS and other swaps must be brought into a comprehensive regulatory scheme. The nearcollapse of AIG-FP was thus one of the more significant reasons for the enactment of Dodd-Frank. (It is ironic in this regard that, at least in the view of some observers, the CDS trades entered into by AIG FP were highly customized CDS on asset-backed securities, in enormous size, of a kind that are not currently clearable and, it appears, will not be required to be cleared or traded under Dodd-Frank.)

2. Options, Including Swaptions. Options come in a number of different forms. In a conventional option to purchase (or sell) property, one party, typically called an "option writer" or "option grantor," grants to another party, an "option holder" or "option purchaser," the right but not the obligation to compel the option writer to deliver (or purchase) designated property for a particular price (the "strike price") prior to the option's expiration. In exchange for this right, the option holder pays a premium, typically, though not necessarily, in the form of an up-front payment. The premium may also be paid over time, usually in equal amounts, although this is less common in the securities markets.

The options described in the preceding paragraph are physically settled options - that is, they are written for the sale or purchase of a designated item of property which, if the option is exercised, is delivered or purchased by the writer, and purchased or sold by the holder. Options may also be cash settled, defined under the Code as "any option which on exercise settles in (or could be settled in) cash or property other than the underlying property." They may also be "net share settled" if the underlying property is shares of stock, in which case the option writer will deliver shares equal in value to the difference between the value of the underlying shares and the option's strike price. ${ }^{6}$

\footnotetext{
${ }^{5}$ I.R.C. $\S 1234(c)(2)(2010)$.

${ }^{6}$ For example, assume that A writes a call option on 100 shares of X pursuant to which B has the right to purchase those shares within the next year for a strike price of $\$ 10 /$ share $(\$ 1000)$. At the end of the year, the $X$ shares are trading for $\$ 12 /$ share. The option may be settled by (i) A delivering 100 shares to B in exchange for $\$ 1000$ (physical
} 
A "swaption" is an option to enter into a swap with the terms provided for in the option. For example, a swaption might provide the holder the right within the next three months to enter into a 5-year interest rate swap under which the holder would pay semi-annual fixed coupons at a $5.5 \%$ rate versus LIBOR, on a notional principal amount of $\$ 1$ million. A swaption is a common type of derivative in the interest rates market. Like other options, a swaption may be physically settled, in which case the parties will enter into the designated swap, or may be cash settled, in which case the option writer will pay the option holder an amount equal to the excess of the value of the swap over a similar swap with then-current market terms. A forward-starting swap is similar, except that it is a forward contract to enter into a swap with specified terms rather than an option to do so.

3. Credit Default Swaps. A conventional single-name CDS is a financial contract to transfer credit risk with respect to debt instruments, such as bonds or loans, of a single named issuer (the "reference entity"), typically for a five-year term. Like other swaps, CDS in the OTC market are generally documented using the standardized documentation for derivatives transactions developed by the International Swaps and Derivatives Association ("ISDA"). ${ }^{7}$ CDS are commonly used to hedge the risk of owning bonds or loans of a particular issuer, termed the "reference entity," or other credit risk to that reference entity. CDS also are widely used to take on credit risk, whether of a particular issuer or a segment of the fixed income market. Like all of the other financial instruments described above, therefore, they can be used either to reduce risk or to create it. The merits or demerits of that state of affairs is outside the scope of this article.

The parties to a CDS contract are referred to as the "protection buyer" and the "protection seller." The contract frequently but not invariably refers to a specific senior debt instrument (the "reference obligation") of the reference entity. ${ }^{8}$ The protection buyer makes one or more payments to the protection seller based on a specified notional principal amount. Ordinarily the payments take the form of a stream of periodic payments in a fixed amount, generally referred to as fixed or "premium" or coupon payments.

settlement, or "gross" physical settlement), (ii) A paying B \$200 (\$1200 value of X shares minus $\$ 1000$ strike price), or (iii) A delivering $16 \mathrm{X}$ shares plus $\$ 8$ of cash to $\mathrm{B}$ (net share settlement; the $\$ 8$ is the cash value of a 0.67 fractional share).

${ }^{7}$ The ISDA website is a font of information about swaps in general. It includes standardized documentation for many different kinds of swaps, including not only the core transactional documentation (the ISDA Master Agreement and a form of Schedule to the Agreement) but also standardized definitions, credit support documents, and related information. See ISDA, http://www.isda.org (last visited Dec. 30, 2010).

${ }^{8}$ An electronic data vendor active in the CDS market offers a standardized list of reference obligations for approximately 3000 reference entities. See Markit, MARKIT CrEDIT INDICES: A PRIMER (Oct. 2010), http://www.markit.com/assets/en/docs/products/data/indices/credit-indexannexes/Credit_Indices_Primer_October\%202010.pdf (last visited Dec. 31, 2010) Markit also provides a wide range of market information about CDS and many other kinds of derivatives. 
The protection seller in turn agrees that in the case of a default on the reference obligation, or in the case of other specified credit events indicating a decline in the creditworthiness of the reference entity, it will buy from the protection buyer an obligation of the reference entity for its face value ("physical settlement," by delivery of a "deliverable obligation") or will make a cash payment to the protection buyer in an amount that represents the decline from par in the fair market value of such an obligation as a result of the credit event ("cash settlement," by reference to the value of a "valuation obligation"). ${ }^{9}$ The protection buyer is not required to have suffered a loss on, or to have owned, any obligation of the reference entity at any time in order to receive payment. In the case of cash settlement, a valuation obligation's fair market value is determined through bids from dealers in that obligation under standard procedures. While market practice has evolved over time, cash settlement for CDS (technically, auction settlement) is now the norm.

Prior to the standardization process described below, there were a number of common variations in the terms of conventional CDS, depending on a number of factors including the nature of the reference entity and the local CDS market. Such variations included the list of credit events (some CDS included a "restructuring" credit event, which in turn had multiple definitions used in different contexts), whether they provided for physical or cash settlement, and various mechanics and critical dates such as the termination date of the CDS. One of the most important variations in terms related to the coupon on a single-name CDS. Broadly speaking, the coupon on a single-name CDS was determined at the time the parties entered into the contract, in much the same way that the coupon on a newly-issued bond would be determined. (This process is described in more detail in Section II.C, below.) Consequently, the coupon on a CDS on a particular reference entity entered into on any given day could and generally did differ from the coupon on an otherwise identical CDS entered into on a different day. Similarly, while the most common tenor for CDS was five years, the clock started running when the parties entered into the CDS, so that there were no standardized maturity dates. ${ }^{10}$

As described above, the Fed did not wait for the enactment of Dodd-Frank in order to initiate the restructuring of the CDS market. This initiative has led to dramatic changes in the CDS market, notably (i) a reduction in the outstanding amount of CDS through an industry-wide process of netting CDS entered into by multiple dealers against each

9 More technically, the determination of whether a credit event has taken place is determined by reference to any "Obligation" of the reference entity, which term includes but need not be limited to the reference obligation.

The text simplifies the description of CDS settlement provisions in a number of ways. Prior to the "Big Bang" discussed infra note 12, the legal terms of single-name CDS in the U.S. markets generally provided for physical settlement, although I understand that in practice the parties usually agreed to cash settlement when a credit event arose. Since the "Big Bang," auction settlement - that is, cash settlement where the cash price is determined via an auction run by ISDA - has become the standard form of settlement for most CDS.

${ }^{10}$ The coupons and maturities of CDS on indices of reference entity obligations, e.g., bonds or loans, were more standardized. For a brief description of CDS of this kind, see infra note 73 . 
other, ${ }^{11}$ (ii) the standardization of terms for conventional CDS, and (iii) the initiation of clearing of CDS. These initiatives were an outgrowth of, or a continuation of, earlier Fed efforts to improve the workings of the CDS market.

The industry-wide netting process began in the fall of 2008. It was referred to as "portfolio compression," and made evident the difficulties of trying to net CDS transactions against each other when they had different terms.

The standardization of terms took place in several steps pursuant to a process led by ISDA starting in the spring of 2009. ${ }^{12}$ For parties who have adhered to the relevant protocols, the result is that CDS entered into since that time have standard terms, including standard coupons (100 basis points or 500 basis points, for CDS on North American corporate reference entities), maturities, settlement mechanisms, definitions and many other mechanically and economically significant terms. ${ }^{13}$ Standardization is discussed in more detail in Section II.C.2, below.

${ }^{11}$ A Fitch report released in 2009 indicates that outstanding notional principal balance of credit derivatives fell in 2009, for the first time since Fitch began keeping track in 2003. Fitch Ratings, Credit Market Research, Global Credit Derivatives SurVey: Surprises, Challenges And the Future 5 (Aug. 2009) (hereinafter “Fitch Report"). The report attributes the decline to collective efforts of market participants and regulators to reduce notional outstandings by compressing trades, as well as the virtual absence of new structured credit deals. The report also notes that the market is now dominated by singlename CDS and index CDS, with a decline in CDS relating to outstanding collateralized debt obligations and other complex products.

12 The most significant of these steps was the "Big Bang," meaning the implementation of a protocol amending ISDA's 2003 Credit Derivatives Definitions (which are part of the ISDA standard documentation for a CDS) to provide for the establishment of (i) committees empowered to make final decisions about contract interpretation issues including with respect to credit events, settlement procedures and acceptable deliverable obligations; (ii) a standardized CDS settlement procedure; and (iii) a standard look-back window during which a party can claim the occurrence of a credit event or other relevant event, resulting in a standard effective date for CDS transactions. While adherence to the protocol was voluntary, it was widespread. See ISDA, ISDA Announces Successful Implementation of 'Big Bang' CDS Protocol; Determinations Committees and Auction Settlement Changes Take Effect (Apr. 8, 2009), http://www.isda.org/press/press040809.html (over 2000 parties adhered to the new protocol by the time it closed on April 7, 2009). A "Small Bang" protocol was made available a few months later. Adoption of these protocols had the effect not only of setting market standards for new CDS but also of amending old CDS between adhering parties.

${ }^{13}$ The standardization of coupons was not hardwired into documentation like the Big Bang Protocol. Instead, ISDA announced that starting in April 2009 a new contract for CDS on North American corporate issuers with standardized terms would be introduced. The new contract would (a) provide for a 100 basis point coupon for investment grade credits and a 500 basis point coupon for high yield credits, (b) provide a calendar of quarterly scheduled termination dates, (c) eliminate Restructuring as a credit event, and (d) modify the accrual start date for coupons and provide that all coupons, including the first coupon, would be paid as full coupons regardless of whether the parties entered into the CDS in the middle of a coupon accrual period (similar to buying a bond with pre-issuance accrued interest). These changes were expected to be the primary method for trading North American corporate CDS going forward. Unlike the Big Bang Protocol, these changes did not affect historic trades, although parties were free to amend existing trades to conform to those terms. 
Finally, the third of these steps was the initiation of clearing of standardized CDS in the fall of 2009. The clearing process is described in more detail in Section II.A.2, below.

4. Futures Contracts. Futures contracts are among the oldest types of derivative financial instrument. Historically, a futures contract was a contract for the sale of a specified amount of grain or another agricultural commodity, of a specified grade, for delivery at a date several months later. They were developed in order to allow farmers and commodity purchasers to hedge their price risk between the date the contract was entered into and the delivery date. Historically they have in practice been very short-dated, with liquidity centered in contracts with a remaining term of one month, two months and three months. In recent decades, the risk classes underlying futures contracts have broadened dramatically, and now include foreign currency, oil and gas and other energy products, metals, stock indices, interest rates, emission allowances and other "environmental" products, real estate indices, and weather indices.

Unlike OTC derivatives, futures contracts are traded on commodities exchanges. Thus, a party who wishes to enter into or close out a futures contract does so on a public market where participants can see every trade. Futures contracts are also subject to clearing through a central counterparty, which results in the clearinghouse becoming the counterparty to every trade. This process is described in more detail in Section III.A.1, below. Clearing is a way of managing credit risk. It also makes it very easy to close out transactions, so that futures contracts in active maturities are very liquid. Dodd-Frank's reforms of the derivatives market are intended to expand the transparency, credit risk management and liquidity of the futures markets to include what have been to date OTC derivatives.

These features come at a price, of course-it can be more expensive to transact through the futures markets than the OTC market, and market participants may prefer to negotiate their trades without the full spotlight of the market on them. The latter point has led to a sort of hybrid contract in recent years, in which parties negotiate a contract privately and then submit it to a central counterparty (a clearinghouse that may or may not be associated with a particular exchange) for clearing. That is, such contracts are centrally cleared but not exchange-traded. Energy swaps and CDS are perhaps the most active contracts of this kind.

\section{B. Overview of Taxation of Common OTC Derivatives.}

1. Notional Principal Contracts. An interest rate or foreign currency swap of the kind described above is a "notional principal contract," or NPC. Although technically a different set of timing and character rules apply to interest rate swaps than foreign currency swaps, those differences are not significant for purposes of this discussion. The term "notional principal contract" is a tax term of art. The closest term used by non-tax lawyers is "swap," but there are swaps that do not qualify as NPCs. To further confuse matters, the NPC timing regulations described below classify NPCs into swaps, caps and floors. 
The term "notional principal contract" or variants on that term are defined in several places in the Code and regulations. ${ }^{14}$ The only comprehensive definition of the term is in Treasury Regulation $\S 1.446-3$, which provides timing rules for NPCs. It defines an NPC as "a financial instrument that provides for the payment of amounts by one party to another at specified intervals calculated by reference to a specified index upon a notional principal amount in exchange for specified consideration or a promise to pay similar amounts." 15 Because this definition is very broad, the regulation goes on to exclude from its scope a section 1256 contract, a futures contract, a forward contract, an option and debt. Accordingly, if a swap constitutes a section 1256 contract or an option, it cannot be an NPC for purposes of these timing rules.

A cap or floor is a series of options, for example a contract to make a payment on any interest payment date over a specified number of years if market interest rates rise above $\mathrm{X}$ percent, equal to [the market rate minus $\mathrm{X}$ percent] times a notional principal amount.

The regulations classify payments under NPCs into three categories: periodic payments, like coupons; nonperiodic payments, such as an upfront payment; and termination payments, which generally are payments to extinguish or assign all or part of an NPC. Technically, a nonperiodic payment is any payment other than a periodic payment or a termination payment.

Periodic payments are deductible or includible on a current accrual basis. ${ }^{16}$ Termination payments are taken into account in the year in which an NPC is extinguished, assigned or exchanged. ${ }^{17}$

Nonperiodic payments are subject to more complicated rules that are conceptually similar to the OID rules but operate differently. In order to prevent front-loading or back-loading of payments under an NPC, the regulations require that taxpayers recognize a nonperiodic payment "over the term of a notional principal contract in a manner that reflects the economic substance of the contract." 18 The regulations then elaborate on this requirement by providing that an upfront periodic payment on an NPC generally be spread over the life of the NPC in accordance with forward rates (or, in the case of a cap or floor, option premiums) or, more frequently, as a series of level payments over the term of the NPC. Thus, if the market rate for an NPC fixed payment is $6 \%$, and the NPC in fact provides for payments at a 5\% rate and an upfront payment from the fixed rate payor to compensate the fixed rate payee for the below-market coupon, under the level payment method the upfront payment would be spread over the life of the NPC in amounts equal to a $1 \%$ periodic payment, and the

\footnotetext{
${ }^{14}$ See, e.g., I.R.C. § 1259(d)(2) (2010) (defining "offsetting notional principal contract"); Treas. Reg. $\S 1.863-7(a)(1)$ (1991). The latter was the first official guidance to use the term "notional principal contract."

${ }^{15}$ Treas. Reg. $\$ 1.446-3(c)(1)(i)(1994)$.

${ }^{16}$ Treas. Reg. § 1.446-3(e) (1994). Different timing rules may apply if the NPC is part of a hedge, straddle or other multiple-position transaction.

${ }^{17}$ Treas. Reg. $\S 1.446-3(\mathrm{~h})(2)(1994)$.

${ }^{18}$ Treas. Reg. $\S 1.446-3(f)(2)(i)$ (1994).
} 
"principal recovery component" of that payment would be treated as a periodic payment on the NPC. A back-end payment is first converted into an initial payment through present valuation, after which the same rule applies.

Under a special rule for NPCs that are swaps (but not for caps and floors), if a nonperiodic payment is "significant," the upfront payment is treated as an amortizing loan providing for level principal and interest payments over the life of the NPC, and the NPC is treated as entered into at market rates. ${ }^{19}$ Using the example in the prior paragraph, if the upfront payment were significant, it would be treated as a loan from the payor to the payee that is repaid in installment payments equal to $1 \%$ periodic payments on the swap, which installment payments are paid at the same time as deemed $6 \%$ payments on the NPC. To take a simplified example, ${ }^{20}$ while the actual cash flows would be:

------> upfront payment $(\$ 4.21 \mathrm{~m})$

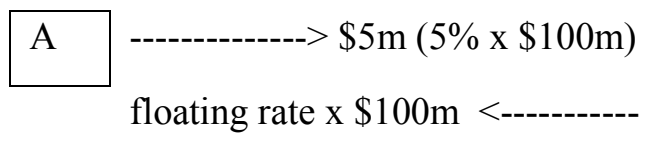

the deemed cash flows would be:

deemed loan

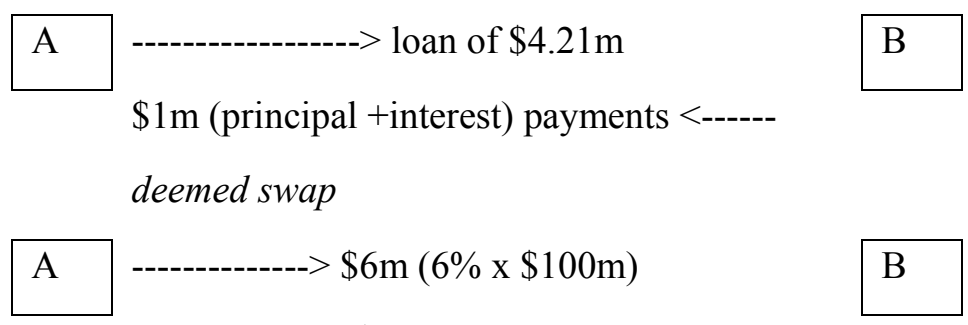

floating rate $\mathrm{x} \$ 100 \mathrm{~m}$

${ }^{19}$ Treas. Reg. $§ 1.446-3(g)(4)$ (1994). The regulation states: "The loan must be accounted for by the parties to the contract independently of the swap. The time value component associated with the loan is . . recognized as interest for all purposes of the Internal Revenue Code." The same rule for currency swaps applies via a cross-reference in the relevant regulations. Treas. Reg. § 1.988-2(e)(3)(iv) (2004).

${ }^{20}$ The example assumes that the parties enter into a 5-year interest rate swap with annual payments at a time when a market rate swap would provide for payments at $6 \% \mathrm{vs}$. a floating rate, multiplied by a $\$ 100$ million notional principal amount. At market rates, the fixed rate payor, Party A, would pay $\$ 6$ million annually in exchange for the floating rate payment. Because Party A will in fact pay only $\$ 5$ million annually, Party A will pay Party $\mathrm{B}$ an upfront payment of $\$ 4.21$ million (the present value, using a $6 \%$ discount rate, of $\$ 1$ million/year). Under the rules described in the text, (a) Party A would be treated as lending $\$ 4.21$ million to Party B, in exchange for annual payments from Party B of principal and interest totaling $\$ 1$ million/year, and (b) Party A would be treated as making annual swap payments of $\$ 6$ million. 
Consequently, the recipient of the upfront payment in this example is treated as paying interest to the payor. Moreover, the Commissioner may treat any nonperiodic swap payment, whether or not it is significant, as one or more loans for purposes of $\S 956$.

As the example above illustrates, these rules were written with interest rate swaps in mind. In the case of an interest rate swap, the relationship between the upfront payment and the foregone, or extra, payments on the swap is mathematically straightforward, once one knows the appropriate discount rate: the upfront payment is simply the present value of the foregone, or extra, payments on the swap as compared to an atmarket swap. These timing rules for nonperiodic payments were adopted initially to prevent taxpayers from refreshing net operating losses by accelerating income through the receipt of upfront payments. ${ }^{21}$ The interest characterization rule is, to the best of the author's knowledge, intended to prevent related parties from using upfront payments on swaps as a way for a non-U.S. affiliate in a non-treaty country to lend money to a U.S. affiliate without suffering U.S. withholding tax on the imputed interest.

The rules described to this point envision that any nonperiodic payment would be a fixed amount known when entering into the NPC. Total return swaps on assets, such as equity swaps, however, typically provide for a final payment that is contingent upon the change in value, if any, of the asset over the life of the swap. Regulations were proposed in 2004 that would provide specific timing rules for swaps with contingent nonperiodic payments. $^{22}$ The proposed regulations would require a taxpayer that enters into a swap with a contingent nonperiodic payment to accrue income (or expense) in respect of that final payment. The methodology provided for in the proposed regulations is complex, but essentially requires a taxpayer to determine a hypothetical future contingent payment, to convert that future payment into an upfront payment, and then to treat the upfront payment under the rules described above.

2. Taxation of Options. An option may be either an option to buy property at a stated "strike" price (a "call" option) or an option to sell property at a stated strike price (a "put" option). The value of the call option in the hands of the purchaser will increase if the value of the underlying property rises above the strike price. The value of a put option in the hands of the purchaser will increase if the value of the underlying property drops below the strike price. The writer of the option is in the opposite economic position. Because the purchaser has the right to profit from the option, and the writer may be obligated to lose money on the option, the purchaser pays the writer a premium to compensate the writer for the risk that the latter is taking. For a conventional option, the premium is usually paid in a single lump sum amount, although it may instead be paid over time.

${ }^{21}$ See I.R.S. Notice 89-21, 1989-1 C.B. 651 (requiring that upfront payments on NPCs be taken into account over the life of the contract under a reasonable method of amortization).

${ }^{22}$ Prop. Treas. Reg. § 1.446-3(g)(6), 69 Fed. Reg. 8,886 (Feb. 26, 2004). 
In general, gain or loss from options is recognized on a wait-andsee (open transaction) basis. ${ }^{23}$ The purchaser capitalizes the cost of the option premium, and the option writer does not immediately include it in income. If the option is exercised by delivery of the underlying property in exchange for payment of the strike price (physical settlement), for tax purposes the party that buys the property acquires it for an amount equal to the strike price paid plus or minus the option premium. That amount is also the amount realized for the seller of the property. If the option is exercised through cash settlement, no property is delivered, and gain or loss is measured by reference to the difference between the cash settlement amount and the premium paid or received. The option may also expire unexercised, in which case the purchaser will have a loss and the writer will have income equal to the premium.

Gain or loss recognized by the purchaser of an option is considered to have the same character as the property to which the option relates in the hands of the option purchaser (or would have if acquired by the purchaser). ${ }^{24}$ Thus, in the case of a purchaser of an option on a bond that is or would be held as an investment, gain or loss will be capital. In the case of an option writer, gain or loss from delivery is typically capital. In the case of the termination of an option other than through delivery of the underlying property, the writer's gain or loss typically is treated as shortterm capital gain or loss, regardless of the term of the contract. ${ }^{25}$

Different rules apply if the taxpayer is a dealer in securities, if the taxpayer is using the option to hedge another position, if the option is a foreign currency option or a "section 1256 contract" (see below), or if other special rules apply. Options may also have terms that vary from the fact patterns described above.

3. Taxation of CDS. CDS are important to the issues discussed in this article for several reasons. First, as noted above, the extraordinary significance attributed to the role of CDS in triggering the near-collapse of the U.S. financial system and other near-catastrophesmost recently, their alleged role in deepening the financial crisis of the Greek economy-has made these once highly exotic and obscure financial instruments the impetus for reform of the derivatives markets in the United States and similar efforts in Europe. Second, for those same reasons, when the Federal Reserve Bank of New York (the "Fed") determined that reform of the U.S. derivatives markets should move forward without waiting for legislation, it encouraged swap dealers to start by clearing CDS. ${ }^{26}$ The

\footnotetext{
${ }^{23}$ See Treas. Reg. § 1.263(a)-4(d)(2)(i)(C)(7) (2004); Rev. Rul. 58-234, 1958-1

C.B. 279 ; Rev. Rul. 78-182, 1978-1 C.B. 265.

${ }^{24}$ I.R.C. $\S 1234$ (a) (2010).

${ }^{25}$ I.R.C. $\$ 1234$ (b) (2010).

${ }^{26}$ The second financial product to attract regulatory attention was interest rate swaps. See Scott Patterson, Fannie, Freddie Touch Off Swaps Scrap, Wall St. J., Apr. 6, 2010, at C1, available at http://online.wsj.com/article/SB10001424052702304620304575166292806663502.html (reporting that the Federal Housing Finance Agency expects Fannie Mae and Freddie Mac to start clearing their interest rate swaps by year-end, regardless of whether Congress adopts financial reform legislation, and that several exchanges are seeking that business).
} 
resulting changes to market practice in the CDS market and the tax issues that arose as a byproduct of these changes provide insight into the path ahead. For those same reasons, perhaps, there is reportedly now a renewed interest by the Treasury and Service in addressing long-standing questions about the tax treatment of CDS.

The tax rules applicable to CDS are unclear, primarily because the proper characterization of CDS for U.S. federal income tax purposes is unclear. The Service officially acknowledged this uncertainty in Notice 2004-52. ${ }^{27}$ Notice 2004-52 describes four possible characterizations of CDS: as notional principal contracts ("NPCs"), options, or in some cases as insurance or guarantees. There are many thoughtful and insightful comments and articles on the characterization question, both predating and following the Notice. ${ }^{28}$ It is fair to say that the ball has been in the

${ }^{27}$ I.R.S. Notice 2004-52, 2004-2 C.B. 168.

${ }^{28}$ Articles discussing the tax considerations relevant to credit default swaps include John N. Bush \& Ahron H. Haspel, Deciphering the Taxation of Credit Derivatives, 14 J. TAX'N InVESTMEnTs 33 (1996); Bruce Kayle, Will the Real Lender Please Stand Up: The Federal Income Tax Treatment of Credit Derivative Transactions, 50 TAX LAW. 568 (1997); David Z. Nirenberg \& Steven L. Kopp, Credit Derivatives: Tax Treatment of Total Return Swaps, Default Swaps, and Credit-Linked Notes, 87 J. TAX'N 82 (1997); Steven D. Conlon, U.S. Tax Issues Relating to Credit Derivatives, DeRIVATIVes 203 (May/June 1998); David S. Miller, An Overview of the Taxation of Credit Derivatives, in 13 TAX STRATEGIES FOR CORPorATE ACQuisitions, SPIN-OFFs, JoInT Ventures. FinANCINGS, AND ReORGANiZATIONS ch. 229 (Practising Law Institute 1999); Viva Hammer \& Frank Kuriakuz, The Tax Treatment of Credit Default Swap Proceeds, 1 DeRIVATIVES \& Fin. InSTRUMENTS, July/August 1999, at 210; David S. Miller, Credit Derivatives: Financial Instrument or Insurance? And Why It Matters, 3 J. TAX'N Fin. Products 31 (Winter 2002); David S. Miller, Distinguishing Risk: The Disparate Treatment of Insurance and Financial Contracts in a Converging Marketplace, 55 TAX LAW. 481 (Winter 2002); Edward D. Kleinbard, Competitive Convergence in the Financial Services Markets, 81 TAXES 225 (Mar. 2003); Erika W. Nijenhuis, Notice 2004-52-One Small Step Forward on Credit Default Swaps, 104 TAx Notes 1287 (2004); Bruce E. Kayle, The Federal Income Tax Treatment of Credit Derivative Transactions, 21 TAX Strategies For Corporate ACQuisitions, SPINofFS, Joint Ventures, Financings, AND ReORganizations ch. 429 (Practising Law Institute 2004), reprinted in updated form in 22 TAX STRATEGIES FOR CORPORATE ACquisitions, SPIn-OFfs, JoInt Ventures, Financings, AND Reorganizations ch. 429 (Practising Law Institute 2009); Alexander F. Peter, Characterization of Credit Default Swaps for Tax Purposes, 8 DERIVATIVES \& Fin. InSTRUMENTS 3 (Jan/Feb. 2006); Nicholas Bogos, A Risk-Based Analysis of Credit Derivatives under SSRP Standard (pts. 1-3), 112 TAX Notes 587, 655, 759 (Aug. 2006); Kevin J. Liss, Are Credit Default Swaps Really Swaps or Options for Tax Purposes? An Economics-Based Approach, 7 J. TAX'N FIN. Products 23 (2008); Ari J. Brandes, Toward a New Framework and a Better

Understanding of Credit Default Swaps, 10 DeRIVATIVES \& Fin. InSTRUMENTS 75 (May/June 2008); Ari J. Brandes, A Better Way to Understand the Speculative Use of Credit Default Swaps, 14 Stan. J.L. Bus. \& Fin. 263 (2009); Andrea S. Kramer, Alton B. Harris \& Robert A. Ansehl, The New York State Insurance Department and Credit Default Swaps: Good Intentions, Bad Idea, 22 J. TAX'N \& REG. FIN. Inst. 22 (Jan./Feb. 2009); David S. Miller \& Shlomo Boehm, New Developments in the Federal Income Tax Treatment of CDSs, $7 \mathrm{~J}$. TAX'N Fin. Products 9 (2009); LAWRENCE LoKkEN, TAXATION OF CREDit DERIVATIVES, available at http://www.taxpolicycenter.org/UploadedPDF/1001350_credit_derivatives.pdf; Alan B. Munro, Revisiting Tax Considerations Regarding Credit Default Swaps, 12 DERIVATIVES \& FIN. INSTRUMENTS 9 (Jan./Feb. 2010).

For comments submitted in response to Notice 2004-52 and other subsequent requests for guidance, see Letter from David Garlock, Howard Leventhal \& Alan Munro to Mark W. Everson, IRS Comm'r (Jan. 7, 2005), reprinted in 106 TAX NoTES 855 (Feb. 14, 2005); Letter from Managed Funds Association to Mark W. Everson, IRS Comm'r, re: 
Service's court for some time. Unofficial comments by officials of the Service suggest that the first likely venue for guidance on the characterization issue may be the reproposal of the long-pending proposed regulations on NPCs with contingent nonperiodic payments, a project aimed a very different class of financial instruments. These regulations are discussed in Section I.B.1, above. The timing of any such guidance is uncertain. This article does not directly address the characterization question but assumes that option and NPC are the relevant treatment alternatives.

If a CDS contract is properly treated as an NPC, then the periodic premium payments would be periodic payments, generally required to be taken into account currently on an accrual basis. It is uncertain whether a cash settlement payment ought to be viewed as a termination payment or as a nonperiodic payment, although the author believes that most market participants treat it as a termination payment. ${ }^{29}$

Under these rules, an upfront payment on the CDS contract would be treated as a nonperiodic payment that must be amortized in some fashion over the life of the CDS. If the CDS were considered a swap (and not a cap or floor) and the upfront payment were a significant nonperiodic payment,

Notice 2004-52 (Credit Default Swaps) (Apr. 26, 2005), available at 2005 TNT 87-20; New York State Bar Association Tax Section, Report on Credit Default Swaps (Sept. 9, 2005), available at

http://www.nysba.org/Content/ContentFolders20/TaxLawSection/TaxReports/1095Report.p df, reprinted in 109 TAX Notes 347 (Oct. 17, 2005); Letter from New York State Society of Certified Public Accountants re: Statement on Credit Default Swaps Provided in Response to IRS Notice 2004-52 (Nov. 7, 2005), available at 2005 TNT 215-12; Letter from SIFMA to Steven A. Musher, Assoc. Chief Counsel (Int'l) (May 26, 2009), reprinted in 1 TAXATION OF FinANCIAl Products AND Transactions $2010 \mathrm{ch}$. 1 (Practising Law Institute 2010).

For a number of requests for guidance (or, in one case, no guidance) on credit default swaps prior to Notice 2004-52, see Letter from Capitol Tax Partners to IRS re: Notice 2002-22 (Guidance Priority List) (May 1, 2002), available at 2002 TNT 96-20; Letter from Capitol Tax Partners to Rob Hanson, Tax Legislative Counsel \& Barbara Angus, Int'l Tax Counsel, re: Follow-up Letter on Credit Default Swaps (July 2, 2002), available at 2002 TNT 148-34; Letter from Gregory May \& Robert Scarborough to Helen Hubbard, Acting Tax Legislative Counsel \& Barbara Angus, Int'1 Tax Counsel, re: Guidance on Credit Default Swaps (Oct. 1, 2002), reprinted in 2 J. TAX'N GLOBAL TRANSACTIONS 72 (20022003); Letter from ISDA to IRS re: Withholding Taxes on Credit Default Swaps (Oct. 24, 2002), available at 2002 TNT 232-21; Letter from ISDA to Barbara Angus, Int'1 Tax Counsel (Nov. 21, 2003), available at 2003 TNT 232-17; Letter from ISDA to IRS re: Notice 2003-26: Comments on Recommendations for the 2003-2004 Guidance Priority List (May 2, 2003), available at 2003 TNT 118-26.

As discussed in Section IV.C.1, below, the tax characterization of "pay as you go" CDSs has been raised as an issue in the bankruptcy of a major financial guarantee insurance company.

${ }^{29}$ Treas. Reg. § 1.446-3 defines a "termination payment" as a payment made or received to extinguish or assign all or a proportionate part of the remaining rights and obligations of any party under an NPC, and defines a "nonperiodic payment" as any payment other than a periodic payment or a termination payment. Treas. Reg. § 1.4463(h)(1), (f)(1) (1994). The Service also has taken the position, however, that a "final scheduled payment" is not a termination payment even though it by definition extinguishes the parties' rights and obligations under the NPC. Prop. Treas. Reg. § 1.1234A-1(b), 69 Fed. Reg. 8886 (Feb. 26, 2004). It is unclear how a final payment that is provided for in the terms of a contract, but that is not scheduled, such as the cash settlement payment on a CDS, fits into this framework. 
then one party to the swap would be treated as lending money, and the other would be treated as paying interest.

In addition, if a cash settlement payment were treated as a nonperiodic payment and not as a termination payment, then it seems likely that the proposed regulations addressing swaps with contingent nonperiodic payments would apply, unless CDS are carved out of their scope. As described above, the proposed regulations would require a taxpayer that enters into a swap with a contingent nonperiodic payment to accrue income (or expense) in respect of that final payment. If these regulations applied to CDS, they could require a protection buyer to accrue income as a result of the possibility that the protection buyer may receive a settlement payment if there is a credit event with respect to the reference entity. Conversely, the regulations could require a protection seller to accrue expense as a result of the possibility that it will have to make a future settlement payment.

The proposed regulations clearly were not drafted with CDS in mind, however, and it is uncertain whether CDS will be included or excluded from the scope of the regulations if and when finalized or reissued in proposed form. Among the uncertainties about whether and how these regulations might apply to CDS are (a) whether a CDS contract is an NPC, (b) if so, whether the CDS contract would be subject to these proposed regulations, (c) whether the cash settlement payment should be viewed as a nonperiodic payment, rather than a termination payment, and (d) if so, how the regulations should be applied in view of the fact that a settlement payment is uncertain not only in amount (which the regulations envision) but also as to timing (which the regulations do not envision), or for that matter whether it will occur at all (the regulations do not envision a nonpayment of a contingent amount). ${ }^{30}$ Some of these issues are discussed further in Section IV.D, below.

If, conversely, a CDS contract is properly characterized as an option or series of options, it generally would be subject to the rules described in Section I.B.2, above. ${ }^{31}$

\section{Overview of Section 1256.}

Section 1256 was enacted in 1981, as part of a package of rules intended to shut down "tax straddle" transactions in which taxpayers sought to obtain timing and character advantages from taking largely offsetting positions in, generally, futures contracts. As enacted, $\S 1256$ required that "regulated futures contracts" ("RFCs") be marked to market at year-end,

${ }^{30}$ For materials addressing the potential application of these regulations to credit default swaps, see Letter from the Investment Company Institute to Gregory F. Jenner, Acting Assistant Secretary for Tax Policy, U.S. Dep't of the Treasury, and Donald Korb, Chief Counsel, IRS (July 21, 2004) (on file with author) (letter concerning Proposed Regulations on Notional Principal Contracts with Contingent Nonperiodic Payments), 2004 TNT 147-14; Lee A. Sheppard, Retail Credit Derivatives, 105 TAX Notes 126 (2004); Munro, supra note 28.

${ }^{31}$ Because NPCs include interest rate caps and floors, which consist of multiple options, it is conceivable although unlikely that if a CDS contract constitutes a series of options, it could be an NPC even though a single option cannot be an NPC. 
meaning that gain or loss on the RFC was required to be taken into account as if the RFC had been sold at year-end. To soften the mark-to-market blow, $\S 1256$ also provided that gain or loss on RFCs would be treated as $60 \%$ long-term and $40 \%$ short-term, notwithstanding the fact that futures contracts typically have a term of no more than three months.

For this purpose, an RFC was defined as a contract (i) that requires delivery of personal property or an interest therein, (ii) with respect to which the amount required to be deposited and the amount which may be withdrawn depends on a system of marking to market, and (iii) that is "traded on or subject to the rules of" a domestic board of trade designated as a contract market by the Commodity Futures Trading Commission ("CFTC") or certain other exchanges. At the time, this definition gave rise to no confusion, as it was tailored to the terms of futures contracts trading on CFTC-approved exchanges.

Very generally, a futures contract of this kind was a contract with standardized terms for the future delivery of a commodity, with a single payment made at maturity in exchange for the delivery of the commodity. The contract was traded on an exchange through "open outcry" (traders standing in pits and signaling each other through hand movements) under CFTC rules. Under the exchange rules, a clearinghouse then interposed itself between the two parties to the contract as effectively a guarantor of the parties' obligations. As a legal matter, the clearinghouse became the legal counterparty to each side of the transaction. The credit support provided by the clearinghouse was derived from collateral and guarantees provided by the futures commission merchants (the equivalent of brokers in the commodities world) acting for each party, as well as a small amount of initial margin required from both parties to the contract. On a daily basis, as the contract gained or lost value as a result of changes in commodities prices and market expectations, the "losing" party was obligated to put up additional "variation margin" in the form of cash, which cash was deposited in the account of the "gaining" party. ${ }^{32}$

The definition of RFC as originally enacted was short-lived. In $1982, \S 1256$ was amended to delete the delivery requirement for RFCs, and to add a new category of financial instruments subject to $\S 1256$, "foreign currency contracts." A foreign currency contract was defined as a contract that requires delivery of a foreign currency in which positions are also traded through RFCs, that is traded in the interbank market, and that is entered into at a price determined by reference to interbank market prices.

Section 1256 was again amended in 1984 and 2000 to add three additional categories of contracts subject to $\S 1256$ - nonequity options, dealer equity options, and dealer securities futures contracts. Dealer equity options are options on single stocks, such as an option on IBM stock, that are traded by options market makers on securities exchanges. The term "nonequity option" is somewhat misleading; it is defined as any listed option that is not an "equity option," a term that has a narrower meaning

\footnotetext{
32 The clearing and trading of futures contracts is described in more detail in Section II.A.1, below.
} 
than might initially appear. As a result of the historical division of responsibility between the Securities \& Exchange Commission ("SEC") (single stocks and narrow-based equity indices) and the CFTC (broad-based equity indices), the term covers listed options on broad-based stock indices, like the S\&P 500, as well as options on truly nonequity risks like options on commodity futures contracts, options on Treasury bond futures, and options on foreign currency futures. Dealer securities futures contracts are futures contracts on single stocks, and options thereon, that are traded by taxpayers treated for tax purposes as dealers therein. Like RFCs, nonequity options and dealer securities futures contracts are traded on CFTC-regulated exchanges. Collectively, the contracts subject to $\S 1256$ are now categorized as "section 1256 contracts." The history of several of these provisions is discussed in more detail in Part III below.

\section{Overview of Other Special Tax Rules for Derivatives}

1. Hedging Transactions. A very common purpose for entering into a derivative financial instrument is to hedge a risk or exposure deriving either from an asset held or to be held by a taxpayer or a liability issued or to be issued by a taxpayer. While the history of the tax rules for hedging transactions is long and not always untroubled, under current law the tax rules for hedging ordinary business assets or liabilities is fairly straightforward.

Section 1221(a)(7) provides that the term "capital asset" does not include any "hedging transaction" clearly identified as such no later than the close of the day it was entered into. Section 1221(b)(2) defines a "hedging transaction" generally to mean any transaction entered into by the taxpayer in the normal course of the taxpayer's trade or business primarily to manage risk of price changes, currency fluctuations, or, in the case of liabilities, interest rate risk, with respect to ordinary property or liabilities of the taxpayer. Treas. Reg. $\S 1.1221-2$ provides more detailed guidance on the implementation of these rules. Thus, generally, if a taxpayer enters into a "hedging transaction" and properly identifies it as such, the taxpayer's gain or loss from the transaction will be ordinary rather than capital. This allows the taxpayer to match the character of its gain or loss from the hedged item and the hedge.

Corresponding timing rules are provided in Treas. Reg. $\S 1.446-4$. They generally conform the timing of income or expense from a hedging transaction to the timing of corresponding expense or income from the hedged item.

Foreign currency hedges generally do not fall within the ambit of $\S$ 1221 , as they already give rise to ordinary income or loss. ${ }^{33}$ There are timing and character distinctions, however, between foreign currency swaps, foreign currency forward contracts and foreign currency futures

\footnotetext{
${ }^{33}$ Treas. Reg. § 1.1221-2(a)(4) (2007) (this section does not apply to determine the character of gain or loss from section 988 transactions). Section 988 generally provides rules for taxing foreign currency gain or loss from transactions in foreign currency, foreign currency-linked debt and foreign currency-linked derivatives.
} 
contracts, which are respectively subject to ordinary character/realization method, ordinary character/mark-to-market and capital character/mark-tomarket rules in the absence of any elections. ${ }^{34}$ Accordingly, it may be necessary or useful to make a hedging election for one of these transactions, depending on the item being hedged. ${ }^{35}$

The tax rules for hedging capital assets are more limited and less favorable. Treas. Reg. $\S \S 1.1275-6$ and $1.988-5$ permit taxpayers to "integrate" certain hedges of debt instruments issued or held by the taxpayer with the debt itself. ${ }^{36}$ Apart from these rules, the principal rules governing hedges of capital assets are the straddle rules of $\S \S 1092$ and $263(\mathrm{~g})$, which are anti-abuse rules of a complex and uncertain nature. Additional rules addressing hedges of capital assets are found in other statutory provisions, including $\S \S 1092(\mathrm{e}), 1256(\mathrm{e})$ and (f)(1), and $475(d)(2)(F)$, but they generally are narrower in scope and have less specific guidance implementing them than the "hedging transaction" rules described above, or are also anti-abuse rules unfavorable to taxpayers. ${ }^{37}$ Thus, for taxpayers hedging capital assets, it is more difficult to ensure that the timing and character of gains and losses from a hedge match those from the hedged item. Consequently, for taxpayers that wish to have such matching, it is more important that the basic tax rules for the hedge and hedged item give rise to similar timing and character results.

Some taxpayers use derivatives to bridge a gap between their assets and liabilities, typically in cases where the assets are fixed income assets that pay on a different basis or have a different duration or timing of payments than their liabilities, e.g., fixed rate liabilities vs. floating rate assets. In the Federal National Mortgage Association case, for example, the principal factor in determining the taxpayer's profit or loss was the spread between the average net yield on its mortgage portfolio and the

${ }^{34}$ See I.R.C. § 988(a)(1) (2010) (general rule that foreign currency gain or loss attributable to any "section 988 transaction" is ordinary income or loss); I.R.C. $§ 1256(\mathrm{~b})(1)$, (2) (2010) (defining any "regulated futures contract" and "foreign currency contract" as section 1256 transactions generally subject to mark-to-market treatment and to capital gain/loss rules unless character otherwise would be ordinary); I.R.C. § 988(c)(1)(B)(iii) (2010) ("section 988 transactions" include any forward contract, futures contract or similar financial instrument that is denominated in or determined by reference to nonfunctional currency); I.R.C. § 988(c)(1)(D)(i) (2010) (I.R.C. § 988(c)(1)(B)(iii) does not apply to regulated futures contracts); I.R.C. § 988(b)(3) (2010) (all gain or loss from section $988(\mathrm{c})(1)(\mathrm{B})(\mathrm{iii})$ transactions is ordinary).

${ }^{35}$ I.R.C. $§ 988(d)$ (2010) also provides for special hedging rules for foreign currency. For a discussion of the special rules applicable to foreign currency transactions used as hedges, see John D. McDonald, Ira G. Kawaller, L.G. "Chip" Harter \& Jeffrey P. Maydew, The Devil is in the Details: Problems, Solutions and Policy Recommendations with Respect to Currency Translation, Transactions and Hedging, 89 TAXES (forthcoming Mar. 2011).

${ }^{36}$ Treas. Reg. $§ 1.988-5$ (1992) also provides favorable rules for certain hedges of foreign currency payables and receivables.

${ }^{37}$ By its terms, the $\S 1256(\mathrm{e})$ hedging exception is more limited than the very similar exception under $\S 1221$. For a discussion of a recent ruling illustrating that point, see Michael (Wei-Chin) Mou \& David H. Shapiro, Does Section 1256 Incorporate an Inadvertent Error Exception, 128 TAX NOTES 1159 (Sept. 13, 2010). The conclusion reached in that ruling was later modified to take into account other provisions of the Code. See Chief Counsel Advice 201046015 (July 14, 2010). 
average cost of its outstanding debt. ${ }^{38}$ The taxpayer entered into several types of derivatives in order to hedge its interest rate and duration risk. Another type of taxpayer that may use derivatives in this manner is a life insurance company, which may face a gap between the rates or duration on its investment assets and the cash flows it expects to need to pay out on its policies. As the FNMA case illustrates, it is crucial for a taxpayer of this kind to be able to treat gains and losses on its hedges as ordinary rather than capital.

2. Mark-to-Market Rules. A taxpayer using a "markto-market" method of tax accounting treats assets or other positions subject to that method as if sold at year-end, generally solely for purposes of determining gain or loss with respect to that position. Future gain or loss, whether from a subsequent mark or from disposition, are adjusted to take the recognized gain or loss into account.

As anyone with even a cursory understanding of U.S. tax rules knows, mark-to-market is not a customary method of accounting for most taxpayers. That is true even for assets that are easy to value and readily turned into cash, like publicly traded stock. Rather, mark-to-market rules generally apply in one of two situations: a taxpayer election or prevention of abuse. Examples of mark-to-market rules include $\S \S 877 \mathrm{~A}$ (expatriates), 1256, 1260 (constructive ownership rules), and 1296 (modified mark-tomarket rules for passive foreign investment companies). ${ }^{39}$

A taxpayer that is a "dealer in securities," however, generally is required to mark its securities to market, under $\S 475$. Unlike $\S 1256$, under $\S 475$ gain or loss from positions held in connection with a dealer's activities as such give rise to ordinary gain or loss. This is to be expected, as gain or loss from ordinary business activities generally is ordinary.

In the case of a dealer in securities who transacts in section 1256 contracts as part of the normal course of its business, there is a potential conflict between the general capital gain/loss rules of $\S 1256$ and the general ordinary income/expense rules of $\S 475$. Sections 475 and 1256 contain several rules intended to clarify when each rule applies. As discussed in more detail in Section III.A, below, however, these rules may work imperfectly. Since a corporate taxpayer generally has no benefit from capital gains under current law, but cannot deduct capital losses except to the extent of capital gains, dealers in securities typically prefer for derivatives that they enter into to be subject to $\S 475$ rather than $\S 1256$.

II. DEVELOPMENTS IN THE MARKETS AND THE LAW.

As described earlier, a number of events, most notably the emergency rescue of AIG by the federal government in the fall of 2008, led many government regulators and other policymakers to the conclusion that

\footnotetext{
${ }^{38}$ Fed. Nat'1 Mortg. Ass'n v. Comm'r, 100 T.C. 541 (1993).

${ }^{39}$ Mark-to-market is also permitted or required by various regulations, including Treas. Reg. $\S \S 1.148-6(\mathrm{e})(5)$ (internal commingled funds), 1.148-9(c)(1)(iv)(B) (allocation rules for refunding issues), 1.1092(b)-3T(b)(6) (identified mixed straddles), and 1.1092(b)4T(c)(5) (mixed straddle accounts).
} 
the CDS market, and more generally the OTC market for derivative financial instruments, must be transformed so it poses less of a risk to the financial system. Among the improvements sought were enhanced market transparency, improved operational processes, a reduction in the level of outstanding trades, and the creation of a single central counterparty for swaps. $^{40}$ It was also envisioned that there would be a single regulator that would have oversight over the entire system. Some of these goals were part of a larger program addressed to the derivatives market as a whole and some were CDS-specific.

In the United States, the Fed took an active role in encouraging dealers in CDS to take several steps to advance these goals. The two steps of interest for purposes of this article are the standardization of CDS terms in the spring of 2009, which was a prerequisite for the clearing of CDS, and the commencement of clearing of CDS by two U.S. clearinghouses in the fall of 2009. CDS are now also being cleared by several European clearinghouses. The U.S. markets for interest rate swaps are moving in the same direction. To date, all of these steps have been nominally voluntary, although as a practical matter the active involvement of the Fed and other regulators has meant that the changes have been adopted on an industrywide basis by swap dealers.

Dodd-Frank now requires that similar steps be taken for other classes of swaps. As described in more detail below, under Dodd-Frank, most swaps will be regulated, some by the SEC and some by the CFTC. In addition, most swaps will be cleared through one or more central clearinghouses and most swaps will be traded on regulated exchanges (or "swap execution facilities") rather than being negotiated in the OTC market. As described in more detail below, however, Dodd-Frank does not require that all swaps be cleared and traded. Rather, it permits trading on markets that do not appear to constitute a "qualified board or exchange" for $\S 1256$ purposes, and it allows certain types of parties to swaps to elect whether to clear their swaps or not. Accordingly, it seems inevitable that there will exist identical swaps that will be traded on a qualified board or exchange in some cases and that will in other cases exist in the bilateral OTC derivatives or other market.

\section{A. The Clearing Process. ${ }^{41}$}

As has been made clear, the clearing of swaps through a central counterparty is now a critical part of the regulatory framework for swaps. It is also critical to understanding the tax issues described in this article. Accordingly, before turning to a description of Dodd-Frank, this Section II.A of the Article describes the clearing process. Because the transformation of the CDS market from an OTC market to a market with

\footnotetext{
${ }^{40}$ See New York Fed Welcomes Further Industry Commitments on Over-theCounter Derivatives, FED. Reserve BANK OF N.Y. (Oct. 31, 2008), http://www.newyorkfed.org/newsevents/news/markets/2008/an081031.html (last visited Dec. 31, 2010).

${ }^{41}$ See attached diagrams illustrating the clearing process for an interest rate swap or CDS negotiated in the OTC market.
} 
trillions of dollars of cleared contracts may provide insights into future developments for other classes of swaps, the new CDS clearinghouses are also described in some detail. The current and imminent state of clearing for interest rate swaps is also briefly described.

It is important, as a preliminary matter, to understand the differences between clearing through a centralized clearinghouse and trading on a regulated exchange. To that end, this section discusses the different mechanisms governing futures contracts (which are both exchange-traded and cleared), CDS, and interest rate swaps (which may be cleared, but are not currently exchange-traded). Very broadly speaking, "trading" has to do with how the parties agree on a price for entering into or terminating a transaction. "Clearing" has to do with the centralization and management of risk and the transmittal of payments after the trade is entered into.

1. Clearing Futures Contracts. Futures contracts are traded on regulated exchanges. Their terms are standard and are set out in the rules of the exchange. Mechanically, a customer wishing to acquire the right to buy corn at some point in the future may go to its brokertechnically, a "futures commission merchant," or FCM-who is a member of a regulated exchange. The FCM will take the client's order and go to the exchange, where the FCM will agree with another FCM to create electronic "buy" and "sell" positions. Each position represents one side's willingness to either accept the obligation to deliver, say, 5000 bushels of a specified type and grade of corn on the specified date at the specified price or to pay the specified price and receive the corn on the specified date. The exchange's proprietary matching engine then connects individual "buy" positions with matching "sell" positions. Once a match is found, the contract is executed, with the parties on either side as counterparties.

It should be noted that while the FCM in this example is carrying out customer transactions, the exchange deals only with the FCM and not with the customer. One can analogize this to a stockbroker dealing with a stock exchange on behalf of a client, but the relationship is more complicated because a futures contract is a contract, not an investment in a third party as to which legal and beneficial ownership can readily be split. Depending on the circumstances, one may acknowledge the role played by the FCM as the face to each of the exchange and the customer. For most tax purposes, however, the FCM is ignored and the customer is treated as if it were executing the trade on the exchange. That convention will be followed here except where the role of the FCM needs to be distinguished from that of the customer or the exchange. Thus, once a futures contract has been executed, the parties to the trade are the customers who are respectively willing to buy and sell corn.

This relationship does not last, however, because the trade then must be cleared through the exchange's central clearinghouse. ${ }^{42}$ The

\footnotetext{
${ }^{42}$ It should be noted that centralized clearing is not a new idea. In 1925, the Chicago Board of Trade Clearing Corp. was the first United States clearinghouse, formed to become a counterparty to all transactions then carried out on the Chicago Board of Trade
} 
clearinghouse steps into the shoes of each side of the trade and becomes the party responsible for both the actual delivery of the 5000 bushels of corn to Party $A$ and the payment for the corn to Party $B$. At the same time, each party now has a responsibility, not to its original counterparty, but to the clearinghouse, to either deliver the corn (in the case of Party $B$ ) or provide the payment (in the case of Party $A$ ). By interposing itself between the parties, the clearinghouse assumes the risk that one party to the transaction will not perform.

The clearinghouse manages this risk through several mechanisms: (i) it takes initial margin (usually a small percentage of the purchase price) and subsequently variation margin, as described below, determined by reference to the party's then-outstanding trades with the clearinghouse, which changes daily; (ii) it nets the FCM's position in the particular contract, as described below; and (iii) it requires that the FCM provide additional collateral (which becomes part of a "guaranty fund") and has the right to assess FCMs for additional guaranty fund contributions (essentially, contingent collateral) to cover the clearinghouse's risks. ${ }^{43}$ In the case of a default by a clearinghouse member-generally only members can be counterparties to the clearinghouse - the clearinghouse attempts to cover any resulting losses by looking first to that member's margin and collateral. Should that be insufficient, however, the clearinghouse can draw upon the collateral provided by other members. If that, too, proves inadequate, the clearinghouse can call upon the guarantees. The risk of failure by a member is thus reduced, through the use of netting and the requirement that the member provide margin and collateral, and mutualized, through the clearinghouse's right to appropriate the assets of other members.

The netting of contracts is possible because the contracts have standardized terms. For example, if on the day after the transaction described above, another customer of FCM $A$ wishes to sell 15,000 bushels of corn pursuant to a futures contract that, but for the quantity and price, has terms identical to the first transaction, FCM $A$ will execute that trade with FCM $C$. Once this contract has been cleared, the clearinghouse will automatically net FCM $A$ 's right to receive 5000 bushels against its obligation to deliver 15,000 bushels into a single obligation to deliver 10,000 bushels in exchange for payment. As a result, at the end of a trading

(generally trade in grain futures), and some form of central clearinghouses existed in Europe prior to that time. Federal Reserve Governor Randall S. Kroszner, Central Counterparty Clearing: History, Innovation, and Regulation, Address at the European Central Bank and Federal Reserve Bank of Chicago Joint Conference on Issues Related to Central Counterparty Clearing (Apr. 3, 2006),

http://www.federalreserve.gov/newsevents/speech/kroszner20060403a.htm\#f5 (last visited Dec. 30, 2010).

${ }^{43}$ The initial margin and variation margin requirements apply in the first instance to customers, who pay or receive these amounts to/from their FCMs, who in turn generally pay/receive these amounts to/from the clearinghouse. Thus, if a futures contract increases in value, one customer will pay variation margin to its FCM, which will pay it to the clearinghouse, which will pay it to the other FCM, which will pay it to the second customer. The netting and additional collateral requirements apply to FCMs, not customers, however, although the cost of the additional collateral requirements may be passed on to customers in the form of pricing. 
day, FCM $A$ will always have a single net position with the clearinghouse with respect to any one type of futures contract, although it will have multiple actual positions because it transacts in multiple types of futures contracts.

2. Clearing CDS. In contrast to futures contracts, CDS are not traded on exchanges. Instead, a CDS is entered into over-thecounter in a private agreement between two parties. As a result of the standardization process described below, the number of variables to be negotiated is limited, primarily to the market quoted level for the couponthat is, the coupon that the market would have agreed to prestandardization - and the maturity ("tenor") of the CDS.

Upon reaching agreement on the terms of their CDS, if the CDS is of a kind subject to clearing, each party novates its contract with the central clearinghouse, which (as in the futures context) steps between and becomes the counterparty to both parties. ${ }^{44}$ As in the futures context, this allows the

${ }^{44}$ The statement in the text is a highly simplified explanation of the actual process, which differs from the process for futures contracts in several regards. Unlike the case with futures, the brokers (dealers) who face customers in the CDS market are not always clearinghouse members. Consequently, in order to clear a CDS, the customer, the executing broker (that is, the swap dealer), and the designated clearing member (which may or may not be the same legal entity as the broker, or an affiliate of the broker) must all cooperate, as the customer-broker transaction will be replaced by a customer-clearing member-clearinghouse transaction. The process for dealing with failures to clear a trade is also different in the futures and CDS markets. In the futures market, the parties simply keep trying to clear a trade. If it fails, no trade exists. In the CDS market, dealer/dealer trades clear weekly on ICE Trust and daily on the CME, although both are working on more rapid clearing cycles. In the interim between agreeing to a transaction and clearing it, a bilateral OTC contract exists between the dealers. If the trade fails to clear, the bilateral OTC contract continues in existence. Dealer/customer CDS trades work differently. If a trade of that kind fails to clear, there are several different possible outcomes: (i) the designated clearing member may be replaced, (ii) the trade may remain a bilateral OTC contract, but likely with different pricing because the credit risk, margin requirements, and possibly regulatory capital requirements are different for OTC-only vs. cleared CDS, or (iii) the trade may be broken. See ISDA, Recommended Common Principles for Relationships between Customer and Executing Broker ("EB") and Clearing Member ("CM"), http://www.isda.org/credit/docs/Recommended-Common-Principles.pdf (last visited Dec. $30,2010)$. All of this is subject to change as the markets continue to develop.

One tax question raised by the clearing process is whether the clearing of a swap will be treated as a taxable disposition of the swap for property differing materially in kind or extent, under $\S 1001$. In the case of newly originated swaps that are intended from the outset to be cleared, this issue appears to be trivial, particularly if as suggested above the terms may change if the swap ultimately is not cleared. Under the step transaction doctrine, it should be the case that the cleared swap is treated as the same swap agreed to by the parties. See discussion infra Section III.B.3 (concerning Revenue Ruling 87-43). Rev. Rul. 87-43, 1987-1 C.B. 252.

The analysis may be different for pre-existing swaps. If pre-existing swaps were submitted for clearing, one would have to consider whether Treas. Reg. $\S 1.1001-4$ or some other basis for non-recognition treatment applies. The regulation treats an assignment as a non-event for the non-assigning party if the assignment (i) is from one swap dealer to another and (ii) is permitted by the terms of the contract. It is an interesting question whether a clearinghouse could be considered a dealer for this purpose. Typically, they would not be, but in other contexts novation to a clearinghouse has been essentially disregarded for U.S. federal income tax purposes so that no consideration has been given to that issue. In this context one might perhaps argue that a clearinghouse serves a function sufficiently similar to that of a dealer to be treated as such for purposes of this rule. 
clearinghouse to net out each party's overall exposure to CDS, resulting in a single net position with respect to any particular CDS (e.g., a CDS on a specified reference entity or a specified series of an index with a specified maturity). In exchange for using the clearinghouse's services in this way, each party must provide collateral and adjust the amount of that collateral on a daily basis to reflect the party's net exposure.

There is, however, at least one significant economic difference between clearing CDS and clearing futures contracts. Futures contracts provide for only a single payment at maturity, so the payment made or received when entering into a futures contract reflects simply the difference between the price specified in the futures contract and the market price at that time. CDS and other swaps, by contrast, provide for periodic payments. Also, CDS generally are, and other swaps may well be, entered into with an upfront payment, or are deemed to do so for tax purposes. Upfront payments on cleared swaps are described in more detail in Section II.C, below. One last point worth understanding is that in the case of CDS clearing, both dealers and certain other major participants in the CDS market benefit from the credit support of the clearinghouse. Those arrangements are intended to provide assurance that if a clearing member fails, a customer's CDS positions will be transferred to another clearing member and the customer's margin will be available to transfer together with the customer's CDS positions. The mechanics of these arrangements differ from clearinghouse to clearinghouse. ${ }^{45}$

As mentioned above, there are currently two U.S. clearinghouses clearing CDS, ICE Trust U.S. and the Chicago Mercantile Exchange ("CME"), in addition to ICE Clear Europe, Eurex, and now LCH.Clearnet in Europe. For tax purposes, there are potentially significant differences between how the two U.S. CDS clearinghouses are organized and operate. Other types of swaps can be expected to be cleared through additional

Voluntary submission of existing swaps to a clearinghouse would not, however, appear to be permitted by the terms of a standard ISDA, which require consent by a counterparty to assign a swap except in very limited situations. If the economic terms of the swap were modified in connection with the novation, that also would pose an obstacle to tax-free treatment. A final concern might be that the regulation applies by its terms only to NPCs, and so does not literally apply to options and other types of derivative financial instruments. Leaving aside for the moment the question of whether economic terms of a swap would change when it is cleared, a more satisfying answer to the non-recognition question could be to conclude that the clearinghouse is essentially simply a guarantor, and consequently that there has been no disposition of a swap when it is cleared. See discussion infra note 132.

Similar issues could arise in connection with the transfer of a customer's positions from one clearing member to another in the event of the failure of the original clearing member. One would have to consider in that regard whether the CME-type agency model for clearing customer trades would be less likely to give rise to a taxable disposition than the ICE Trust-type principal model. See the text below for discussion of these two regimes.

${ }^{45}$ For extensive discussion of proposals made by U.S. and European central clearinghouses for protecting CDS customers in the event that a clearing member fails, see ISDA, Report to the Supervisors of the Major OTC Derivatives Dealers on the Proposals of Centralized CDS Clearing Solutions for the Segregation and Portability of Customer CDS Positions and Related Margin, http://www.isda.org/credit/docs/Full-Report.pdf (last visited Dec. 30, 2010) [hereinafter The Buy-Side Report]. These arrangements are briefly described supra note 43. 
clearinghouses, which may also have different legal and functional structures.

(a) ICE Trust U.S. ICE Trust U.S. is organized as a New York trust company, and is regulated by the Federal Reserve and the New York State Banking Department. ${ }^{46}$ ICE Trust is one of several subsidiaries of IntercontinentalExchange ("ICE"), which operates exchanges in the United States, Canada, and Europe and also operates several OTC markets. ICE Trust is a standalone clearinghouse for clearing CDS. That is, its sole function is to clear, and the sole contracts that it clears are CDS.

ICE Trust received regulatory approval from the New York State Banking Department in December 2008. In March 2009, it received regulatory approval from the Fed to provide central counterparty services by clearing CDS and from the SEC to perform the functions of a clearing agency for cleared CDS. ${ }^{47}$ ICE Trust began clearing CDS in March 2009, and clears both single name CDS and index CDS. According to ICE, the volume of gross notional amount cleared by ICE Trust exceeded $\$ 7$ trillion by the end of September 2010, and open interest in cleared CDS was just under $\$ 500$ billion. $^{48}$

ICE Trust operates under a set of rules that set out conditions for membership, the terms of the CDS that it clears, the details of how clearing takes place, how determinations of various kinds are made, and other related topics. These rules are also standalone, meaning that they relate solely to ICE Trust.

ICE reports daily settlement prices, daily trading volume, and endof-day open interest for each CDS contract that it trades. ICE does not provide other price information for cleared swaps, but bid/ask quotes can be obtained by calling a market participant.

\footnotetext{
${ }^{46}$ In November 2008, the SEC, the CFTC and the Fed executed a Memorandum of Understanding under which they agreed to cooperate and coordinate in their respective approval, supervision, and oversight of Central Counterparties (a "CCP") for CDS. The MOU notes that a CCP for CDS may be one or more of the following: a state-chartered bank that is a member of the Fed, a derivatives clearing organization ("DCO") regulated by the CFTC, or a "clearing agency" regulated by the SEC. Memorandum of Understanding Between the Board of Governors of the Federal Reserve System, the U.S. Commodity Futures Trading Commission, and the U.S. Securities and Exchange Commission Regarding Central Counterparties for Credit Default Swaps, U.S. DeP'T OF THE TREASURY, http://www.treasury.gov/resource-center/fin-mkts/Documents/finalmou.pdf (last visited Dec. $30,2010)$.

${ }^{47}$ For the New York State Banking Department approval, see Banking Department Approved Intercontinental Exchange, Inc. to Form Trust Company to Clear Credit Derivatives, STATE OF N.Y. BANKING DeP'T, http://www.banking.state.ny.us/pr081204.htm (last visited Dec. 31, 2010). The Fed approval was granted as a Board order, dated March 4, 2009. For the SEC approval, see Securities Exchange Act Release No. 34-59527 (Mar. 6, 2009), 74 Fed. Reg. 10791 (Mar. 12, 2009). The SEC order was a temporary order that has since been renewed. As these approvals indicate, ICE Trust operates, as contemplated by the MOU, as a state-chartered bank and as a clearing agency.

${ }^{48}$ See Clearing: ICE Trust, INTERCONTINENTALEXCHANGE, https://www.theice.com/ice_trust.jhtml (last visited Dec. 30, 2010).
} 
(b) The CME Clearinghouse. The CME is a subsidiary of the CME Group, which is a holding company for the CME, the Chicago Board of Trade ("CBOT"), the New York Mercantile Exchange ("NYMEX"), and the Commodity Exchange ("COMEX"). Each of these is a separate legal entity that is a contract market designated as such by the CFTC (a "designated contract market," or "DCM") and operates as a futures exchange.

The CME's clearing operations are a separate division from the exchange, but are housed in the same legal entity as the CME exchange. The CME clearinghouse is separately regulated by the CFTC as a "derivatives clearing organization" (a "DCO"). ${ }^{49}$ CME Clearing clears for both the CME and CBOT. Once a CDS contract submitted for clearing has been accepted, the CME becomes the legal counterparty to the contract in its capacity as a clearinghouse.

In December 2008 the CME certified plans to provide clearing services for CDS, and in March 2009, temporary regulatory approval (since renewed) was granted to allow the CME to perform the functions of a clearing agency for cleared CDS, subject to various conditions. ${ }^{50}$ The CME began clearing CDS in December 2009, and it now clears index CDS. As of the end of September 2010, the CME reported total open interest in cleared CDS of $\$ 35$ million. ${ }^{51}$ Margin provided by clearing members in respect of CDS currently is held in a segregated account. ${ }^{52}$ The CME has

\footnotetext{
${ }^{49}$ A point that may be worth noting in this regard is that the CFTC regulates a number of different types of entities, of which DCMs and DCOs are only two examples. Other regulated trading markets include derivatives transaction execution facilities ("DTEFs"), which are trading facilities with a lower level of regulation; exempt boards of trade ("EBOTs"), which limit transactions to selected participants and commodities; and exempt commercial markets ("ECMs"), which limit trading to principal-to-principal transactions between selected participants on selected commodities. See generally Trading Organizations, U.S. COMMODITY FUTURES TRADING COMM'N, http://www.cftc.gov/IndustryOversight/TradingOrganizations/index.htm (last visited Dec. 31, 2010); see also Andrea S. Kramer, Financial Products: TaXation, Regulation, AND DESIGN $\S 4.02$ (types of commodities markets), $\S 62.01$ (discussion of qualified boards or exchanges) (CCH 3d ed. 2006); William R. PomiERSKI, Special Rules for Certain Energy Futures Contracts and Options, in ENERGY AND ENVIRONMENTAL TRADING: US LAW AND TAXATION ch. 18 (Andrea S. Kramer \& Peter C. Fusaro eds., Cameron 2008). Additional types of trading markets and related acronyms can be expected to be added as a result of the enactment of Dodd-Frank.

${ }^{50}$ See CFTC Announces That CME Has Certified a Proposal to Clear Credit Default Swaps (Dec. 23, 2008), http://www.cftc.gov/PressRoom/PressReleases/pr559208.html (last visited Dec. 31, 2010); Order Granting Temporary Exemptions Under the Securities Exchange Act of 1934 in Connection With Request of Chicago Mercantile Exchange Related to Central Clearing of Credit Default Swaps, 74 Fed. Reg. 11781 (Mar. 19, 2009). As these approvals indicate, the CME clearinghouse operates, as contemplated by the MOU, as a DCO and as a clearing agency.

${ }^{51}$ See CME Group, CDS Market Data Reports, http://www.cmegroup.com/trading/cds/cds-data.html (last visited Dec. 31, 2010).

${ }^{52}$ Very generally speaking, customers clearing CDS through the CME maintain a clearing relationship with a futures commission merchant (an "FCM"), which serves as the customers' agent and guarantor in respect of cleared CDS. From the CME's perspective, its counterparty for cleared CDS consists of each clearing member, with the clearing member acting as agent for unidentified principals - e.g., the customers. Thus, the CME clearing arrangements for CDS resemble those for futures contracts. Under applicable law, FCMs
} 
submitted a request for permission to commingle this margin with margin securing other types of derivatives traded by the CME.

Several chapters of the CME Rulebook deal with clearing. Those rules provide that the Exchange shall maintain and operate a clearing house. Chapter 8F of the CME Rulebook deals with "Over-the-Counter Derivative Clearing." Chapter $8 \mathrm{~F}$ provides rules for submitting an OTC trade on ClearPort and rules providing for the substitution of the CME as counterparty to each side of the trade and the clearing house's guarantee of cleared trades. Chapter 801 of the CME Rulebook deals specifically with clearing CDS.

The CME Group reports daily settlement prices, daily volume, open interest and net changes therein for OTC swaps. The CME Group does not provide bid/ask prices for cleared swaps, as they are not part of the open outcry or electronic trading platform available for futures; instead, bid/ask quotes can be obtained by calling a market participant.

3. Clearing Interest Rate Swaps. ${ }^{53}$ Like a cleared CDS, a cleared interest rate swap is a privately negotiated contract that is submitted to a clearinghouse. The oldest such clearinghouse is known as LCH.Clearnet. LCH.Clearnet is an independent clearinghouse. It clears for many exchanges as well as clearing non-exchange-traded contracts like interest rate swaps.

generally must segregate any property received from a customer as margin for various categories of derivatives and hold it in an account identified as a customer account at a qualified financial institution. CFTC regulations and CME rules impose this segregation requirement on margin provided by CDS customers.

ICE Trust has a different structure. Clearing members under ICE Trust's clearing framework act as principals vis-à-vis both the clearinghouse and customers, rather than as agents. If a customer executes a CDS trade with its clearing member that both parties agree to clear through ICE Trust, the result of the clearing process is that the clearing member will have three principal trades open - a "customer" trade with ICE Trust (that is, a clearing member-ICE Trust trade that is designated as relating to a customer transaction) that is offset by a back-to-back or mirror trade with the actual customer, and a "house" trade with ICE Trust that is the real risk position for the clearing member. (If the clearing member is not the executing dealer, these arrangements involve four parties rather than three.) Thus, from ICE Trust's perspective it deals with the clearing member as a principal, and from the customer's perspective it too deals with the clearing member as a principal. The margin that the clearing member collects from its customer under the mirror trade with the customer can be on-pledged to ICE Trust, as customer margin, under the "customer" trade that the clearing member has with ICE Trust. As in the case of the CME, this margin is segregated for the benefit of the customer.

For discussion of the operation of these rules and open issues under the law prior to Dodd-Frank as to how effective they are to protect CDS customers, see The Buy-Side Report, supra note 45, pts. III.A.1 (CME) \& III.A.2 (ICE Trust); Letter from CME Group to Securities \& Exchange Commission re: Request for Order Exempting Certain Persons from Broker-Dealer Registration and Related Requirements, and from Clearing Agency

Registration and Related Requirements (Dec. 14, 2009), available at http://www.sec.gov/rules/exorders/2009/34-61164-incoming.pdf; Letter from ICE Trust to Securities \& Exchange Commission re: Supplemental Request for Exemption from Certain Provisions of the U.S. Securities Exchange Act of 1934 with Respect to ICE Trust U.S. LLC and its Clearing Members and Request for Extension of the March 6, 2009 Order (Dec. 4, 2009), available at http://www.sec.gov/rules/exorders/2009/34-61119-incoming.pdf.

${ }^{53}$ The information under this heading comes primarily from the websites of LCH.Clearnet, http://www.lchclearnet.com; and IDCG, http://www.idcg.com. 
LCH.Clearnet has cleared interest rate swaps since 1999, and currently clears about forty percent of the global interest rate swap market, in fourteen different currencies. According to LCH.Clearnet's rules, parties enter into interest rate swaps first under bilateral ISDA documentation; when cleared by LCH.Clearnet, the economic terms are preserved but the LCH.Clearnet becomes the legal counterparty to each trade and the legal terms of the trade become LCH.Clearnet standard terms. Accordingly, unlike cleared CDS, the periodic payments made under interest rate swaps cleared by LCH.Clearnet are not standardized. LCH.Clearnet's rules specify payment dates and calculation methodologies for payments and margin determinations.

A more recent entrant to the market is the International Derivatives Clearing House ("IDCH"), a clearinghouse owned by the International Derivatives Clearing Group ("IDCG"), a subsidiary of NASDAQ. Like the $\mathrm{CME}$, the IDCH is regulated by the CFTC. IDCG offers trading in interest rate futures contracts on NASDAQ OMX, a designated contract market that trades many other types of futures contracts. In addition, IDCH offers to clear interest rate swaps through exchange for swap transactions in which bilateral interest rate swaps are exchanged for futures contracts that have economic terms identical to the bilateral interest rate swaps. Thus, as with LCH.Clearnet, the cleared instruments do not have standardized terms. Unlike LCH.Clearnet, however, a party that transacts with IDCH winds up with a contract that is a futures contract as a regulatory matter even though its payment terms are those of a typical interest rate swap.

IDCH first offered this service in December 2008, although it appears that trading has begun only very recently. ${ }^{54}$ This may reflect the fact that IDCH currently has only four clearing members, none of whom are swap dealers; rather, IDCH appears to be oriented primarily towards major participants on the "buy side" or in the futures market. The current volume of open interest appears to be very small. ${ }^{55}$ IDCH nets outstanding contracts only if they have the same fixed rate payment and the same maturity. ${ }^{56}$

The CME began clearing interest rate swaps on October 18, 2010. ${ }^{57}$ The CME also offers a "swap futures" contract that is similar to its other futures contracts except that the settlement at expiration is determined by

${ }^{54}$ See Jeremy Grant, Newedge Swaps Deal Uses IDCH for Clearing, FInANCIAL TIMES, Sept. 15, 2010, available at http://www.ft.com/cms/s/0/600c9bd0-c0ad-11df-94f900144feab49a.html (reporting that Newedge, a futures broker, had brought interest rate swap trades of over $\$ 100$ million to IDCH for clearing).

${ }^{55}$ The IDCH website listed nearly 3900 open contracts as of the end of December 2010 , but it is not clear to this observer what type of contracts they are. See International Clearinghouse Derivatives Group, IDCG Swap Drop,

http://www.swapdrop.com/MarketReport.aspx (last visited Dec. 31, 2010).

${ }^{56}$ IDCH Notice to Members (June 25, 2010), available at http://www.idcg.com/pdfs/idch_bulletins/20100625Noticetomembers.pdf.

${ }^{57}$ See CME Group Begins Clearing OTC Interest Rate Swaps (Oct. 18, 2010), http://cmegroup.mediaroom.com/index.php?s=43\&item=3073\&pagetemplate=article (last visited Dec. 31, 2010) (announcing the beginning of clearing of interest rate swaps, in conjunction with a "group of premier swap dealers, clearing firms, and buy-side market participants"). 
reference to the value of an interest rate swap that pays a 4 percent coupon vs. 3-month LIBOR and has a specified maturity and other terms.

B. Summary of Dodd-Frank's Provisions Relating to Derivatives.

Dodd-Frank repeals existing restrictions on the substantive regulation of OTC derivatives and establishes a regime of substantially parallel regulation for swaps involving single non-exempt securities, loans and narrow-based security indices - to be administered by the SEC - and swaps involving other financial interests and commodities-to be administered by the CFTC. ${ }^{58}$ Important questions affecting the tax consequences of these new rules include (i) the types of "swaps" that are subject to these rules, (ii) the types of exchanges that swaps will be required to trade on, and (iii) the parties that are subject to or exempt from these rules,

Under Dodd-Frank, swaps and the market participants that enter into them will be subject to comprehensive regulation, in some ways more restrictive than existing regulation of the securities markets. Requirements will include: registration and capital, margin and business conduct requirements for swap dealers and major swap participants; mandatory clearing and trading requirements for potentially all standardized swaps; real-time public transaction reporting; and a provision limiting the scope of permitted swap activities that may be conducted by certain swap entities that receive Federal assistance. Notwithstanding the many complex definitional and other issues that will need to be resolved in order to implement these new rules, they will, for the most part, come into effect roughly one year after enactment.

1. Definition of "Swap". The term "swap" is broadly defined to include most widely traded types of OTC derivatives, although it excludes certain specified categories of transactions such as options on securities (as determined for securities law purposes). More specifically, the statutory definition of the term "swap" generally includes puts, calls, collars, forwards, a list of 22 specified types of swaps, and any transaction that is or in the future becomes commonly known to the trade as a swap. ${ }^{59}$ As the list may be relevant to the analysis of the scope of Dodd-Frank's amendment to $\S 1256$, it is provided here:

(I) an interest rate swap;

(II) a rate floor;

(III) a rate cap;

(IV) a rate collar;

\footnotetext{
${ }^{58}$ Dodd-Frank Wall Street Reform and Consumer Protection Act, Pub. L. No. 111203, § 721, 124 Stat. 1376, 1658-72 (2010) (amendments to the Commodity Exchange Act, including the definition of "swap"); § 761, 124 Stat. 1376, 1754-59 (2010) (amendments to the Securities Exchange Act of 1934, including the definition of "security-based swap").

${ }^{59}$ The definition of "swap" takes four single-spaced pages in the official printed version of Dodd-Frank.
} 
(V) a cross-currency rate swap;

(VI) a basis swap;

(VII) a currency swap;

(VIII) a foreign exchange swap;

(IX) a total return swap;

(X) an equity index swap;

(XI) an equity swap;

(XII) a debt index swap;

(XIII) a debt swap;

XIV) a credit spread;

(XV) a credit default swap;

(XVI) a credit swap;

(XVII) a weather swap;

(XVIII) an energy swap;

(XIX) a metal swap;

(XX) an agricultural swap;

(XXI) an emissions swap; and

(XXII) a commodity swap. ${ }^{60}$

Technically, a "swap" is subject to the CFTC's jurisdiction and a "securitybased swap" is subject to the SEC's jurisdiction. For purposes of this article, since the clearing and trading rules applicable to these two categories are parallel, both will be referred to as "swaps."

The definition of "swap" excludes futures contracts, although the distinction between a swap and a futures contract is not entirely clear. It also excludes any foreign currency contract traded on an exchange, presumably to preserve the current regulatory treatment of various foreign currency-linked products now trading on commodities exchanges, and grants authority to Treasury to exclude foreign exchange swaps and/or foreign exchange forwards from certain provisions of Dodd-Frank. ${ }^{61}$ Given the breadth of these definitions, it is clear that at least some "swaps" subject

\footnotetext{
${ }^{60}$ Dodd-Frank Wall Street Reform and Consumer Protection Act, Pub. L. No. 111203, § 721(a)(16), 124 Stat. 1376, 1663 (2010) (adding new paragraph 47 to $\S 1$ a of the Commodity Exchange Act, 7 U.S.C. 1a).

${ }^{61}$ Id. The Treasury Department has requested public comment on whether to exercise this authority. Determination of Foreign Exchange Swaps and Forwards, 75 Fed. Reg. 66426 (Oct. 28, 2010). A number of financial industry associations and market participants have submitted letters recommending that such contracts be excluded from "swap" treatment to the extent permitted by Dodd-Frank.
} 
to the new rules will be treated as something other than NPCs for tax purposes.

Dodd-Frank expressly pre-empts regulation of swaps as insurance under state insurance law, but does not draw a clear distinction between swaps, on the one hand, and insurance products, on the other. ${ }^{62}$ This prohibition is of particular relevance for CDS, as there were a number of efforts by state insurance regulators and legislators after AIG FP's bailout to define CDS that are used to hedge risks as insurance, to prohibit any other CDS, i.e., to ban "naked" or speculative CDS, and to require that a permitted CDS be written by an insurance company. ${ }^{63}$

2. Clearing and Exchange-Trading Requirements. Swaps subject to mandatory clearing through a central counterparty will be designated by the CFTC or SEC, as applicable. ${ }^{64}$ Ordinarily it is likely that a clearinghouse will propose that a category of swap be so designated. The agencies may also act on their own initiative, in which case if a clearinghouse does not then decide to clear the swap, transactions in that product would effectively be prohibited. In determining whether a swap should be required to be cleared, the relevant agency must consider various factors, including liquidity, adequate pricing data, effect on mitigation of systemic risk and legal certainty in the event of the insolvency of the clearinghouse. Swaps in existence at the time of Dodd-Frank's enactment

${ }^{62}$ Id. § 722(b), 124 Stat. 1376, 1673 (2010) (a "swap" shall not be considered to be insurance and shall not be regulated as an insurance contract under any state law), $\S 767,124$ Stat. 1376, 1799-800 (2010) ("security-based swaps" may not be regulated as insurance under state law).

${ }^{63}$ Historically, CDS were not treated as insurance, based largely on a June 2000 opinion from the State of New York Office of the General Counsel ("NYOGC") that examined a particular type of CDS and determined that the absence of an insurable risk rendered CDS not insurance. Funding Agreement Securitizations, State of New York Office of General Counsel (Apr. 18, 2000), available at http://www.ins.state.ny.us/ogco2000/rg004181.htm. In late 2008, however, the NYOGC announced that it was reconsidering the issue, and testimony from Eric Dinallo, New York's Superintendent of Insurance, before the House Committee on Agriculture (which oversees the CFTC) suggested that CDS used for hedging purposes might be regulated as insurance. State of New York, Insurance Dep't, Office of Gen. Counsel, "Best Practices" for FinANCIAL GUARANTy ISSUERS, CirCUlAR LETTER No. 19 (Sept. 22, 2008), available at http://www.ins.state.ny.us/circltr/2008/cl08_19.htm; Hearing to Review the Role of Credit Derivatives in the U.S. Economy: Hearing Before the H. Comm. on Agriculture, 110th Cong. 79-81 (2008) (statement of Eric Dinallo, Superintendent, Insurance Department, State of New York), available at http://agriculture.house.gov/testimony/110/h91120/Dinallo.pdf. For a discussion of the actions taken by the New York State Insurance Department, see A. Kramer, A. Harris \& R. Ansehl, supra note 28. The insurance regulators of some other states also asserted jurisdiction over CDS. State insurance regulators subsequently drafted a model law that, if adopted and not preempted by federal law, would have banned CDS unless used to hedge another position and would have required all permitted CDS to be written by insurance companies. National Conference of Insurance Legislators, Proposed Credit Default Insurance Model Legislation, available at http://www.ncoil.org/schedule/200930Day/Annual30Day/CDIModel.pdf.

${ }^{64}$ The clearing requirements for swaps are in Section 723 of Dodd-Frank. There are parallel rules for security-based swaps in Section 763 of Dodd-Frank. Dodd-Frank Wall Street Reform and Consumer Protection Act, Pub. L. No. 111-203, § 723, § 763, 124 Stat. $1376,1675-82$ (2010). 
are not subject to mandatory clearing and trading, but may be subject to the margin requirement described below.

Margin for cleared swaps will be subject to requirements generally similar to those that currently apply to FCMs for futures, and a dealer in swaps (but not security-based swaps) will be required to register as a FCM in order to accept such margin. ${ }^{65}$ Swaps that are not cleared also will be subject to initial margin and variation margin requirements imposed by regulators. The level of margin that will be required for such swaps is unclear, but colloquies on the floor of Congress indicate that they are intended to be less onerous than the margin requirements for cleared swaps.

Swaps subject to the mandatory clearing requirement will be required to be traded on a national securities exchange, a designated contract market or new type of regulated trading facility called a "swap execution facility," unless no exchange or swap execution facility makes the swap available to trade. A swap execution facility is defined as a trading system in which multiple participants have the ability to execute or trade swaps by accepting bids and offers made by multiple participants in the system. ${ }^{66}$ The agencies are currently considering what types of arrangements will be treated as satisfying this standard.

The "unless" clause above may be significant. The CFTC and SEC are required to prescribe rules defining the universe of swaps that "can" be executed on a swap execution facility. ${ }^{67}$ The standard to be used in applying this provision is not clear. However, swaps falling outside this universe will be permitted to be executed through any other available means of interstate commerce. Thus, it may be the case that some categories of swaps are subject to mandatory clearing but not mandatory trading requirements.

3. Swap Dealers, Major Swap Participants and EndUsers. Dodd-Frank provides specific rules for categories of persons termed swap dealers, major swap participants and end-users. ${ }^{68}$ Swap dealers and major swap participants are subject to the mandatory clearing and trading requirements described above. They must register with the CFTC and SEC, and are subject to new capital and disclosure requirements.

The term "swap dealer" generally includes any person who is a dealer or market maker in swaps or who "regularly enters into swaps with counterparties as an ordinary course of business for its own account", but not someone who enters into swaps other than as part of a regular business. A non-dealer will be treated as a "major swap participant" if (i) it maintains

\footnotetext{
${ }^{65}$ Dodd-Frank Wall Street Reform and Consumer Protection Act, Pub. L. No. 111203, $\S 724,124$ Stat. 1376 (2010) (adding subsection (f) to $\S 4 \mathrm{~d}$ of the Commodity Exchange Act, 7 U.S.C. 1a).

${ }^{66} I d . \S 721,124$ Stat. 1376 (2010) (adding paragraph (50) to $\S 1$ a of the

Commodity Exchange Act, 7 U.S.C. 1a).

${ }^{67}$ Id. $\S 733$, 124 Stat. 1376 (2010) (adding subsection (d) to $\S 5 \mathrm{~h}$ of the Commodity Exchange Act, 7 U.S.C. 1a).

${ }^{68}$ Id. $\S 721,124$ Stat. 1376 (2010) (adding paragraph (49) to $\S 1$ a of the Commodity Exchange Act, 7 U.S.C. 1a).
} 
a substantial position in swaps, other than positions held for hedging or mitigating commercial risk, (ii) its outstanding swaps create "substantial counterparty exposure that could have serious adverse effects on the financial stability of the United States banking system or financial markets," or (iii) it is a "financial entity" that is "highly leveraged relative to the amount of capital it holds" and maintains a "substantial position" in swaps (whether or not such swaps are held for hedging purposes), unless it is subject to bank capital requirements. ${ }^{69}$

Dodd-Frank exempts an "end user" from the mandatory clearing (and therefore mandatory trading) requirements. ${ }^{70}$ The end user exemption was intended for operating companies that use derivatives to hedge their business risks. An "end user" is defined as a person who (a) is not a "financial entity," (b) is using swaps to hedge or mitigate commercial risk and (c) notifies the CFTC or SEC, as applicable, how it generally meets its financial obligations associated with entering into non-cleared swaps. End users may, however, require that a swap be cleared, in which case they may designate the clearinghouse to which the swap is to be submitted.

Parties that do not fall into these three categories presumably are subject to the mandatory clearing and trading requirements, but not the other regulatory rules applicable to swap dealers and major swap participants.

\section{Upfront Payments.}

An unexpected byproduct of clearing swaps is that it can, and has in the case of CDS, give rise to regular upfront payments on those swaps, or potential deemed upfront payments for tax purposes. As described in Section I.B.1, above, under the timing rules applicable to NPCs, an upfront payment on an NPC is required to be taken into account over the life of the NPC, will be treated as a deemed loan for U.S. federal income tax purposes if the amount of the upfront payment is "significant," and may be treated as an investment in United States property whether or not it is "significant." Accordingly, it is useful to understand the causes of upfront payments and the corresponding cash flows that they give rise to.

1. Standardization of Coupons - In General. If the coupons on a swap eligible for clearing are permitted to be set only at prescribed levels, there will ordinarily be an upfront payment on the swap in order to bring the cash flows of the swap as a whole back to a market level. This was illustrated in Section I.B.1, above, for interest rate swaps, where it was assumed that the market level for the fixed leg of an interest rate swap was 6 percent but that the periodic payment on the swap was 5 percent. In the case of interest rate swaps, an upfront payment will be equal to the present value of the difference between the standard coupon and the market coupon over the stated term of the swap. Accordingly, determining

\footnotetext{
${ }^{69} I d$. $\S 721,124$ Stat. 1376 (2010) (adding paragraph (33) to $\S 1$ la of the Commodity Exchange Act, 7 U.S.C. 1a).

${ }^{70}$ Id. $\S 723,124$ Stat. 1376 (2010) (adding paragraph (7) to $\S 2(\mathrm{~h})$ of the Commodity Exchange Act, 7 U.S.C. 1a).
} 
the upfront payment is relatively straightforward, as long as the parties agree on the appropriate discount rate.

As described above, currently no clearinghouse clearing interest rate swaps requires standardized coupons. Even if a clearinghouse does not require standardized coupons, however, individual trades may be entered into off-market for hedging or other purposes, or conceivably a segment of the market might choose regularly to enter into swaps with standardized coupons in order to more easily net their outstanding swaps and to reduce the costs of maintaining their swap portfolio. For interest rate swaps, therefore, it is uncertain how common it will be for cleared swaps to be entered into with an upfront payment but it does not seem to be an unlikely possibility.

As described earlier, the CDS market historically traded with market-level coupons in the case of single-name CDS, and with a fixed coupon in the case of index CDS. As a prelude to the beginning of clearing of CDS in the fall of 2009, it was necessary to standardize the legal terms of CDS. Coupons also were standardized for new CDS, as part of the same process. Because the process and its results may be relevant for other classes of swaps, that transformation is described below in more detail.

2. Standardization of CDS Coupons. ${ }^{71}$ As discussed earlier, one significant consequence of the move towards the standardization of the terms of CDS is that coupon payments for CDS are now either 100 basis points or 500 basis points multiplied by the notional principal amount. ${ }^{72}$ Although the standardization of coupons was adopted as a prelude to clearing CDS through a regulated clearinghouse, bilateral CDS in the OTC market also now use these standardized coupons. It seems reasonable to think that this phenomenon - the adoption by the OTC market of conventions used for cleared swaps - will recur, in order to accommodate parties transacting in both markets.

This change to the payment terms of CDS did not affect the market's perception of the risk associated with buying or writing protection on a particular reference entity. In more technical terms, the market quoted level for a CDS coupon was not affected by the standardization of coupons. As a result, the advent of standardized coupons for single-name CDS also brought with it the need for one party to the CDS to make an upfront payment to keep the other party whole. To give an example, if the market quoted level of a particular CDS was 175 basis points, and the standardized coupon for that swap is 100 basis points, the party that will be making the below-market coupon payments will be obligated to make an upfront

\footnotetext{
${ }^{71}$ I am indebted to Biswarup Chatterjee of Citigroup Global Markets for his insights into the pricing of CDS and the operation of the converter described below, for the examples set forth below, and for reviewing this section of the article. Any errors in the discussion are of course mine. Possibly it would help if I had understood calculus.

${ }^{72}$ This is true for North American corporate reference entities and for emerging market corporate and sovereign reference entities. There are more standard coupon levels for European reference entities. The discussion in this Section II.C assumes that the CDS described is a CDS on a single North American corporate reference entity.
} 
payment to the other party in order to keep it whole. (The payor will receive back an equivalent amount as collateral - more on this below.)

Upfront payments in the CDS market are not entirely new. A CDS on an index of reference entities ordinarily fixes a coupon for each series of the index when the composition of the series is fixed. Any trades entered into at a later time on that same series of the index will be entered into with the same coupon even if that coupon is no longer at market, in which case one party will need to compensate the other through an upfront payment. ${ }^{73}$ Since most indices create a new series semi-annually, and since the market tends to prefer the "on the run" series, it seems likely that upfront payments were smaller for index CDS than is now the case for single-name CDS, although there is no information publicly available to confirm this point.

Unlike interest rate swaps, the determination of an upfront payment on a standard coupon CDS is quite complex. It is helpful in understanding the calculation of upfront payments on standard coupon CDS to start by discussing the pricing of pre-standardized CDS, since upfront payments are determined by "converting" the difference between standard coupons and market-level coupons into a single lump sum payment.

(a) Coupons on Pre-Standardized CDS. The coupon level for a pre-standardized CDS was struck at the market quoted level, determined in a manner similar to determining the yield at which a bond trades. A bond at issuance might have a coupon of 6 percent, for example, in which case one would expect the coupon level for a CDS on that bond to reflect the credit spread on the bond, say 4 percent (400 basis points). If the issuer's financial condition weakened, the bond would trade at a discount, i.e., with a yield greater than 6 percent, and a new CDS entered into at that time would have a higher coupon; the reverse would be true if the issuer's financial condition improved. Consequently, a CDS entered into on any given day on a particular reference entity could and often did have a coupon different from a CDS on the same reference entity on any other day. Other terms of the CDS, for example maturity date, also could differ.

As described earlier, the coupons would be paid over the life of the trade, or until the date of a credit event, if any. On a daily basis, at least one party to the trade (the dealer) would mark the CDS to market by reference to the present value of the difference between the original coupon and the now-current market level on which the same CDS could be executed. Again, this mark-to-market valuation was similar to determining the current

\footnotetext{
${ }^{73}$ An example of such an index is the CDX.NA.IG, which is an index of 125 North American investment grade issuers. Information about this index is available through Markit. See Markit Indices, http://indices.markit.com/default.asp (last visited Dec. 31, 2010). In the case of CDS on an index of reference entities, typically the index is reformulated every 6 months to adjust the relative weightings of the index names and/or to add or subtract reference entities so that the index continues to reflect the relevant segment of the fixed income market - much like the process followed for rebalancing and reconstituting standard equity indices. Each reformulation is a new "series" of the index. CDS trades on the index may reference any series created to that point, although more typically they reference the most recent series.
} 
price for a bond by discounting the cash flows on the bond by current interest rates and credit spreads. The CDS had a zero mark-to-market value on the trade date, meaning that the present value of the coupons was equal to the value of the protection provided by the CDS. Most CDS trades matured without ever having credit event settlement payments. ${ }^{74}$

(b) Calculating the Upfront Payment on a Standardized CDS. A standardized CDS also provides for periodic coupon payments, at the 100 basis points or 500 basis points level. If the current market quoted level for a CDS with a standard 500 basis points coupon is 400 basis points, the protection seller will make an upfront payment to the protection buyer to compensate the protection buyer for overpaying coupons by 100 basis points as compared to the market level. If the market coupon for the CDS is 550 basis points, the protection buyer will make an upfront payment to the protection seller to compensate the protection seller for the 50 basis points shortfall in standard coupon payments as compared to the market quoted level. Thus, an upfront payment may be made by either party to a standardized CDS.

Before turning to the calculation of the upfront payment, it is worth discussing how the market quoted level for a CDS is determined. Very generally speaking, the market quoted level for a CDS is determined primarily by reference to (a) an estimate of the probability of default by the reference entity, and (b) an appropriate (interest rate) discount curve. ${ }^{75}$ The first of these variables is actually not a single number, as pricing models estimate the probability of default at multiple times during the term of the CDS, and those estimates are path-dependent. For example, it may be very unlikely that issuer $\mathrm{X}$ will default in years 1 and 2, much more likely in year 3 because the issuer has outstanding debt coming due in that year, and then less likely in year 4 because the issuer will survive to year 4 only if it can manage its liabilities in year 3.

\footnotetext{
${ }^{74}$ I have been advised that historically, a very small percentage of the reference entities for which CDS are traded have experienced credit events, and that this is true even taking the credit crisis and recession into account, because (a) CDS exist on only a limited number of reference entities, which do not include all of the companies that have failed, and (b) an issuer may be perceived by the market to have failed without triggering a CDS credit event, for example if the issuer is rescued from actual failure by being acquired. As of the end of December 2010, ISDA listed 4 reference entities as having active credit events, and over 50 reference entities with prior credit events, for CDS (including loan-only CDS) on corporate reference entities. By way of comparison between healthy and troubled markets, there are only 6 credit events listed for the years 2007 (0), 2006 (3) and 2005 (3), which is as far back as the ISDA information goes, with all of the remainder arising in 2008, 2009 and 2010. See ISDA Credit Derivatives Determinations Committees, http://www.isda.org/credit (last visited Dec. 31, 2010).

${ }^{75}$ This discussion does not address a CDS on a reference entity considered highly likely to default in the near term. The upfront payment on such a CDS would be determined primarily by reference to the expected recovery in bankruptcy for a holder of the issuer's debt. In the market's jargon, a CDS of this kind would be "quoted upfront" or quoted as "points upfront," rather than quoted using a par spread.

The upfront payment generally does not take into account the creditworthiness of the parties. In the case of cleared CDS, that is because the clearinghouse becomes the legal counterparty to the trade. In the case of OTC-only CDS, the parties typically manage credit risk by taking or providing collateral.
} 
It is in the nature of things that the two parties to a CDS ordinarily will have different judgments about these variables. That is, the reason one party is willing to buy protection and the other is willing to sell protection at a specified market quoted level is because they have different views as to what the "right" market level should be. Furthermore, the fact that a CDS on reference entity $\mathrm{X}$ has the same market quoted level as a CDS on reference entity $\mathrm{Y}$ does not mean that the probabilities of default are the same for $\mathrm{X}$ and $\mathrm{Y}$. Even if all other variables are held constant, if $\mathrm{X}$ (as above) is at greatest risk for default in year 3 while $\mathrm{Y}$ is at greatest risk for default in year 2 but perhaps is considered overall more creditworthy, the shape of the "survival curve" for $\mathrm{X}$ and $\mathrm{Y}$ will differ.

The parties to a CDS will, therefore, first agree on a market quoted level for a CDS, in the same manner as they did prior to CDS standardization. They will then "convert" the difference between the agreed market quoted level and the standardized coupon into a single lump sum payment. (The upfront payment also adjusts for the coupon amount that has accrued prior to entering into the trade, a refinement that will be ignored for purposes of this discussion.)

Calculating the upfront payment is not for the faint of heart. Fortunately, in order to avoid disputes, the market has developed a standard "converter" that can be used to convert market coupons into an upfront payment. ${ }^{76}$ The converter is based on a number of simplifying assumptions with respect to both the terms of a CDS and key economic variables. ${ }^{77}$ As a result, using the converter for a standardized CDS is mechanically straightforward - one simply inputs the trade date; whether one is acting as protection buyer or seller; the standardized coupon, maturity date and recovery rate; ${ }^{78}$ the notional principal amount; and the currency - and out pops a number.

Note that the simplified assumptions used by the converter with respect to the discount and survival curve are likely to differ from the inputs used by the parties when agreeing on the market quoted level. For example, because the market quoted level for CDS on reference entities $\mathrm{X}$ and $\mathrm{Y}$ described above is the same, the converter would assume that the survival curve for reference entities $\mathrm{X}$ and $\mathrm{Y}$ is also the same. This

\footnotetext{
${ }^{76}$ The standard upfront calculator was developed by ISDA. Markit helpfully provides a "converter" on its website that requires inputting only the variables described in the text above. See Markit CDS, http://www.markit.com/cds (last visited Dec. 31, 2010).

${ }^{77}$ In particular, the converter uses a yield curve derived from certain money market deposits and interest rate swaps maturing at different times and using flat forward rates to determine the yield for interpolated dates (dates on which no deposit or swap matures). The converter also derives an assumed probability of default for a series of specified dates (the survival curve) - analogous to looking at interest rates for specified dates - and assumes that the probability of default is constant between those dates. The probability of default is determined by reference to the ratio between the risk-free interest rate and the credit spread for the particular reference entity. The assumed yield curve and survival curve are then input into a formula that is beyond me to describe, having cheerfully forgotten all the calculus I ever knew.

${ }^{78}$ The "recovery rate" is the amount that a holder of a debt instrument would recover in bankruptcy. For purposes of the upfront calculator, the recovery rate input for senior debt is assumed to be $40 \%$, and for subordinated debt it is assumed to be $25 \%$.
} 
divergence from more realistic assumptions does not matter on the trade date, but as discussed below can affect the amount of variation margin paid during the term of the CDS. In the case of an OTC-only CDS, the parties are not bound to use the same assumptions or methodology as the converter described above in order to determine initial margin for the CDS, but typically will in fact follow the ISDA-recommended guidelines.

(c) Examples. It is helpful in understanding how the standard converter described above works to see some examples. ${ }^{79}$ In each of these examples, Party A buys protection from Bank (and so pays coupons to Bank) on XYZ Corp. as reference entity; the notional amount is $\$ 10$ million; the CDS has a term of 5 years; and the market coupon and the standard coupon differ by 75 basis points.

Example 1 (standard coupon 75 basis points below market level)

- Underlying market level 575 basis points, standard coupon 500 basis points

- Party A1 (buyer of CDS) pays $\$ 244,000$ upfront, and pays 500 basis points per year

Example 2 (standard coupon 75 basis points below market level)

- Underlying market level 175 basis points, standard coupon 100 basis points

- Party A2 (buyer of CDS) pays $\$ 335,000$ upfront, and pays 100 basis points per year

Example 3 (standard coupon 75 basis points above market level)

- Underlying market level 25 basis points, standard coupon 100 basis points

- Party A3 (buyer of CDS) receives (not pays) $\$ 377,000$ upfront, and pays 100 basis points per year

It is worth dwelling on these examples for a few minutes. First, if we compare examples 1 and 2, which both involve cases where the market quoted level is 75 basis points above the standard coupon, we see that the upfront payment is less for CDS \#1, where the standard coupon is 500 basis points than for CDS \#2, where the standard coupon is 100 basis points. That is because the implied risk that there will be a credit event with respect to the reference entity during the term of the CDS is higher for CDS \#1 than for CDS \#2. Since coupon payments will cease to be paid if there is a credit event, the value of the right to receive the "missing" stream of 75 basis point periodic payments is less for CDS \#1 than for CDS \#2.

To put this differently, as an economic matter one cannot simply translate the upfront payments on these CDS into a 5-year annuity paying 75 basis points on a periodic basis, because the risk that the annuity will be

${ }^{79}$ These examples assume that the risk-free interest curve is the same in each case, another "unrealistic" assumption. See attached diagram for illustrations of these examples. 
cut short is significant enough to affect the value of the annuity. Moreover, given the path-dependent nature of the default probability curve, it would be a simplification to treat the upfront payment as representing the present value of a stream of 75 basis point amounts to a fixed date, say year 3 for CDS \#1 and year 4 for CDS \#2. Consider the example referred to above of issuer $\mathrm{X}$, which may fail in year 3 but if it survives is likely to be in stronger condition in year 4 . Given those facts, the foregone right to receive 75 basis points in year 4 will have some current value for both CDS $\# 1$ and \#2, but a different value.

Examples 2 and 3 demonstrate the same point. Because the risk of a credit event for CDS \#3 is considered very low, the value of the upfront payment is higher for CDS \#3 than for CDS \#2. Moreover, since the coupons Party A3 will pay are higher than the true cost of the protection Party A3 is buying, Party A3 will receive rather than pay the upfront amount. This last point is not unique to CDS; the same would be true if Party A3 were a party to an interest rate swap and had agreed to pay an above-market coupon. It is less intuitive, however, as one tends to think of Party A3 as buying the right to a potential future cash settlement payment on the CDS, and therefore as a payor rather than a payee prior to a credit event.

(d) Mark-to-Market; Collateral. As described earlier, once the parties have entered into a standardized CDS and it has been accepted for clearing, on a going-forward basis the CDS will be marked to market on a daily basis. The mark-to-market value of each trade is calculated by estimating the value of the difference between the standard coupon and the underlying market quoted level at which the same trade could be executed on the current date, using the converter to determine the then-value of the CDS. The mark-to-market is the same for both parties, positive to one party (treated as the "in-the-money" party) and negative to the other (treated as the "out-of-the-money" party). As described above, variation margin will be paid on a daily basis by the out-of-the-money party to the in-the-money party.

A less obvious point is that the need to exchange variation margin (collateral) is created immediately when the parties enter into a standard coupon CDS - that is, variation margin for a standard coupon CDS reflects not merely changes in value on a going-forward basis, but also the terms of the CDS at the very moment when entered into. Returning to example 1 above, the CDS is off-market by $\$ 244,000$ when entered into. Ignoring the upfront payment, the CDS is in-the-money to Party A1 (i.e., the CDS has "gained" value for Party A1 compared to a CDS with market level coupons), because Party A1 is only required to pay 500 basis points while the market level is 575 basis points. Conversely, the CDS is out-of-themoney to Bank (i.e., the CDS has "lost" value for Bank). Consequently, the day 1 mark-to-market requires Bank to provide $\$ 244,000$ of collateral to Party A1. The day 1 cash flows-the upfront payment and the corresponding variation margin - thus net to zero, assuming that the CDS is valued at the end of the day at the same market level that it was executed 
at during the day. ${ }^{80}$ This point is potentially of great significance for tax purposes, since in at least some observers' minds it calls into question whether the conventional rules for upfront payments on NPCs should apply to upfront payments on cleared swaps.

Another way to understand the reason for the immediate and offsetting variation margin payment is that if Bank were to go bankrupt immediately after receiving Party A1's upfront payment of $\$ 244,000$, Bank would neither return the foregone stream of 75 basis point payments nor provide any protection to Party A1. Party A1 would have a claim against Bank based on the unwind value or mark-to-market value of the CDS contract. Party A1 therefore has $\$ 244,000$ of credit risk to Bank, which Bank must collateralize by providing initial variation margin. Over time, assuming no other changes to the market or the reference entity, Party A1 would repay that collateral to Bank. Because the repayment is determined by reference to daily marks to market, and as described above as a practical matter the default probabilities for a particular issuer vary at different times during the term of the CDS, the repayment would not be paid in level 75 basis point amounts. Rather, in the case of issuer $\mathrm{X}$ described above, relatively small amounts of collateral would be repaid in years 1 and 2, and a larger amount in year 3 if the issuer survives. Of course, in reality, the collateral would be adjusted daily to take actual changes in the value of the CDS into account.

Similarly, if other types of swaps with standardized coupons are submitted to a clearinghouse, one can expect that upfront payments will also give rise to an immediate and offsetting payment of initial variation margin.

There are two other aspects of the collateral arrangements described in this Section II.C2(b) that have larger implications. The first is that while the bilateral OTC market historically has required collateral, usually from a customer to a dealer but not vice versa, except in unusual circumstances, actual collateral arrangements varied from customer to customer, depending on the sophistication of the customer, the level of credit risk it posed and the dealer's willingness to please the customer. The OTC market is now moving towards collateral arrangements that are much closer to those for cleared swaps. Accordingly, while upfront payments are becoming more common, the actual net cash flows associated with them may not be.

The second is that clearinghouses net outstanding cleared contracts daily, in a manner similar to the netting of futures contracts described in Section II.A.1, above. Accordingly, if a dealer enters into a CDS today with a notional principal amount of $\$ 100$ and makes an upfront payment of $\$ 7$, and tomorrow it enters into an identical but offsetting CDS with a

${ }^{80}$ If the CDS value has changed by the end of the day, the cash flows will not net perfectly. For purposes of the discussion in the remainder of the article, it is assumed that notwithstanding this circular flow of cash, the upfront payment is treated as "real," unless otherwise stated.

A diagram illustrating the cash flows described in the text is attached. 
notional principal amount of $\$ 25$ and receives an upfront payment of $\$ 2$, the clearinghouse will net the dealer's outstanding contracts so that at the end of the second day it has a single contract with the clearinghouse with a notional principal amount of $\$ 75$. Under these circumstances, it seems reasonable to treat the dealer as having received back $\$ 2$ of its original $\$ 7$ on the second day, rather than - as assumed by the NPC regulations - over the life of the CDS.

3. Other Types of Upfront Payments. Upfront payments made be made, or possibly deemed made, on cleared swaps for reasons other than standardization. Three such circumstances are closing out cleared swaps, "backloading," and clearing member default.

To close out a cleared swap, a party engages in the same process as to enter into one. That is, it agrees with another party on a private bilateral basis to enter into a swap and to submit the swap for clearing. The swap will have terms that offset its existing swap, e.g., if the first swap calls for the party to pay 6 percent $\mathrm{x} \$ 100$ million for five years, the second swap will call for the party to receive 6 percent $x \$ 100$ million for five years. As described above, the clearinghouse will net those two swaps, leaving the party with a zero net position. If the value of the swap has changed in the party's favor since the party entered into the first swap, it will have received variation margin on the first swap, which in effect it will be entitled to keep once the swap is closed out. That is, the variation margin will have turned into realized gain.

Because the new swap offsets the first swap, the party also will be obligated to make an upfront payment on the second swap (which it will get back as variation margin, as described above) ${ }^{81}$ As a result, although the second swap just closes out the first swap, it looks like a new transaction with a new upfront payment. As a practical matter, it may be difficult to keep track of when a new swap is really a new transaction as opposed to the closing out of an old transaction. And since a swap is likely to have changed in value when it is closed out, upfront payments on close-out swaps are expected to be common.

Backloading and clearing member defaults may or may not give rise to deemed upfront payments. Backloading is the process of moving historic bilateral swaps into a central clearing system. Since those swaps will be off-market when cleared, there will be an immediate variation margin payment made. Posting cash collateral is a type of deposit or loan (although not an investment in United States property, under § 956(c)(2)(I), at least for dealers). Moreover, if the clearing of the swap is treated as a "section 1001 event," the "new" swap would be deemed to have an upfront

${ }^{81}$ That is, assuming that the original swap is now $\$ 5$ in the money to this party, the party will have received $\$ 5$ of variation margin on the first swap, will make a $\$ 5$ upfront payment on the second swap and will receive back $\$ 5$ of variation margin on the second swap. When all is said and done, the party has $\$ 5$ that it is entitled to keep outright. 
payment. $^{82}$ A clearing member default raises similar issues, because the defaulting member's swaps may be transferred to another clearing member.

With apologies to the reader for the lengthy and meandering prelude, Part III next turns to the first principal issue discussed in this article, namely the meaning and implications of Dodd-Frank's amendment to $\S 1256$.

\section{THE DODD-FRANK AMENDMENT TO SECTION 1256.}

Dodd-Frank has sixteen titles covering 849 pages in the official printed version. On the very last of those pages, there is an amendment to $\S$ 1256. As this placement suggests, the $\S 1256$ amendment was added to Dodd-Frank very late in the legislative process, during the conference between the House and Senate to reconcile their differing versions of the bill. The legislative history to this amendment consists of a single sentence. The operative provision in the amendment and the legislative history are as follows:

Amendment:

The term 'section 1256 contract' shall not include-

"(B) any interest rate swap, currency swap, basis swap, interest rate cap, interest rate floor, commodity swap, equity swap, equity index swap, credit default swap, or similar agreement." 83

Legislative history:

[Title 16] contains a provision to address the recharacterization of income as a result of increased exchange-trading of derivatives contracts by clarifying that section 1256 of the Internal Revenue Code does not apply to certain derivatives contracts transacted on exchanges. ${ }^{84}$

At a high level, the questions raised by this amendment are (i) what financial instruments are within its scope - more specifically, what constitutes a "similar agreement," and (ii) whether OTC financial instruments outside the amendment's scope that are traded on an exchange pursuant to Dodd-Frank currently constitute section 1256 contracts. The

\footnotetext{
${ }^{82}$ See supra note 44, for a discussion of the potential for a deemed exchange of swaps under $\S 1001$ when an existing swap is cleared by a regulated clearinghouse.

${ }^{83}$ Dodd-Frank Wall Street Reform and Consumer Protection Act, Pub. L. No. 111203, § 1601, 124 Stat. 2223 (2010), amending § 1256(b). Section 1256(b) defines the term "section 1256 contract" and provides certain exclusions to that term.

${ }^{84}$ H.R. REP. No. 111-517, at 879 (2010) (Conf. Rep.).
} 
rather limited legislative history does not provide a great deal of insight into these questions, but when one takes into account the history of $\S 1256$ and the backdrop to this amendment, some answers suggest themselves. In view of the magnitude of the stakes and the scanty legislative history, however, it is highly desirable that answers be forthcoming from a more authoritative source, meaning the Treasury and Service. Service officials have unofficially acknowledged the importance of these issues and the utility of guidance, so it is possible that enlightenment will be forthcoming.

Before turning to a discussion of the questions set forth above, therefore, it is worth stopping to consider what policy considerations might inform any such guidance. Those considerations might include (i) the Administration's clear preference to limit the scope of $\S 1256,{ }^{85}$ (ii) the reasonably consistent approach taken by Congress, the government and the courts over time to interpret the definition of "regulated futures contract" and other types of section 1256 contracts in a manner that limits the definition to the type of financial instruments under consideration by Congress when that term was added to the Code - this history is discussed in Section III.B, below, (iii) more broadly, the general lack of interest by lawmakers to require taxpayers to mark assets to market notwithstanding the policy arguments that can be made in favor of a broader mark-to-market regime, ${ }^{86}$ and (iv) the lack of any intent on Congress's part to change the

${ }^{85}$ See, e.g., DEP'T OF THE TREASURy, GenERAL EXPLANATIONS OF THE Administration's Fiscal Year 2011 ReVEnUE Proposals 32 (February 2010) (proposing to eliminate $60 / 40$ treatment for dealers in commodities and commodities derivatives), available at https://www.treas.gov/offices/tax-policy/library/greenbk10.pdf.

${ }^{86}$ Arguments for and against a broader mark-to-market regime have been made by a number of academics and other commentators over the years. See, e.g., Yoram Keinan, Mark-to-Market for Derivatives, 128 TAX Notes 1269 (Sept. 20, 2010); David S. Miller, A Progressive System of Mark-to-Market Taxation, 121 TAX Notes 213 (2008); Clarissa Potter, Mark-to-Market Taxation as the Way to Save the Income Tax-A Former Administrator's View, 33 VAL. U. L. REV. 879 (1999); Robert H. Scarborough, Different Rules for Different Players and Products: The Patchwork Taxation of Derivatives, 72 TAXES 1031 (1994); David J. Shakow, Taxation Without Realization: A Proposal For Accrual Taxation, 134 U. PA. L. REV. 1111 (1986); David A. Weisbach, Tax Responses to Financial Contract Innovation, 50 TAX L. REV. 491 (1995); Edward D. Kleinbard \& Thomas L. Evans, The Role of Mark-to-Market Accounting in a Realization-Based Tax System, 75 TAXES 788 (1997). The most common arguments raised against a mark-to-market tax regime are concerns about valuation and liquidity. A mark-to-market regime requires the periodic valuation of assets, which can be difficult to value (the valuation concern). The second concern is that taxpayers may not have the cash to pay the tax on property that is marked-tomarket until they sell the property (the liquidity concern). Miller, supra note 86, at 213; Potter, supra note 86 , at 882 ; Shakow, supra note 86 , at 1118 ; Weisbach, supra note 86 , at 511.

Advocates of a mark-to-market regime argue that it would combat the perceived inadequacies of realization-based taxation. They argue that the realization requirement creates inequity between taxpayers in the same economic position by applying different rules based on the form rather than the substance of a transaction. The complex rules required to define realization invite abuse, leading to anti-abuse provisions and increasing the overall complexity of the system. A mark-to-market regime, it is said, would decrease the complexity caused by the realization rule. It would also increase the overall fairness of the tax system by more closely approximating the Haig-Simons measure of income, which equates a taxpayer's income in each period to consumption plus change in wealth for the period and is seen by many as a superior method of taxation. Keinan, supra note 86, at 1279- 
tax treatment of OTC derivatives in enacting Dodd-Frank. These considerations would suggest a broad reading of the amendment and/or guidance limiting the scope of $\S 1256$ with respect to derivatives not covered by the amendment.

Relevant considerations might also, however, include (v) acknowledgement that the rationale for imposing $\S 1256$ 's mark-to-market rules on the first type of section 1256 contract, regulated futures contract, was based on the existence of daily variation margin - giving rise to ready cash available to pay taxes on a known amount of gain - and that when other contracts become subject to daily variation margin payments similar treatment may be appropriate, and (vi) the lack of any intent on Congress's part to change the tax treatment of contracts now traded on commodities exchanges in enacting Dodd-Frank. These considerations would suggest a narrower reading of the amendment and/or guidance to the effect that $\S$ 1256 does apply to some or all derivatives not covered by the amendment. Another consideration that surely should be taken into account are the benefits of having as many derivatives as possible subject to the same tax rules, to prevent whipsaw and arbitrage, although it is unclear whether that militates in favor or against a broad reading of the amendment.

80; Miller, supra note 86, at 213-14; Potter, supra note 86, at 879; Scarborough, supra note 86, at 1048; Kleinbard \& Evans, supra note 86, at 790.

Of more direct concern to the issues discussed herein, some of those in favor of mark-to-market agree that because of the valuation and liquidity concerns, a pure mark-tomarket regime for measuring all economic gain or loss would be administratively untenable and instead argue for a limited mark-to-market regime for derivatives. One proposal is to require taxpayers who mark gains and losses to market for purposes of GAAP to do the same for tax purposes, and allow taxpayers not subject to GAAP to elect mark-to-market. Because companies subject to GAAP have been required to value their derivatives for book purposes since the issue of FAS 133 in 1998, such a proposal would not raise the standard valuation concerns. Another proposal is to require high-income and high-net-worth taxpayers to mark-to-market derivatives and publicly traded securities. It is argued that concerns about liquidity are not as strong for taxpayers who are capable of borrowing against their securities and derivatives. Keinan, supra note 86, at 1279-81; Miller, supra note 86, at 213, 216-18; Scarborough, supra note 86, at 1048; Kleinbard \& Evans, supra note 86 , at 790 .

Other commentators have argued against such limited mark-to-market regimes for derivatives on the basis that they create a lack of consistency, which is unjustified given that the failure of realization-based taxation to deal with deferral is not generally considered to be unacceptable. In addition, if derivatives were marked to market, valuation costs would increase, and the models used to value certain derivatives would be difficult for the Service to monitor. Others argue that the line between what is and what is not subject to a limited mark-to-market regime would be difficult, if not impossible to draw. It is cautioned that if publicly traded stocks were marked to market, and derivatives based on them were not, taxpayers would simply 'substitute' one for the other and shift from positions in stock and securities to derivative positions. Further, if some derivatives were subject to mark-tomarket and others were not, a new form of derivative not subject to the system would be easily substituted. Potter, supra note 86, at 888-99; Deborah H. Schenk, An Efficiency Approach to Reforming a Realization-Based Tax, 57 TAx L. REV. 503, 527-29 (2004); Reed Shuldiner, Consistency and the Taxation of Financial Products, 70 TAXES 781-83 (1992). Thus, no harmony has been reached in or outside the academy on the merits of a general mark-to-market regime for derivatives. It is probably fair to say that, to date, tax administrators and legislators have evinced even less interest in such a regime. 
A final consideration is that wherever the line is drawn, it will be "wrong." That is, it appears impossible given the current state of the law and the many complexities of Dodd-Frank to avoid a situation where similar financial instruments may be subject to different tax regimes. Such differences may arise, for example, (a) if similar swaps are traded on a designated contract market or national securities exchange, on the one hand, and a swap execution facility, on the other, because the former are and the latter are not, QBEs; (b) if one class of swaps is required to be cleared and traded on a regulated market while a class of similar or related swaps is not - examples of this are discussed in Section III.A.1, below; (c) if commodities exchanges offer products subject to $\S 1256$ that compete with similar products covered by the amendment; (d) if similar swaps are entered into by an end-user that does not clear its swaps and another party that does; and (e) if "bespoke" swaps not subject to clearing and trading on regulated markets are hedged with swaps that are subject to those requirements. ${ }^{87}$ Differences of this kind exist today, of course, but it is unfortunate that Dodd-Frank seems to have multiplied them, as the tools available under the Code to mitigate mismatches or prevent taxpayers from taking advantage of them have limitations, as described in Section III.A, below. And these differences are in at least some respects within the power of the government to address, for example by using its power under $\S 1256(\mathrm{~g})(7)(\mathrm{C})$ to designate swap execution facilities as QBEs. But the general point remains that it is difficult to see how to avoid an arbitrary line-drawing of some kind. If that is correct, then a further consideration that may affect guidance is the desirability of drawing a line that is easy to see, for example by declaring that any financial instrument designated by the CFTC as a futures contract constitutes a section 1256 contract and that no other financial instruments traded on Dodd-Frank exchanges, other than certain options and dealer contracts specified in the statute, qualify as such.

A better course of action would be for Congress to act to alleviate as much of the line-drawing pressure as possible. Probably the best solution would be for a considered reevaluation of what the proper scope of $\S 1256$ should be, as that question is properly for Congress in the first instance rather than for Treasury and the Service. Alternatively, pending a true overhaul of $\S 1256$, legislative amendments could (a) revise $\S 475$ so that current rule to the general effect that a contract that can be both a section 1256 contract and a $\S 475$ "security" is subject to $\S 1256$ and not $\S$ 475 is made elective, ${ }^{88}$ (b) revise $\S 1256(\mathrm{~d})$ or (e) to permit taxpayers to elect out of $\S 1256$ treatment for hedges of a capital asset other than a

\footnotetext{
${ }^{87}$ Another possibility is that swaps cleared or traded by U.S. taxpayers or controlled foreign corporations on non-U.S. clearinghouses and exchanges may be subject to different rules than those cleared or traded in the United States. Issues relating to non-U.S. clearing and trading call deserve further consideration, but will not be addressed in this article.

${ }^{88}$ Assuming that the amendment had the effect of overriding the character rules of $\S 1256$, an amendment of this kind would address the character whipsaw issues faced by $\S 475$ dealers in securities and traders who elect $\S 475$ treatment, but would not alleviate the timing problems that $\S 1256$ treatment would give rise to for other taxpayers.
} 
"traditional" section 1256 contract, ${ }^{89}$ or some combination of the above..$^{90}$ Legislation could address swap execution facilities, so that there is no tax (dis)advantage to trading on such a facility compared to a CFTC designated contract market or a SEC-regulated national securities exchange. ${ }^{91}$ Consideration could also be given to modifying the rules of $\S 1256$ that limit the ability to pass long-term capital gain treatment through to limited partners of dealers organized as partnerships ( $\S 1256(f)(4))$, as those rules now apply only to dealer equity options and dealer securities futures contracts.

Section III.C, below, lists and evaluates a number of different interpretations of the scope of the amendment, from narrow to broad, and concludes that the most plausible interpretations of the amendment are that it covers either (i) NPCs and CDSs, but not other derivatives, or (ii) NPCs, CDSs, and derivatives so closely connected to those instruments that they should be subject to the same tax rules. It also argues that derivatives outside the scope of the amendment should be treated as section 1256 contracts only if they are clearly instruments of a kind that Congress intended to be subject to $\S 1256$, and possibly derivatives so closely connected to those instruments that they should be subject to the same tax rules. Those conclusions are informed by reflection on the consequences of drawing the line in various possible places, and by the history of $\S 1256$. Before turning to a detailed discussion of the amendment, therefore, Sections III.A and III.B explore those considerations.

${ }^{89}$ An amendment of this kind would have to be evaluated to make sure that it does not open the door to some of the problems that $\S 1256$ was enacted to prevent. One possible approach might be to limit the election to hedges of assets that constitute "actively traded personal property" within the meaning of $\S 1092$, so that the straddle rules would operate to prevent acceleration of losses and conversion of character.

It may also be useful to clarify that hedging credit risk comes within the ambit of a hedging transaction within the meaning of $\S 1221$ or any capital asset hedge, as the term "hedging transaction" for an asset hedge is generally defined under $\S 1221(\mathrm{~b})(2)(\mathrm{A})(\mathrm{i})$ as a transaction that manages "risk of price changes." While that term is fairly broad, it was not written with the intent of capturing default risk.

${ }^{90}$ A prior version of this article suggested that $\S 1256$ be amended expressly to exclude NPCs and CDS. See Nijenhuis, supra note 1, at 1238, at note 9. As discussed infra Section III.C, this is one plausible reading of the Dodd-Frank amendment to $\S 1256$. The article noted, however, that an amendment of this kind would mean that while CDS and other NPCs would not be treated as section 1256 contracts, it would not cover all derivative financial instruments now traded in the OTC market that may be required under Dodd-Frank to be cleared and/or traded, such as options. Id. This implicit call for broader legislative change obviously failed to have any immediate effect. The author understands that it was not possible under Congressional rules to consider any broader changes to the Code than the $\S 1256$ amendment without bringing Dodd-Frank under the jurisdiction of the tax-writing committees. It may be possible, therefore, for future tax legislation to address these issues.

${ }^{91}$ There are now various types of trading markets that did not exist when $\S 1256$ was enacted, and that are not QBEs - that is, SEC-regulated national securities exchanges or CFTC-regulated designated contract markets - but that may nevertheless be subject to some form of regulation by securities or commodities regulators. These markets may become obsolete with the passage of Dodd-Frank. If that is not the case, they too should be addressed. 


\section{A. Effect of Section 1256 Treatment for OTC Derivatives.}

The impact of $\S 1256$ treatment depends partly on the type of financial instrument and partly on the tax characteristics of the taxpayer. For example, is the taxpayer an individual that can benefit from $60 / 40$ treatment or a corporation? Is the taxpayer using a realization method of accounting or does the taxpayer mark its positions to market for tax purposes? In order to illustrate what is at stake, this Section III.A considers two hypothetical situations. The first is a taxpayer who is considering one of a number of financial instruments that have the payment terms of an interest rate swap or an economic equivalent thereof and who does not use a mark-to-market method of accounting. The second is a dealer in securities who has a rates book that includes a variety of U.S. dollar interest ratelinked financial instruments. In both of these examples, $\S 1256$ treatment is unfavorable. Section III.A ends with a brief comment on situations where broader $\S 1256$ treatment could be favorable.

1. Interest Rate Swaps and Swap Futures Contracts. A taxpayer interested in interest rate swap economics can of course enter into a conventional privately negotiated bilateral OTC interest rate swap. Other alternatives, described in Section II.A.3, above, would be to enter into a interest rate swap futures contract of the kind offered by the IDCG, whether directly or as a result of an exchange of an interest rate swap for such a futures contract through the IDCH, or to enter into a swap futures contract of the kind offered by the CME. As described above, the IDCG contract has payment terms similar to those of an interest rate swap, that is, periodic exchanges of fixed for floating payments determined by reference to a notional principal amount, while the CME futures contract provides for a single payment determined by reference to the value of a hypothetical interest rate swap. ${ }^{92}$

Under current law, the interest rate swap is subject to the accrual rules described in Section I.B.1, above, and as a result of the Dodd-Frank amendment to $\S 1256$, that will continue to be the case regardless of whether the swap is cleared and/or traded on a regulated market. There is no express guidance on the CME futures contract, but it presumably qualified as a "regulated futures contract" prior to the Dodd-Frank amendment, and for purposes of this discussion, it is assumed that that treatment continues post-Dodd-Frank. The puzzle, therefore, is how to characterize the IDCG contract post-Dodd-Frank. Is an "interest rate swap" within the meaning of the Dodd-Frank amendment, or is it a futures contract that qualifies as a "regulated futures contract" subject to $\S 1256$ ?

It is immediately obvious that this question is one that has no "right" answer, or at least no right answer that does not raise new questions.

\footnotetext{
92 One non-tax question raised by the IDCG contract is what defines a "futures" contract as a regulatory matter? Is it simply a matter of obtaining CFTC approval for such characterization, and subjecting the contract to all the regulatory rules that apply to futures contract? From the uninformed perspective of a tax lawyer, this seems to be the equivalent of sprinkling CFTC pixie dust over the contract, particularly if one compares it to an interest rate swap that is cleared and perhaps traded on a similar regulated market.
} 
If the IDCG contract is not a section 1256 contract, then there will be a divergence between the tax rules applicable to some futures contracts and to other futures contracts, raising questions about how those lines should be drawn. On the other hand, if the IDCG contract is a section 1256 contract, then two contracts that are essentially identical from an economic perspective - the interest rate swap and the IDCG contract - will be subject to radically different tax rules, with all of the potential for whipsaw and arbitrage that that raises. It can be expected in that case that taxpayers for whom $\S 1256$ treatment is attractive would migrate to the IDCG contract and taxpayers who wish to avoid $\S 1256$ treatment would enter into the interest rate swap. In part for that reason, and in part because of the technical reasons described in Section III.C, below, to this observer the better answer is that the IDCG contract should be treated as an "interest rate swap" and not as a section 1256 contract.

That conclusion is also based on the fact that $\S 1256$ does not address how periodic payments on a section 1256 contract should be treated. This is hardly surprising in light of the fact that no contract expressly intended by Congress to be subject to $\S 1256$ provides for periodic payments. As described below, the application of $\S 1256$ to such a contract would appear to have potentially unfortunate results.

As described in Section I.B.1, above, under the timing regulations for NPCs, a swap characterized as an NPC ordinarily would be treated as giving rise to current income or deductions in the amount of the periodic coupon payments and a portion of any upfront payment made or received to enter into the NPC. Absent an early termination of the swap, therefore, all income and expense from a conventional swap ordinarily is treated as ordinary income and expense. Because the definition of an NPC in the NPC timing rules excludes any section 1256 contract, however, a swap that is classified as a section 1256 contract is not subject to the NPC timing rules, including the rules that create deemed loans and deemed interest. ${ }^{93}$ This makes perfect sense for method of accounting purposes, since both $\S$ 1256 and the NPC rules deal with timing and there is no reason to apply multiple sets of rules. ${ }^{94}$

\footnotetext{
${ }^{93}$ Treas. Reg. § 1.446-3(c)(1)(ii) (1994).

${ }^{94}$ However, the government has in the past taken the view in certain contexts that both the "normal" timing rules and also mark-to-market rules should apply to the same financial instruments. Under Treasury Regulation $\S 1.446-3, \S 475$ generally overrides the timing regulations' rules for periodic and nonperiodic payments. It is not clear, however, whether $\S 475$ also overrides the rules that create a deemed loan if there is a significant nonperiodic payment. It may well be the case that it does not, since the author's understanding is that the principal reason for the deemed loan rule was a withholding tax concern, namely that related parties could use NPCs to lend money/pay economic interest to each other without being subject to U.S. withholding tax, i.e., in a situation where the party making the upfront payment (the "lender") is resident in a country that does not have an income tax treaty with the United States providing for a zero rate of withholding tax on interest. See also Treas. Reg. $\S \S 1.475$ (a)-1(a)-1(e), 60 Fed. Reg. 397, 401 (Jan. 4, 1995) (taxpayers required to accrue OID and bond premium before marking debt instruments held as assets to market); Treas. Reg. $§ 1.446-3(\mathrm{~g})(1), 69$ Fed. Reg. 8886, 8892 (Feb. 26, 2004) (mark-to-market election; part of proposed rules for swaps with contingent nonperiodic payments, discussed in Section I.B.1, above); Treas. Reg. $§ 1.446-3(\mathrm{~g})(6), 69$ Fed. Reg.
} 
Consequently, the timing of income or expense with respect to periodic payments would be governed by the general rules of the Code. In view of the fact that the NPC timing rules, which are clear reflection of income rules, provide for current accrual of NPC periodic payments, one likely answer would be to conclude that a periodic payment on a swap should be accrued on a current basis. As a current income/expense item, the payment would not affect the basis of the swap for purposes of determining gain or loss. Furthermore, as in the case, for example, with a bond with accrued interest, the mark-to-market of the swap at year-end should not take into account accrued ordinary income or expense. Otherwise, that amount would be double-counted: once as income/expense and once as an increase/decrease in value.

Assume for example that Parties A and B enter into a conventional at-market swap under which Party A agrees to pay 6 percent multiplied by $\$ 100$ million and Party B agrees to pay LIBOR multiplied by $\$ 100$ million, annually (for ease of calculation) for 5 years. During the course of the first year, LIBOR is 4 percent and a net 2 percent coupon accrues and, at or just before year-end, is paid. Party A therefore has $\$ 2$ million of swap expense and Party B has $\$ 2$ million of swap income. If the swap has not changed in value at year-end, the parties will take those amounts into income/expense and nothing else. If, however, the swap also has changed in value in Party A's favor, say by $\$ 10$ million, Party A will have $\$ 2$ million of ordinary deduction and \$10 million of capital gain, while Party B will have \$2 million of ordinary income and $\$ 10$ million of capital loss. That is, the coupon payments on this swap are items separate from the mark-to-market gain or loss.

This is a highly unusual fact pattern, since typically mark-to-market arises either under $\S 475$ for a dealer or trader for whom any gain or loss is ordinary, ${ }^{95}$ or under $\S 1256$ with respect to contracts that do not give rise to ordinary income or expense. One very broadly comparable fact pattern is a mixed straddle in which at least one position is ordinary and at least one position is capital; in that case, Congress has granted authority to Treasury to write regulations mitigating the whipsaw potential. ${ }^{96}$

A taxpayer in this situation may be concerned not only about ordinary/capital mismatches from the swap itself, but also with timing and possibly character mismatches with and asset or liability that the swap hedges. As described above, interest rate and foreign currency swaps are widely used by corporate and other taxpayers to hedge assets and liabilities,

8886,8892 (Feb. 26, 2004) (requiring creation of deemed loans and then the application of a complex quasi-mark-to-market regime whose principal purpose seems to be to encourage taxpayers to elect to use the "real" mark-to-market regime in subsection (i)). Taxpayers have strongly objected to both of these proposed regulations as unnecessarily cumbersome and serving no purpose.

${ }_{95}$ It is possible for mark-to-market gain or loss to be capital for a dealer in securities, if the securities in question are not held in connection with the dealer's activities as a dealer in securities. I.R.C. $\S 475$ (d)(3)(B)(ii) (2010). Dealers generally take the position, however, that all or most of their activities are connected to their securities dealer activities.

$$
{ }^{96} \text { I.R.C. } \S 1092(b)(2)(D)(2010) .
$$


including debt, that have interest rate terms or are otherwise interest ratesensitive. In any case where a swap is entered into as a hedge, the taxpayer is likely to wish the timing of its income and expense from the swap to correspond to the timing of the related income and expense from the hedged position. The taxpayer is likely to be unhappy about being required by law to use a mark-to-market method of accounting.

The taxpayer that is hedging its position is also likely to find itself subject to the tax straddle rules of $\S 1092$. Such a taxpayer would be taxable on mark-to-market gain from the swap, but likely would not be able to deduct mark-to-market losses as a result of economically offsetting gains on the hedged position. Assuming that the hedged position is a capital asset, the taxpayer could not make a $\S 1221$ hedging transaction election or a $\S 1256(\mathrm{e})$ election to remove the swap from the application of $\S 1256$. Depending on the facts, the taxpayer also might not be able to make an integration election under Treasury regulation $\S 1.1275-6$, for example because the precision in matching timing and amounts of cash flows required by that section may not be satisfied. The taxpayer could potentially make one of various elections under the straddle rules, including the "identified straddle" election of $\S 1092(a)(2)$, the "straddle-by-straddle identification" election of $\S$ 1092(b)(2)(A)(i)(I) for mixed straddles, or the "mixed straddle account" election of $\S$ 1092(b)(2)(A)(i)(II), but each of these elections have complexities, limitations and disadvantages that make them generally highly imperfect solutions. In many cases, the taxpayer's best option may be a "mixed straddle" election under $\S 1256(\mathrm{~d})$ to remove the contract from the scope of $\S 1256$, as $\S 1256(d)$ imposes relatively modest conditions.

There is no discernible tax policy reason that would favor subjecting taxpayers of this kind to a mark-to-market regime for swaps. Indeed, the fact that an onerous anti-abuse rule may well apply if the taxpayer could elect to use a mark-to-market method of accounting for a swap suggests to this observer that uncertainty over the scope of $\S 1256$ should be resolved in favor of not requiring taxpayers to mark their swaps to market.

In practice, if a taxpayer's treasury department consults in advance with its tax department (which should not be assumed to take place as a matter of course), these issues will not be a problem for interest rate swaps, because the taxpayer can always choose to enter into a non-futures interest rate swap. However, the discussion above illustrates the potential problems that could arise if other types of derivatives with periodic income/expense payments were treated as section 1256 contracts. Only mischief, whether for the government or for taxpayers, could result from rules under which periodic payments give rise to ordinary income/expense while mark-tomarket payments give rise to capital gain/loss. It is fervently to be hoped that the government will take the view that an express Congressional mandate is necessary before taxpayers who will be required by law to transact in swaps in this manner will be subject to arbitrary and capricious rules reminiscent of the treatment of hedging transactions prior to the 
Fannie Mae case and the issuance of Treasury Regulation $\S \S 1.1221-2$ and $1.446-4 .{ }^{97}$

2. Interest Rate Swaps and Hedges Thereof. A second fact pattern that illustrates the anomalies that may arise in a world in which the scope of $\S 1256$ is expanded involves a dealer in securities, within the meaning of $\S 475$, that enters into all of the following types of financial instruments in the ordinary course of its dealer business in interest rate swaps: long and short positions in Treasuries, Treasury futures contracts and exchange-traded options thereon, the IDCG and CME swap futures described above, forward rate agreements, and swaptions. Similar issues may arise for electing traders in securities under $\S 475(\mathrm{f})$, or possibly for taxpayers who have taken the view that they can elect mark-to-market as a form of self-help under $\S 446$ 's clear reflection of income rules, under the general ambit of proposed Treasury regulation $\S 1.446-3(i){ }^{98}$ Securities dealers generally do, and electing traders must, treat the mark-to-market gain or loss as ordinary under $\S 475 .{ }^{99}$

Section 475 provides, however, that a section 1256 contract generally does not qualify as a "security" to which $\S 475$ applies, ${ }^{100}$ presumably because at the time $\S 475$ was enacted commodity dealers and traders lobbied to remain outside its scope. ${ }^{101}$ (This $\S 1256$ priority rule

${ }^{97}$ The Fannie Mae case resolved an issue raised by Arkansas Best, namely whether Arkansas Best's general repudiation of the business assets doctrine also overturned the specific holding of Corn Products that a hedge of inventory could itself be treated as an ordinary asset. Corn Prod. Ref. Co. v. Comm'r (Corn Products), 350 U.S. 46 (1955); Fed. Nat'l Mortg. Assoc. v. Comm'r (Fannie Mae), 100 T.C. 541 (1993); Ark. Best Corp. v. Comm'r, 485 U.S. 212 (1998). If that were the case, taxpayers would be subject to unmanageable whipsaw risk, because it is in the nature of hedges that sometimes they produce losses that would be capital under a broad reading of Arkansas Best. The Fannie Mae case concluded that Congress had effectively legislatively adopted the Corn Products doctrine. Treasury and the Service then threw in the towel and issued Treasury Regulation $\S \S 1.1221-2$ and 1.446-4 to provide specific rules for hedging transaction. Congress then endorsed that result by enacting $\S 1221(\mathrm{a})(7)$ and (b)(2), providing statutory rules treating hedging transactions as non-capital assets. Congress thus both implicitly and explicitly endorsed the harmonization of character from transactions that hedge ordinary assets or liabilities.

${ }^{98}$ Prop. Treas. Reg. § 1.446-3(i) 69 Fed. Reg. 8886, 8892 (Feb. 26, 2004). Treas. Reg. $\S 1.446-3$ (i) generally would permit a taxpayer to mark an NPC to market, provided that the NPC is actively traded, or the taxpayer marks the NPC to market for financial accounting purposes, or the counterparty agrees to provide its tax marks. Some taxpayers have taken the position that the proposed regulations, while not currently in effect, demonstrate that marking an NPC to market clearly reflects income from the NPC, and that taxpayers therefore may mark to market NPCs of the kind that would fall within the proposed regulations even if the taxpayer is not subject to $\S 475$.

${ }^{99}$ I.R.C. $\S 475(\mathrm{~d})(3)$ (2010) (generally providing that dealer gain or loss from securities subject to $\S 475$ is ordinary); I.R.C. $\S 475(\mathrm{f})(1)(\mathrm{C})$ (2010) (rules similar to rules of $\S 475(\mathrm{~d})$ apply to electing traders).

${ }^{100}$ I.R.C. $\S 475(c)(2)(E)$ and the flush language at the end of $\S 475(c)(2)$.

Section 475 applies to securities and, on an elective basis, commodities. The term "security" is defined in $\S 475(\mathrm{c})(2)$.

${ }^{101}$ The development of the definition of the term "security" as $\S 475$ was being considered by Congress is consistent with the presumption in the text. As originally introduced in the House in February 1992, the term was defined to include (i) any derivative financial instrument in securities, but not including any futures contracts, and (ii) any 
does not apply to interest rate swaps, foreign currency swaps and equity swaps.) As a result, absent the hedging rules described below or another special rule, a dealer or trader that generally recognizes ordinary gain or loss from its securities activities may be required to recognize capital gain or loss from any section 1256 contracts that it holds. The potential adverse consequences of that are obvious.

Of the various types of positions described above, the interest rate swaps and the long and short positions in Treasuries clearly are not section 1256 contracts; the Treasury futures and options thereon and presumably the CME swap futures are section 1256 contracts; and it is uncertain whether the IDCG futures contract and, if traded on an exchange, the forward rate agreement and the swaption are section 1256 contracts. The forward rate agreement potentially could be a regulated futures contract, if that term were interpreted broadly, and the swaption could be a non-equity option, unless either constituted a "similar agreement" within the meaning of the Dodd-Frank amendment to $\S 1256$. Thus, a substantial portion of the dealer's book may consist of section 1256 contracts with the potential for capital losses.

There is an escape from this unhappy state of affairs, because a section 1256 contract that hedges a $\S 475$ "security" may itself be treated as a $\S 475$ "security." 102 However, this hedging election is available only if the hedge is clearly identified on the dealer's records as a $\S 475$ hedge before the close of the day on which it was entered into. As a practical matter, a swap may not hedge a $\S 475$ security, or it may be difficult to determine whether it does so with any certainty, or it may be difficult to do so in a manner that satisfies the close-of-day identification requirement. That is because dealers generally hedge their positions on an aggregate basis rather than on a position-by-position basis. Also, the higher the portion of a dealer's book that consists of section 1256 contracts, the more

notional principal contract other than a commodity-linked notional principal contract. DANiEl RostenKowski, COMM. OF CONFERENCE, TECHNICAL EXPLANATION OF TAX FAIRNESS AND ECONOMIC GROWTH BILl OF 1992, H.R. 4287, 102d Cong. (as introduced in the House on Feb. 22, 1992). A month later, after consideration by the Senate, the NPC language was unchanged but the catch-all provision now referred to a derivative financial instrument in any security otherwise described, but not including any contract to which $\S$ 1256(a) applies. FAmily TAx FAirness, Economic Growth, And Health CARE ACCess BILl OF 1992, H.R. 4210, 102d Cong. (as reported in the Senate Mar. 9, 1992). The legislative history gives no explanation for the change from "futures contract" to "any contract to which $\S 1256$ (a) applies," but it seems plausible that the change was intended to clarify that the definition excluded futures contracts subject to $\S 1256$, and not other futures contracts. Finally, in the conference bill passed later that month (and vetoed by the President), the NPC clause was revised to read as it now does, referring to interest rate, currency or equity NPCs. DANIEL RosTENKOWSKI, COMM. OF CONFERENCE, TAX FAIRNESS AND ECONOMIC GROWTH BILl of 1992, H.R. ReP. No. 102-461 (1992) (Conf. Rep.).

${ }^{102}$ I.R.C. $\S 475(\mathrm{c})(2)(\mathrm{F})(2010)$; see also $\S 1256(\mathrm{e})$ for a broadly similar hedging exception. 
difficult it may be to establish that any one such contract hedges a nonsection 1256 contract. $^{103}$

As described above, the principal purpose of $\S 1256$ is to require taxpayers to mark section 1256 contracts to market, and the mandate that gain or loss from section 1256 contracts be treated as long-term and shortterm capital gain was a sweetener intended to mitigate the blow of marking

${ }^{103}$ There are some other possible avenues for relief from capital treatment, under $\S$ 1256(f)(2) and/or $\S 1256(f)(3)$, but as discussed below they do not seem to change the overall picture in any significant way.

Section 1256(f)(2) provides that $\S 1256($ a)(3) (requiring 60/40 capital gain/loss) does not apply to any gain or loss which, but for such paragraph, would be ordinary income or loss. This provision was enacted at a time when the Corn Products doctrine, which treated business assets, including hedges, as ordinary rather than capital assets, was considered good law. Corn Products, 350 U.S. at 53-54. At the time $\S 1256$ was enacted, therefore, a taxpayer using a futures contract to hedge its inventory could treat the gain or loss from the hedge as ordinary, because it would be ordinary absent $\S 1256$ under the Corn Products doctrine and thus was exempt under $\S 1256(\mathrm{f})(2)$ from capital gain/loss treatment. However, the Corn Products doctrine was repudiated in Ark. Best. and has effectively been replaced by the hedging transaction rules of $\S 1221(\mathrm{~b})(2)$ and hedging transaction regulations under $\S 446$. Ark. Best Corp., 485 U.S. at 212-13. The hedging transaction regulations apply to hedges of ordinary assets and liabilities and suffer from practical obstacles to utilization in the dealer context similar to the problems described above with the $\S 475$ hedging exception.

Section 1256(f)(3) also has a complicated history. Prior to the amendment of $\S$ 1256 in 1984, market-makers in equity options traded on securities exchanges took the position that they were entitled to ordinary income and loss from their options transactions. The 1984 amendment was intended to limit such treatment to the fact pattern where the taxpayer was also, independently of its option transactions, a dealer in the underlying property. This was accomplished by (i) adding "dealer equity options" as a category of section 1256 contracts, and (ii) adding $\S 1256$ (f)(3), which provides that gain or loss from "trading" (this phrase evidently was intended to include market-making in) section 1256 contracts is treated as capital gain or loss, unless the section 1256 contract is held to hedge property loss from which would be ordinary in the taxpayer's hands. Accordingly, if a dealer in swaps is also a dealer in the underlying property, and the swaps hedge that property, it may be possible under this rule for the dealer to have ordinary rather than capital gains and losses from its swap transaction.

The relationship between $\S 1256(\mathrm{f})(2)$ and $\S 1256(\mathrm{f})(3)$ is not entirely clear. They were enacted at different times, for different purposes, and thus it is possible that both are available to swap dealers. If that were the case, then $\S 1256(\mathrm{f})(2)$ could provide considerable relief. For example, it could allow dealers to treat the character of gains and losses for swaps entered into in connection with their dealer business as ordinary, under $\S 475(d)(3)$. Separately, it might alleviate concerns for an option, because under $\S 1234(a)(1)$ gain or loss from purchased options would be ordinary if the underlying property would give rise to ordinary gain or loss in the taxpayer's hands, and under $\S 1234(\mathrm{~b})(3)$ gain or loss from writing options is ordinary if granted in the ordinary course of the taxpayer's trade or business of granting options. Consequently, under $\S 1234$ gain or loss from dealing in exchange-traded options could be ordinary in the absence of $\S 1256(\mathrm{a})(3)$. However, $\S 1256(\mathrm{f})(3)(\mathrm{A})$, providing that gain or loss from trading section 1256 contracts is capital gain or loss, was enacted precisely to prevent options marketmakers from taking that position. Moreover, $\S 1256(\mathrm{f})(2)$ merely provides that $\S 1256(\mathrm{a})(3)$ does not apply, while $\S 1256(\mathrm{f})(3)(\mathrm{A})$ states that it applies "for purposes of this title." I.R.C. $\S 1256(f)(3)(A)(2010)$. Accordingly, it seems quite possible that $\S 1256(f)(3)$ overrides $\S 1256(\mathrm{f})(2)$, and that relief is available only if a swap hedges an asset (not a liability) that would give rise to ordinary loss in the taxpayer's hands. See Beverly Gordon v. Comm'r, 73 T.C.M. (CCH) 2638 (1997) (rejecting taxpayer argument that hedging rule of $\S 1256(\mathrm{f})(3)$ applies because of failure of proof); I.R.S. F.S.A. 1999-1130 (concluding hedging rule of $\S 1256(f)(3)$ does not apply to hedges of anticipated liabilities). 
to market. Given that history, it would not merely serve no tax policy goal to require taxpayers currently marking derivatives to market under $\S 475$ to mark them to market instead under $\S 1256$, it would be positively perverse.

Moreover, while the exclusion of section 1256 contracts from the definition of the term "security" for $\S 475$ purposes may have originally served to ensure that commodities dealers and traders were not subject to $\S$ 475 , those taxpayers subsequently had a change of heart and lobbied successfully for an election into $\S 475$ treatment. Conceivably, therefore, the Service could exercise its regulatory authority under $\S 475(\mathrm{~g})$ to apply the $\S 1256$ carve-out to the definition of "security" in a more limited manner. For example, the carve-out could be applied, as it does today, for purposes of determining whether a taxpayer such as a market-maker on a commodities exchange or a dealer in fixed income instruments is a $\S 475$ dealer in securities and would be subject to the same rules as is the case today (treating section 1256 contracts as non-"securities" for this purpose). The carve-out could cease to apply once the fixed income dealer was treated as a dealer in securities, however, with the result that any section 1256 contracts the dealer entered into would be treated as $\S 475$ securities. An approach of this kind does not square too easily with the statutory definition of "security," but in view of the historic and current connection between $\S 1256$ and the commodities markets it is again perverse that electing dealers and traders in commodities treat gain or loss from section 1256 contracts as ordinary under $\S 475$, while dealers and electing traders in securities generally must apply the capital gain/loss rules of $\S 1256 .{ }^{104}$ In any event, this hypothetical also demonstrates the benefits of taking a narrow view of the scope of $\S 1256$ going forward.

3. Benefits of Section 1256 Treatment. Of course, $\S$ 1256 treatment is not always disadvantageous. For individuals who trade derivatives, or who are investors in pass-through entities that trade derivatives, $\S 1256$ treatment can be highly desirable, since it provides $60 \%$ long-term capital gain for short-term positions. The significance of this is not trivial, since $60 / 40$ treatment was viewed as the carrot to balance the mark-to-market stick when $\S 1256$ was enacted, and the desire to preserve parity with existing section 1256 contracts has been the principal reason why the list of section 1256 contracts has grown over time. Therefore, for taxpayers who can live with mark-to-market treatment, particularly for short-term contracts like most contracts traded on commodities exchanges today, the balance may favor $\S 1256$ in the case of individuals.

Congress has from time to time acted to limit the extent to which $60 / 40$ treatment is available. For example, in 1984, when dealer equity options were added to the list of section 1256 contracts, Congress took care to ensure that options market-makers could not set themselves up as limited partnerships and pass the benefits of $60 / 40$ treatment on to limited partners.

${ }^{104}$ Electing dealers and traders in commodities mark "commodities" to market. I.R.C. $\S \S 475(\mathrm{e})-(\mathrm{f})(2010)$. The definition of this term includes futures contracts and does not exclude section 1256 contracts. I.R.C. § 475(e)(2) (2010). Electing dealers and traders in securities mark "securities" to market, which as discussed in the text does generally exclude section 1256 contracts. 
Section 1256(f)(4) provides that gain or loss from dealer equity options allocable to limited partners is always short-term. When dealer securities futures contracts became section 1256 contracts, § 1256(f)(4) was amended to apply to them as well. A natural conclusion is that, absent similar legislative action, traders in swaps treated as section 1256 contracts will be able to use partnerships in order to allow investors to share in long-term capital gains generated from a trading or dealing business. Some hedge funds might find such an opportunity attractive. Mutual funds might also welcome the opportunity to derive additional long-term capital gain, although absent certainty about whether $\S 1256$ does or does not apply, mutual funds might be more concerned about the lack of certainty about the timing of income than attracted to the potential for long-term capital gain. And query whether taxpayers' annual year-end quest to accelerate capital losses to offset realized capital gains, or, after a down market, the search for capital gains to offset expiring capital losses, might be facilitated by the existence of similar swaps, some of which are section 1256 contracts and some of which are not.

Interestingly, it appears that the Congressional Budget Office and Joint Committee on Taxation were of the view that the fisc had more to lose than to gain from $\S 1256$ treatment of cleared and exchange-traded swaps, possibly on the theory that if there is uncertainty about whether $\S 1256$ applies, taxpayers will use that uncertainty to their advantage. ${ }^{105}$ Presumably, the Dodd-Frank amendment to $\S 1256$ was intended to eliminate that uncertainty and the corresponding revenue loss. And it is certainly the case that the amendment makes clear that large portions of the derivatives market will not be subject to $\S 1256$. It is unclear how large the remaining part of the market is, or how the market will develop in the future.

Accordingly, Section III.B. next reviews the history of $\S 1256$, with a view to persuading the reader that uncertainty of this kind has historically been resolved by construing $\S 1256$ narrowly. Section III.C. will then argue that a similar approach is appropriate today.

B. A Discourse on the History of Section 1256.

The need to look to the history of $\S 1256$ becomes evident if one tries to determine how $\S 1256$ applies to derivatives currently in the market that are not traditional exchange-traded contracts but have some link to an exchange or clearinghouse. Since the Dodd-Frank amendment to $\S 1256$ will take effect for taxable years after the year of enactment, meaning in

${ }^{105}$ See Letter from Congressional Budget Office to Senator Christopher Dodd (May 3, 2010), available at http://www.cbo.gov/ftpdocs/114xx/doc11476/s3217amendmt.pdf (analyzing effects on direct spending and revenues of the Dodd-Lincoln substitute bill, projecting an estimated revenue loss of over $\$ 1$ billion from the possible $\S 1256$ treatment of derivative financial instruments required to be cleared and traded as provided in the bill, and noting "considerable uncertainty" as to the size of the expected revenue losses); see also Congressional Budget Office, Cost Estimate, H.R. 4173, Restoring American Financial Stability Act of 2010, at 7 (June 9, 2010), available at http://www.cbo.gov/ftpdocs/115xx/doc11560/hr4173senatepassed.pdf (same estimate). 
2011 for most taxpayers, and since its scope is uncertain, being able to ascertain whether $\S 1256$ applies to such derivatives remains important today and will have some significance in the future. This Section III.B therefore begins by ignoring the Dodd-Frank amendment and attempting to determine whether $\S 1256$ applies to such derivatives, and in particular whether any of them might constitute a "regulated futures contract."

1. Construing "Regulated Futures Contract". An RFC is defined under current law as:

"a contract -

(A) with respect to which the amount required to be deposited and the amount which may be withdrawn depends on a system of marking to market, and

(B) which is traded on or subject to the rules of a qualified board or exchange."

A "qualified board or exchange" is defined as a national securities exchange registered with the SEC, a domestic board of trade designated as a contract market by the CFTC, or any other exchange, board of trade, or other market which the Secretary determines has rules adequate to carry out the purposes of $\S 1256 .^{107}$

On its face, this definition is very broad, as it requires only that "a contract" be traded on a CFTC- or SEC-regulated exchange and be subject to daily variation margin requirements. As discussed in more detail below, this very breadth has raised questions in the past as to whether non-futures contracts, in particular "commodity options," constitute RFCs. The fact that Congress resolved that issue by amending $\S 1256$ to specify when commodity options will and will not be treated as section 1256 contracts suggests that whatever the definition of RFC, it should not apply to every contract traded on a CFTC-approved exchange. Similarly, the fact that Congress amended $\S 1256$ to include foreign currency contracts and nonequity (including foreign currency) options suggests that the RFC definition should not include contracts linked to foreign currencies. Instead, the definition should apply to some subset of traded contracts. The logical way to narrow the scope of the definition is to read into the term "a contract" the implied qualification that it is "a [commodity futures] contract," since those were the only contracts to which the RFC definition applied when it was enacted. As discussed in more detail in Section III.B.3, below, however, while the Service appears to have taken that position, there is no authoritative guidance to that effect. ${ }^{108}$

\footnotetext{
${ }^{106}$ I.R.C. § 1256(g)(1) (2010).

${ }^{107}$ I.R.C. $\$ 1256(\mathrm{~g})(7)(2010)$.

${ }^{108}$ Recent remarks by Service officials suggest that guidance to this effect may be forthcoming. See Amy S. Elliott, IRS May Restrict Definition of Swap to Notional Principal Contracts (Dec. 15, 2010), available at 2010 TNT 240-3; Diane Freda, IRS May Hold to Narrow View of Futures Under Dodd-Frank Wall Street Reform (Dec. 15, 2010), 239 DTR G-3, available at www.bna.com.
} 
A further source of uncertainty arises because an RFC is defined as a contract "traded on or subject to the rules of" a qualified board or exchange ("QBE"). The "subject to" (or is it "traded ... subject to"?) language is ambiguous. To focus attention on that ambiguity, it may be helpful to review some of the different kinds of transactions that currently exist that have or may have some connection to a QBE but are not expressly within or outside the scope of $\S 1256$. Primarily because it is convenient to do so, the list below mostly describes a number of contracts that have some connection to the CME or its affiliate exchanges, the Chicago Board of Trade ("CBOT") or the New York Mercantile Exchange ("NYMEX"). ${ }^{109}$

The mutual offset system. Since 1984, the CME and the Singapore Exchange (formerly the Singapore International Monetary Exchange, or SIMEX) have been parties to an agreement that allows traders to open a futures contract on one exchange and have it automatically transferred overnight to the other exchange. For example, during SIMEX business hours, a trader could enter into a Eurodollar futures contract on SIMEX; when the CME opens, the trader may send the contract to the CME, in which case, once accepted, the SIMEX trade will be offset and the trade will become a position on the CME. From that point forward, the futures contract is identical to any other Eurodollar futures contract on the CME.

Exchange for physical. An exchange for physical ("EFP") transaction is a privately negotiated (that is, OTC rather than exchange-traded) and simultaneous exchange of a position in a physical asset for a related futures contract. For example, a party owning live cattle, natural gas or foreign currency may exchange that asset for a futures contract on the same product, provided that the asset satisfies specified conditions. Once accepted, the futures contract is identical to any other futures contract traded on the exchange. The general rule for such transactions is in Rule 538 of the CBOT's Rulebook.

Exchange for swap. ${ }^{110}$ An exchange for swap ("EFS") transaction on NYMEX is like an EFP, except that the parties exchange a futures contract vs. a swap rather than a physical asset. Typically, such transactions are submitted for clearing within one hour of the parties' agreement to the terms. In the energy markets, where there are many EFS, a standard confirmation states that if the transaction is not accepted for clearing it will be void. Such transactions are also subject to CBOT Rule 538.

\footnotetext{
${ }^{109}$ The information described below is taken primarily from the CME Group's website, www.cmegroup.com.

${ }^{110}$ See Pomierski, supra note 49, § I.F.5; Kramer, supra note 49, § 62.01[B][1]. Pomierski and Kramer conclude that these contracts constitute RFCs. It appears that NYMEX also takes that position.
} 
Cleared agricultural swap. A cleared agricultural swap is a privately negotiated contract that is submitted to the CME for clearing, as a result of which the CME becomes the legal counterparty to both sides of the contract. These swaps are listed, for clearing only, on the CBOT. That is, unlike the transactions described above, the contract does not become a futures contract.

There are several variations of such swaps, all of which provide for cash-settlement on expiration in an amount determined in part by reference to the settlement price for a specified futures contract. For each type of swap, CBOT rules set forth their terms. Not surprisingly, given the pricing connection to futures contracts, these terms generally mimic those of the related futures contract. ${ }^{111}$ Such swaps are also subject to the general provisions of CME Rule 8F, which deals with clearing OTC derivative contracts.

Because most of the terms of the swaps, once cleared, are fixed under the rules described above, negotiations are limited, generally to the price, settlement date, and in some cases, one or two other terms. It is understood by the parties that the swap is entered into for clearing, and market practice is to submit the swap for clearing immediately after agreeing to its terms. There is no separate documentation such as a confirmation for the swap before it is cleared.

Cleared interest rate swap. As described in Section II.A.3, above, a cleared interest rate swap is a privately negotiated contract that is submitted to a clearinghouse such as the CME or LCH.Clearnet (which does not give rise to a futures contract) or IDCH (which does).

Cleared CDS - CME. As described in Section II.A.2(b), a CME cleared CDS is a privately negotiated contract that is submitted to the CME for clearing in the same manner as described above for cleared agricultural swaps. It does not become a futures contract. Cleared CDS contracts are subject to CME Rule 8F, described above, and specific

\footnotetext{
${ }^{111}$ For example, in a "calendar" swap, one party agrees to pay a fixed price per bushel and the other agrees to pay an amount determined by reference to the settlement price for the futures contract expiring in the stated month of the contract. The CBOT rules set forth the expiration date, the unit of clearing (the number of bushels), the minimum price increments, position limits (e.g., the number of contracts net long or net short in any single contract month), the time at which the contracts will be cash settled, and the settlement terms.

ICE also clears agricultural swaps under similar arrangements. Pomierski describes cleared energy swaps on ICE that appear to work similarly to the cleared agricultural swaps described in the text. Pomierski, supra note 49, at $\S$ I.F.5; see also Kramer, supra note $49, \S 62.01[\mathrm{~B}][2]$.
} 
rules addressing the clearing and settlement of CDS contracts. The CME permits parties to submit already outstanding bilateral CDS transactions for clearing, although the terms of those CDS will be restated in standardized terms.

Cleared CDS - ICE Trust. As described in Section II.A.2(a), above, an ICE Trust cleared CDS is similar to a CME cleared CDS. However, ICE Trust U.S. is a standalone clearinghouse - that is, unlike the $\mathrm{CME}$ clearinghouse, its only function is to clear CDS. ${ }^{12}$

The $\S 1256$ tax treatment of these various contracts as "traded on or subject to the rules of" a QBE is clear only with respect to a few of the contracts on the list. In the case of the mutual offset system, Revenue Ruling 87-43 concludes that contracts traded on SIMEX and transferred to the CME are RFCs. ${ }^{113}$ The Revenue Ruling is discussed in more detail in Section III.B.3, below. The gist of the Ruling is essentially that under step transaction principles, the taxpayer has entered into an RFC in such a case. These principles would seem to apply to EFPs and EFSs that result in futures contracts as well. Market participants apparently take that view, but no authority addresses the issue.

Conversely, the CDSs cleared by ICE Trust are traded on an OTC basis and are "subject to the rules of" a clearinghouse only. Those rules are independent of any rules of any exchange. A QBE, as described above, means an SEC-regulated national securities exchange, a domestic board of trade designated as a contract market by the CFTC, or any other market that the Treasury determines has rules that are adequate to carry out the purposes of $\S 1256$. A stand-alone clearinghouse fits neither of the first two categories, and ICE Trust has not been designated by the Service as a QBE. Accordingly, CDSs cleared by ICE Trust are not "subject to" the rules of an exchange, and are therefore not section 1256 contracts. ${ }^{114}$

Interest rate swaps cleared by LCH.Clearnet are not section 1256 contracts for the same reason, and the author is aware of no debate over that issue. Admittedly, it is possible that the lack of interest in this topic has something to do with historic lack of awareness in the tax community that many interest rate swaps are cleared.

The principal conclusion from examining the other contracts on the list is that the statutory language is in need of some gloss. For example, what does it mean to be "traded" on a QBE? That word ordinarily connotes the purchase and sale of an asset. RFCs, however, are not bought and sold in the usual sense. An RFC is a contract that a taxpayer enters into. When

\footnotetext{
${ }^{112}$ ICE Trust is a joint venture between the IntercontinentalExchange ("ICE") and a consortium of dealers. ICE operates a number of exchanges, but their operations are separate from those of ICE Trust.

${ }^{113}$ Rev. Rul. 87-43, 1987-1 C.B. 252.

${ }^{114}$ Some commentators have speculated about whether this issue was considered when ICE Trust was formed. As the principal tax advisor on issues relating to the clearing process, I can confirm that it was.
} 
the taxpayer wishes to dispose of its interest in the RFC, it enters into an offsetting RFC, and its original RFC is terminated. This has very much the same effect as if the taxpayer had sold its original RFC to its counterparty in the close-out transaction, but it is technically an offset and neither a sale nor assignment. The definition of "foreign currency contract," discussed below, also requires that such a contract be "traded in the interbank market," a market in which contracts also typically are not assigned but instead are entered into and closed out with the original counterparty. That definition also requires that a foreign currency contract be "entered into" at arm's length at a price determined by reference to the interbank market price, which could be read to suggest that there is a difference between "trading" a contract and "entering into" a contract.

One is driven, therefore, to the conclusion that (1) futures contracts and foreign currency forward contracts are not section 1256 contracts because they are not "traded" in the traditional sense, which would hardly be a popular position, (2) that the term "traded" includes entering into a contract, at least under some circumstances, or (3) perhaps that trading does not refer to how an interest in a contract is acquired or disposed of but rather contemplates an active market in which contracts can readily be entered into, closed out and valued - that is, trading has to do with liquidity and valuation. ${ }^{115}$ There are, however, futures contracts that trade on an exchange in very low volume, and it is hard to believe that would affect their status as section 1256 contracts. ${ }^{116}$ What then does it mean to be "traded on" a QBE — that is, does the word "traded" have any independent significance, and if so, what is it?

Another question is what it means to be "[traded] subject to the rules of" a QBE. The phrase could, for example, apply to any contract that is treated as a futures contract on a QBE, even if not originally entered into as such; it could also apply to any contract that has economic terms that depend on the rules that apply to futures contracts; it could also apply to any contract that is subject to any rule that is in the rulebook of a QBE; or it could apply only to some of those or conceivably even more broadly. The first of these seems clearly right, as the discussion of Revenue Ruling 87-43 below indicates. Further indirect support may come from history. While the legislative history of $\S 1256$ does not say where the "subject to"

${ }^{115} C f$. Treas. Reg. $\$ 1.1092(d)-1(c)$ (1993) (interest rate swaps treated as "personal property of a type that is actively traded" if contracts based on similar indices are "purchased, sold or entered into" on an established financial market, including an interbank market). This regulation was issued to resolve a similar conundrum. Section 1092 and, at the time, section 1234A applied to personal property of a type that is actively traded. The market for interest rate swaps is deep and liquid, but interest rate swaps are not typically assigned from party to party. Rather, parties enter into them and close them out. The regulation provides that entering into such swaps in the interbank market qualifies as active trading within the meaning of the relevant statutory provisions.

${ }^{116}$ To take a random example, according to the CME website, at the close of business on November 12, 2010, open interest in soybean oil futures expiring March 2012, May 2012 and July 2013 were 6,8 and 26 contracts, respectively, and none of those contracts traded on that day. CME GROUP, http://www.cmegroup.com/daily_bulletin/preliminary_voi/VOIREPORT.pdf(last visited Dec. 31, 2010). 
language comes from, a likely source is the Commodity Exchange Act. The author has been advised by commodity law experts that at the time $\S$ 1256 was enacted, exchange for physical transactions existed and were governed by the CEA. The "subject to" language therefore may have been intended to refer to futures contracts that are not traded on an exchange but are otherwise identical to, and subject to all the rules governing, other futures contracts. That would not answer the question of how much further the term reaches. ${ }^{117}$

Conversely, the meaning of the term QBE is clear, but may be in need of some rethinking. As described above, the CFTC now regulates many different kinds of markets (DCMs, DTEFs, EBOTs and ECMs, as well as DCOs). ${ }^{118}$ As a policy matter, it is undesirable to treat contracts traded on a DCM as (possible) section 1256 contracts and to treat identical contracts traded on a swap execution facility or another type of regulated market as non-section 1256 contracts. The Service has the authority to address this problem by determining that these other markets should be treated as QBEs, but that decision surely would be better made by Congress.

Returning to an analysis of the type of contracts on the list above, one could reach the conclusion that cleared agricultural swaps ought to be treated as section 1256 contracts in view of their very close economic connection to futures contracts, the fact that they essentially do not exist prior to being cleared, and the technical point that they are in fact subject to the rules of an exchange because the legal entity that is the CME, as it happens, is both an exchange and a clearinghouse. The last point becomes considerably less attractive, however, when one considers that it is also true of CME-cleared CDS. Surely it cannot be the case that CME-cleared CDS could be section 1256 contracts when ICE Trust-cleared CDS are not? At least it would not be so in a rational world.

Despairing, therefore, of any technical conclusion to this question, the article turns below to an examination of the history of $\S 1256$. That history is far more illuminating than the statute itself. As it happens, the question of whether the statutory definitions mean what they appear to say has been the subject of repeated inquiry. Strikingly, the government's

117 The Dodd-Frank Act does not directly address the issue, but there is at least one provision that suggests that clearing alone may not be the equivalent of "traded on or subject to" the rules of an exchange. That provision is part of the definition of the key term "swap" in $\S 721$ of the Dodd-Frank Act. It provides that "[a]ny foreign exchange swap and any foreign exchange forward that is listed and traded on or subject to the rules of a designated contract market or a swap execution facility, or that is cleared by a derivatives clearing organization" is subject to the Dodd-Frank Act. The phrase or very close variants of it are used in several other places in the bill, but not ones bearing directly on the issues discussed herein. See See Dodd-Frank Wall Street Reform and Consumer Protection Act, Pub. L. No. 111- 203, §§ 721, 124 Stat. 1376, 1683-84 (2010), 210(c)(8)(D)(iii)(IV), 124 Stat. 1376, 1483-84 (2010) (definition of “commodity contract"), 730, 124 Stat. 1376, 1701-03 (2010) (modifying large swap trader reporting requirements under Commodity Exchange Act), \& 737, 124 Stat. 1376, 1722-25 (2010) (modifying position limits under Commodity Exchange Act).

\footnotetext{
${ }^{118}$ See supra note 49.
} 
answer has consistently, with one apparent and temporary oversight to the contrary, been "no." As described below, the government has interpreted the statutory definitions in light of Congressional intent, with the result that they have been read to apply more narrowly than a literal reading would suggest. The one court that has reviewed an issue of this kind has heartily endorsed this narrow approach.

2. The 1983 Controversy over the Scope of the RFC Definition. ${ }^{119}$ As described above, when enacted in 1981 and as amended in 1982, § 1256 applied only to regulated futures contracts. After the 1982 amendment, § 1256 applied to a "regulated futures contract," defined as "a contract" that was subject to mark-to-market margin requirements and traded on or subject to the rules of a DCM or other qualified board or exchange.

New contracts that then began to trade raised both technical and policy questions about the scope of $\S 1256$, including cash-settled options such as options on a stock index, options on stock index futures contracts and "commodity options." As described in more detail below, Congress revised $\S 1256$ in 1984 to address these issues. Among the important goals of these amendments were to ensure that similar products traded on different kinds of exchanges (stock index options as opposed to stock index futures options) were subject to the same rules, and to avoid the proliferation of "mixed straddles" (transactions in which one position is a section 1256 contract but an offsetting position is not). An active debate took place prior to those amendments on both the question of how thencurrent law applied to these new contracts, and also the question of how the law should apply.

The part of the debate that is most relevant here concerned whether "commodity options" constituted RFCs under then-current law. A commodity option is a contract under which the writer grants to the holder the right to enter into a futures contract to buy (or sell) a designated commodity for future delivery at the strike price during the option period. Accordingly, if the option is exercised, the purchaser of a "call" commodity option enters into a "long" RFC (an RFC to buy a commodity), and the writer of that option enters into the corresponding "short" RFC (an RFC to sell the commodity); the purchaser and writer of a "put" commodity option correspondingly enter into a "short" or "long" RFC, respectively, on exercise. Like other options, a commodity option may also expire unexercised.

Commodity options were traded on CFTC-regulated exchanges and thus satisfied the second clause in the definition of RFC. Their margin arrangements were more complicated. The grantor of a commodity option must post "good faith" margin, a fixed amount negotiated at the outset, and "premium" margin, an amount equal to the current premium for the margin,

${ }^{119}$ For a contemporary description of the issues and the various proposals made to resolve them, see James W. Wetzler, The Tax Treatment of Securities Transactions Under the Tax Reform Act of 1984, 25 TAX NOTES 453 (1984); see also Kramer, supra note 49, § $62.03[\mathrm{C}]$, pages $62,027-31$ (describing the positions taken by different groups of taxpayers). 
marked to market daily. The purchaser of the option is not required to deposit additional funds during the life of the contract. In addition, the purchaser is not entitled to receive collateral posted by the grantor during the life of the contract, regardless of any variation in the value of the contract. Rather, the collateral remains the property of the grantor, who is entitled to a return on the collateral. Thus, the commodity option margin system resembled in some respects the mark-to-market system for futures contracts insofar as grantors of options are concerned, but not insofar as purchasers of options are concerned. Thus, it was possible that written commodity options were RFCs but purchased commodity options were not.

The New York Coffee, Sugar and Cocoa Exchange, Inc. (the "CSCE"), a commodity exchange, took the position that commodity options should be taxed like the futures contracts that underlie these options. The CSCE argued to the Treasury Department that the commodity option margin system for option writers was a system of marking to market that fell within the definition of a mark-to-market system for RFCs. The CSCE conceded that purchased commodity options were not subject to such a mark-to-market system and were not RFCs, but argued that gain or loss on commodity options held by a taxpayer nevertheless should be subject to $60 / 40$ treatment. $^{120}$

Treasury disagreed with that conclusion. In testimony submitted for a hearing before the House Ways \& Means Committee, Assistant Secretary for Tax Policy John Chapoton stated "In our view, commodity options are taxed under the same rules that apply to physical options." $\mathrm{He}$ then summarized the arguments made by the commodities exchanges, and stated "Irrespective of policy considerations that may favor this result, we believe that this interpretation of current law cannot be sustained under the present statute." ${ }^{121}$ Unfortunately, the basis for Treasury's conclusion was not explained.

The Joint Committee on Taxation (the "JCT") prepared a pamphlet for this same hearing that discusses the positions taken by various parties. The pamphlet states "[t]he staff does not believe that [the treatment of

${ }^{120}$ The CSCE argued that under the general option rules of section 1234, gain or loss from the sale or exchange of an option has the same "character" as the property underlying the option (i.e., RFCs), and that because $\S 1256$ determined the charactertechnically, the holding period - of gain or loss on futures contracts (as $60 \%$ long-term and $40 \%$ short-term capital gain or loss), the character of gain or loss on purchased commodity options should also be governed by $\S 1256$. These arguments were made in a May 1982 ruling request to the Internal Revenue Service, and a September 1982 memorandum to Treasury, copies of which became part of the legislative history of the 1984 amendments to $\S 1256$. Letter and Supporting Memorandum on the Tax Treatment of Options on Commodity Futures Contracts, from Donald Schapiro on behalf of the Coffee, Sugar and Cocoa Exchange to John Chapoton, Assistant Secretary of the Treasury (Sept. 29, 1982), reprinted as Tax Notes Document No. 82-9883. Several securities exchanges submitted memoranda criticizing these arguments and making alternative proposals.

${ }^{121}$ Federal Tax Treatment of Capital Gains and Losses: Hearing Before the H. Comm. on Ways and Means, $98^{\text {th }}$ Cong. $1^{\text {st }}$ Sess., 31, 32 (1983) (statement of John E. Chapoton, Assistant Secretary for Tax Policy, Dept. of the Treasury). 
written commodity options as RFCs] was intended by Congress in 1981."122 The pamphlet also expresses similar concerns about the argument that purchased commodity options were entitled to $60 / 40$ treatment. $^{123}$

As this history indicates, it was clearly Treasury's position and it appears to have been the JCT's position that notwithstanding the broad definition of RFCs all commodity options were subject to the rules applicable to conventional options. Thus, Treasury expressly rejected the conclusion that a contract (option) traded on a QBE that required parties (writers) to that contract to provide daily margin if the contract lost value and to receive it back if the contract gained value constituted a RFC. Moreover, Treasury reached this conclusion as a technical matter under then-current law.

Possible bases for Treasury's position may include: (i) the 1981 legislation clearly did not contemplate options, (ii) the daily margin rules applicable to writers of commodity options did not result in the passing through of that margin to option purchasers, and could never give rise to the net receipt of margin by the option writer, and so was not the type of markto-market system contemplated by Congress in 1981, or (iii) the argument made by the commodities exchanges strained credibility because it treated commodity options as RFCs for option writers but not option purchasers. Treasury clearly also was concerned about the potential for arbitrage that existed under then-current law because of the uncertainty as to how commodity options should be treated, and wanted to ensure that commodity options were subject to the same rules as RFCs going forward to avoid future arbitrage. Treasury's discussion of arbitrage concerns is separate from its discussion of technical issues, however, which is consistent with the statement quoted above stating that it considered the policy issues separately from its technical analysis.

3. History of "Foreign Currency Contracts. While not directly relevant to the scope of the RFC definition, the government's position on the scope of the definition of another type of section 1256 contract, foreign currency contracts, is also instructive. Foreign currency contracts were added to $\S 1256$ in 1982. A "foreign currency contract" is defined as:

"a contract

(A) which requires delivery of , or the settlement of which depends on the value of,] a foreign currency which is a currency in which positions are also traded through regulated futures contracts,

(B) which is traded in the interbank market, and

\footnotetext{
122 StafF OF JoInt COMM. ON TAXATION, TAXATION OF CAPITAL GAINS AND Losses: Scheduled for Hearings Before the Comm. on Ways and Means 23, JCS-5283 (Nov. 1, 1983).

${ }^{123}$ See id.
} 
(C) which is entered into at arm's length at a price determined by reference to the price in the interbank market."124

The legislative history makes clear that the reason for adding this new class of contract subject to $\S 1256$ was that there were taxpayers trading in both foreign currency futures and foreign currency forward contracts with banks on the same currencies, and that the amendment was intended to eliminate mismatches in timing and character for taxpayers trading in both markets that is, to avoid mixed straddles. ${ }^{125}$

In 1988, the Service issued Private Letter Ruling 8818010, which concluded that a currency swap on a currency that is traded through the futures market did not fall within the definition of "foreign currency contract." The PLR first concludes that the swap in question satisfies the requirement of clause (A) cited above. The PLR then turns to the legislative history of the 1982 amendment, and states that Congress intended to bring bank OTC forward contracts within the scope of $\S 1256$ because "they are economically comparable to and used interchangeably with" regulated futures contracts. The PLR goes on to conclude that currency swaps do not meet this standard, because they account for interest rate differentials through present and continuing exchanges of payments rather than through a single payment at maturity. The PLR also notes that Congress in 1982 and in later amendments to $\S 1256$ did not refer to currency swaps. On this basis, the PLR concludes that the swap fails to satisfy the requirements of clauses (B) and (C), and that the swap therefore does not constitute a "foreign currency contract."

This conclusion is rather remarkable as a technical matter. Currency swaps are entered into between banks in the interbank market, and thus are priced by reference to interbank market prices, which is what clauses (B) and (C) require on their face. The PLR simply determines that those clauses must be read in light of the legislative history of the term "foreign currency contract," and that Congress's purpose and its silence with respect to currency swaps (for which no market existed in 1981) properly lead to the conclusion that such swaps are outside the scope of $\S$ 1256. Perhaps one way to restate the analysis in the PLR is that it effectively reads the statutory language "a contract" to mean "a [bank forward] contract."

Many practitioners believed that the conclusion in the PLR was correct and that its reasoning could be extended to support the further conclusion that foreign currency options traded in the OTC market also did not constitute section 1256 contracts notwithstanding the fact that they too are traded between banks in the interbank market and priced by reference to interbank market prices. The issue was, however, uncertain. The

${ }^{124}$ This definition, as amended in 1984, is now found in I.R.C. $§ 1256(\mathrm{~g})(2)$

(2010). The bracketed language was added in 1984, as discussed in more detail below.

${ }^{125}$ S. REP. No. 97-592, at 25-28 (1982); H.R. REP. No. 97-986, at 24-26 (1982) (Conf. Rep.). 
government formally addressed that question first in Notice 2003-81, and subsequently in Notice 2007-71. ${ }^{126}$

Notice 2003-81 designates certain transactions in which taxpayers took offsetting positions in foreign currency options as "listed transactions." A key part of the intended operation of the transaction was that some of the options were on currencies traded through RFCs, and were treated by the taxpayers described in the Notice as "foreign currency contracts," and some were on currencies not traded through RFCs and thus clearly were not "foreign currency contracts." The Notice states as fact that the OTC foreign currency options on RFC-traded currencies constitute foreign currency contracts. The Notice contains no analysis of the issue, and it appears likely that at least some of the drafters of the Notice did not realize the significance of this statement. ${ }^{127}$

A mild uproar ensued, as practitioners questioned this off-hand conclusion. ${ }^{128}$ In 2007, the Service reversed its position in Notice 2007-71, which modifies Notice 2003-81, describes the statement in the earlier Notice about foreign currency options as a mistake, and states that the Service and Treasury do not believe that a foreign currency option on a currency traded though RFCs falls within the definition of "foreign currency contract" and will challenge taxpayers who take that position.

The Notice's technical reasoning is somewhat tortuous. The analysis begins by referring to the definition of the term as enacted in 1982, at which time clause (A) quoted above stated that a foreign currency contract "requires delivery of" an RFC-traded currency - that is, there was no reference to cash settlement. The Notice then states that an option does not "require" delivery of anything, because of the possibility that the option might not be exercised. This is an interesting point of view, since an option does create legally binding obligations on the writer, notwithstanding the possibility that the writer may not have to perform on exercise. A hypertechnical reader might wonder whether under this analysis a call (but not a put) option becomes a section 1256 contract upon exercise, since at that point the obligation to deliver foreign currency ceases to be contingent.

In any event, the Notice then goes on to address the 1984 amendment to the definition that modifies the delivery requirement by adding the language "or the settlement of which depends on the value of," as shown above. The legislative history makes clear that this amendment

${ }^{126}$ I.R.S. Notice 2003-81, 2003-2 C.B. 1223; I.R.S. Notice 2007-71, 2007-35 I.R.B. 472.

${ }^{127}$ The Service had taken the opposite position in I.R.S. F.S.A. 200025020 (June $23,2000)$, reasoning that Congress intended to extend $\S 1256$ treatment only to foreign currency forward contracts, and noting that the legislative history to 1984 amendments to the nonequity option rules states that only "certain" foreign currency contracts are treated as RFCs. The FSA also notes that reading "foreign currency contract" broadly to include foreign currency options would effectively override the limitations of $\S \S 1256(\mathrm{~g})(3)$ and (g)(4), dealing with options listed on a QBE.

FSAs officially have no authoritative weight whatsoever, and the Chief Counsel's office has ceased to issue them.

${ }^{128}$ See Michael J. Feder, L.G. “Chip” Harter \& David H. Shapiro, Notice 2003-81: Are OTC Currency Options 1256 Contracts?, 101 TAX NOTES 1470 (2003). 
was intended to bring cash-settled OTC foreign currency forwards on RFCtraded currencies within the scope of $\S 1256$. The Notice states that there is no indication in the legislative history-again reasoning by reference to silence - that this amendment also was intended to broaden the scope of "foreign currency contract" to foreign currency options. ${ }^{129}$ Finally, the Notice cites to the legislative history of certain 1986 amendments to $\S$ 988 - which is not technically legislative history to a 1982 amendment to $\S$ 1256 - as confirmation of Congress's understanding of the definition as not covering foreign currency options.

In short, the Notice also effectively reads the statutory definition as applying to "a [bank forward] contract," notwithstanding the apparently broad scope of the statutory definition of "foreign currency contract." The Notice thus demonstrates the crucial nature of legislative history and Congressional intent in the government's interpretation of the scope of $\S$ 1256.

The conclusion reached in the Notice was adopted by the Tax Court in Summitt. In a remarkable feat of vision, the court reaches its conclusion based on the plain meaning of the statute, and looks to legislative history only to confirm its conclusion. The "plain meaning" in this case includes the statutory changes made to the definition, thus suggesting that a similar historical view is appropriate with respect to regulated futures contracts. The case helpfully also states that "[w]hen Congress has specified the types of contracts that come within the definition of a section 1256 contract, exclusion of others from its operation may be inferred." 130 Summitt thus provides at least moral support for the narrow interpretation of $\S 1256$ that this article advocates.

4. Other Service Guidance on the Scope of the RFC Definition. Turning from legislation to regulatory guidance, there are a handful of items of guidance addressing the scope of $\S 1256$ 's definitional provisions. To the extent one can extract something from them, they too suggest that the Service has interpreted that definition by starting with a sensible conclusion and working backwards to find what support there is in the statutory language.

The only published guidance on the scope of the RFC definition is Revenue Ruling 87-43, which as briefly described above considers whether futures or option contracts established pursuant to the mutual offset system between the CME and a foreign exchange then known as SIMEX are considered "traded on or subject to the rules of" a qualified board or exchange. ${ }^{131}$ The Ruling concludes that contracts executed on one

\footnotetext{
${ }^{129}$ See H.R. REP. No. 98-432, at 1646 (1984). The Notice could also have noted that this change was a technical amendment.

${ }^{130}$ See Summitt v. Comm'r, No. 13893-07, 2010 WL 2010950, at*12 (134 T.C. No. 12, May 20, 2010).

${ }^{131}$ Rev. Rul. 87-43, 1987-1 C.B. 252. The options were "nonequity options" of a kind subject to sections $1256(\mathrm{~g})(3)$ and $1256(\mathrm{~g})(5)$ if traded on the CME. Sections $1256(\mathrm{~g})(3)$ and $1256(\mathrm{~g})(5)$ provide that any option, other than a right to acquire stock from an issuer, that is "traded on or subject to the rules of" a qualified board or exchange is a
} 
exchange and transferred to the other exchange should be analyzed by reference to the second exchange. Thus, futures contracts executed on SIMEX and transferred to the CME constitute regulated futures contracts, and futures contracts executed on the CME and transferred to SIMEX do not.

The Ruling is based on the step transaction doctrine. Because a customer wishing to enter into a futures contract that ultimately will be a CME futures contract originally contacts a clearing member of the CME, the Ruling concludes that since the first step in the transaction and the end result are the same as for a contract executed on the CME. Under the step transaction doctrine, the intervening steps should be ignored. There is a suggestion in the Ruling that the basis for this conclusion is that the futures contract is "subject to the rules of" the CME as if it had originally been executed on the CME because that is how the contract is described in the facts, but the analysis part of the Ruling does not make clear whether the futures contract is deemed "traded on" the CME, notwithstanding the fact that it is actually executed on SIMEX, or whether the Ruling relies on the "subject to the rules of" leg of the regulated futures contract definition.

The Ruling states that in determining whether the "traded on or subject to" condition is satisfied, "it is necessary to ascertain the legal relationships that exist between the parties to the transaction." That statement seems perfectly reasonable. The Ruling goes on, however, to describe "the parties" in a way that does not shed much light on larger issues.

A key point in the Ruling's reasoning is a statement that in a conventional CME futures contract transaction, the fact that an exchange clearing house is interposed between the original parties to the transaction should be ignored, because "the legal relationship between the investor and the broker remains unchanged." The meaning of this statement is unclear, particularly given the fact that the interposition of the clearing house between the clearing members has significant real-world consequences. It is also unclear why the statement focuses on the relationship between the investor and the clearing member, since generally the investor is treated for tax purposes as if it had directly entered into the futures contract on the exchange rather than as entering into an independent contract with the clearing member or the clearing house. ${ }^{132}$ By analogy, it would be rather

section 1256 contract as long as it is not an "equity option" (generally, a single-stock option or an option on a narrow-based stock index).

${ }^{132}$ Every other reference to a clearing house that the author is aware of treats the clearinghouse as a mere intermediary or guarantor. See Rev. Rul. 85-158, 1958-2 C.B. 175 (clearing corporation guarantees payment); I.R.S. Priv. Ltr. Rul. 88-11-053 (Dec. 22, 1987) (clearing organization plays role of intermediary), I.R.S. Priv. Ltr. Rul. 87-18-008 (Jan. 14, 1987) (refers to Options Clearing Corporation as guaranteeing options, and treats stock index options as having no issuer), I.R.S. Priv. Ltr. Rul. 83-28-005 (Mar. 23, 1983) (assumes that clearing house links buyers and sellers), I.R.S. Gen. Couns. Mem. 37,233 (Aug. 25, 1977) (treats clearing organization as merely a mechanism to link buyers and sellers, and not as a real party to a cleared listed option); $c f$. Treas. Reg. § 1.6045-1(b) (Example 2) (2006) (generally excluding clearing houses from treatment as a broker). It is also our 
unusual to give controlling weight to the taxpayer's relationship with its broker if one were analyzing the effects of a purchase of exchange-traded stock, except in highly unusual circumstances.

It is possible that the statement is simply intended to convey that for tax purposes the pre-clearing and post-clearing arrangements should not be treated as two separate contracts, and that the pre-clearing contract should instead be viewed as a temporary state of affairs that has no independent significance in analyzing the overall transaction. ${ }^{133}$ The Ruling seems to view the "original parties" to the transaction as the two clearing members, however, which would suggest the reverse, namely that it is the first step rather than the ultimate result that determines whether the transaction is within the scope of $\S 1256$. Again, it is hard to square treating the clearing house members as the true parties to the transaction with the tax law's treatment of the investor as the party that enters into the futures contract.

Like other $\S 1256$ rulings, therefore, the Ruling appears to reach the "right" result through technical reasoning that does not provide a basis for drawing conclusions with respect to other types of contracts or transactions. The best explanation of the Ruling's conclusion may simply be the common sense observation that all CME futures contracts should be treated in the same way regardless of whether they were executed on or off the CME. This is a less formal way of expressing the step transaction doctrine.

A field service advice issued in 2000 discusses the meaning of both the terms "regulated futures contract" and "foreign currency contract."134 Unfortunately, the FSA does not describe the actual transactions carried out by the taxpayer, except to say that they were foreign currency contracts in the colloquial sense. The FSA also appears to use the term "futures contract" to include what many people would refer to as a forward contract, which does not add to its clarity. In any event, the FSA appears to take the position that only a "futures contract" can qualify as a RFC, and that a futures contract must be subject to CFTC regulation in order to qualify as a RFC.

Another FSA from 2000 analyzes whether OTC foreign currency futures, forwards and options constitute RFCs, and concludes that they do not. ${ }^{135}$ While this result is hardly surprising, the analysis in the FSA is of interest because it turns on the meaning of the "on or subject to" language in the RFC and nonequity option definitions. The FSA interprets the statutory definition to mean that a contract must be (a) traded on an exchange, apparently testing this at the instant in time when the contract is executed, or (b) traded in a manner that causes the contract to be subject to

understanding that clearing houses do not treat themselves for purposes of filing their own tax returns as parties to the transactions they clear.

${ }^{133}$ A private letter ruling issued in the same timeframe analyzing the same transactions adds this gloss, stating that the steps involved in the typical exchange clearing process are not analyzed separately but are viewed as component parts of a single transaction. I.R.S. Priv. Ltr. Rul. 87-39-051 (June 30, 1987).

${ }^{134}$ I.R.S. F.S.A. 200025020 (Mar. 17, 2000).

${ }^{135}$ I.R.S. F.S.A. 200041006 (June 23, 2000). 
the rules of the exchange on an on-going basis, identifying the required use of a clearing house and the required use of mark-to-market as evidence of the "continuing nature of [the] relationship between the commodity futures contract that was, at one time, traded on the exchange, and the exchange."

The reader will not be surprised to hear that this analysis is based on legislative history. The FSA takes as its premise that Congress "created $\S 1256$ based on the actual operation of the futures markets," and then cites a sentence in a JCT report that futures contracts are "subject to the rules" and regulations of the exchange where they are traded. The Service's position thus appears to be that only futures contracts traded on an exchange can be RFCs.

If that continued to be the Service's position, CDS that were cleared but not exchange-traded would not be treated as section 1256 contracts. This technical analysis does not fully address the issues at hand, however, because the Service has never had occasion to consider a contract that is not traded on an exchange but that might nevertheless be considered to be subject to an exchange's rules. Indeed, the FSA's emphasis on clearing as satisfying the requirement that a contract be subject to the rules of an exchange could point towards a conclusion that CME-cleared CDS are "subject to" the rules of an exchange. The more significant lesson from the FSA seems to be that the Service will faithfully adhere to what it sees as Congressional intent in enacting $\S 1256$.

In summary, while there is no guidance on point, in the almost thirty years that $\S 1256$ has been on the books, it has always been interpreted in a manner intended to bring within the scope of that section those instruments that Congress specifically identified in legislative history, and to exclude all other instruments. As noted by the Tax Court in Summitt, Congress has implicitly approved this approach by leaving the definition of RFC unchanged, and adding additional categories of section 1256 contracts as it thought proper. Congress also has made clear that it considers it bad tax policy to create or permit a tax regime in which some contracts are subject to $\S 1256$ while other very similar contracts - here, cleared/traded swaps versus bilateral OTC-only swaps with standardized terms - are not. Extending that approach here would give rise to a simple conclusion, namely that neither cleared swaps nor exchange-traded swaps constitute section 1256 contracts, until and unless Congress speaks to the contrary.

Returning to the present, the task that still remains undone now that Congress has spoken is to divine its meaning. Section III.C. endeavors to do so.

C. The Dodd-Frank Amendment to Section 1256.

The Dodd-Frank amendment lists nine specific types of derivatives and states that they and "any similar agreement" do not constitute section 1256 contracts. Because the precise composition of the list may be important, the list is repeated here, along with two other potentially relevant lists: 
Dodd-Frank definition of swap

(I) interest rate swap

(VII) currency swap

(VIII) foreign

exchange swap

(VI) basis swap

(III) rate cap

(II) rate floor

(IV) rate collar

(V) cross-currency rate swap

(XXII) commodity swap

(IX) total return swap

(XII) equity swap

(X) equity index swap

(XII) debt index swap

(XIII) debt swap

(XIV) credit spread

(XV) credit default swap

(XVI) credit swap

(XVII) weather swap

(XVIII) energy swap

(XIX) metal swap

(XX) agricultural swap

(XXI) emissions swap

agreement known as similar agreement swap

The Dodd-Frank definition of swap is both broader and narrower than what is described above. It is broader because the list is only one component of the definition. But it is also narrower, because there are
NPC definition

interest rate swaps

currency swaps

basis swaps

interest rate caps

interest rate floors

commodity swaps

equity swaps

equity index swaps similar agreements 
various carve-outs to the definition. Those refinements are for the most part not relevant to this discussion.

The NPC definition comes from Treasury regulation $\S 1.446-$ 3(c)(1)(i). That regulation defines an NPC functionally, as a financial instrument with certain payment terms. It then goes on to say "[n]otional principal contracts governed by this section include" the list above. Thus, in the NPC context, the list is illustrative only, although the illustration helps to illuminate the meaning of the definition.

It is obvious from a quick glance at these lists that the Dodd-Frank definition of swap contains many types of swaps not included in the DoddFrank $\S 1256$ amendment, and has some minor differences in wording. It is also obvious that the composition, the wording and the ordering of the list in the amendment precisely tracks the list in the NPC regulations, except for the addition of CDSs. A natural conclusion that could be drawn is that the $\S 1256$ amendment was intended to refer to NPCs and CDSs. However, other alternatives have been suggested. Among the alternative interpretations of the scope of the $\S 1256$ amendment are:

(a) the nine contracts enumerated in the amendment and no others; a "similar" agreement is one essentially identical to one of the nine enumerated contracts;

(b) NPCs and CDSs; a "similar" agreement is an NPC that is not specifically enumerated;

(c) NPCs, CDSs and agreements that are similar in that they are based on NPCs or CDSs, for example a forward or option to enter into an NPC;

(d) "modern" contracts, i.e., contracts historically traded on commodities exchanges should remain section 1256 contracts, but more recently developed types of derivatives should not become section 1256 contracts; or

(e) any swap listed in the definition of Dodd-Frank; a "similar" agreement is one that is a Dodd-Frank "swap." Since the DoddFrank definition of swap excludes futures contracts, this should be understood to mean all derivatives other than futures contracts and other types of contracts specifically excluded from the Dodd-Frank definition of swap. ${ }^{136}$

Other alternatives are possible. For example, another possibility would be that the $\S 1256$ amendment applies to any specifically enumerated swap and any other derivative on the same underlying risk.

To this observer, the most likely of these alternatives is that the core of the amendment is that it applies to NPCs, meaning that alternatives (b) and (c) are the most likely possibilities. To explain this conclusion, a

${ }^{136}$ For some discussion of these various alternatives, see Amy S. Elliott, IRS May Restrict Definition of Swap to Notional Principal Contracts (Dec. 15, 2010), available at 2010 TNT 240-3. 
few observations are in order before considering what additional insight the legislative history may provide.

The first alternative offers the impression of simplicity but suffers from the fact that it seems entirely arbitrary. Why include an equity swap but not a swap on debt instruments? What is the difference between a currency swap and a foreign exchange swap? In view of the fact that agricultural products and natural resources are commodities, what would it mean to include commodity swaps but exclude agricultural swaps, energy swaps and metal swaps? The fact that slightly different wording is used in the $\S 1256$ amendment and the Dodd-Frank swap definition for interest rate caps and floors also suggests that the drafter of the amendment was not looking to the swap definition.

The second alternative has the virtues that on its face it corresponds to existing law (the NPC definition) and can be interpreted by reference to well-known rules; it is principled in that it takes into account that $\S 1256$ has no rules for derivatives with periodic payments; and it covers a large part of the derivatives market, which seems like a necessary condition in view of the fact that the amendment eliminated the estimated revenue loss from the derivatives Part of Dodd-Frank. ${ }^{137}$ However, it is not possible to prove that the correspondence with the NPC definition was deliberate. ${ }^{138}$ This alternative also would exclude derivatives that one might believe should be within the scope of the amendment, as for example swaptions.

The third alternative treats the specifically named contracts as NPCs and CDSs, but takes a broader view of what constitutes a "similar agreement." The principal difficulty with this interpretation is that it is difficult to articulate the outer boundaries of what constitutes a similar agreement. This is of particular concern when trying to ensure that the definition does not inadvertently turn derivatives that were section 1256 contracts prior to the enactment of Dodd-Frank into non-section 1256 contracts. If the government were to adopt this alternative, an incremental approach of identifying contracts as they begin to trade on a regulated market as within or outside the scope of the amendment might be the most feasible approach, although that would provide less guidance to taxpayers anticipating the onset of such trading.

The fourth alternative would be comforting: "Chicago" products would be subject to $\S 1256$, while "New York" products would not. But alas the distinction is not so easy to make. As has been described above, the range of products offered by commodities exchanges has expanded greatly over time. For that matter, so has the range of products available in

\footnotetext{
${ }^{137}$ See Congressional Budget Office, Cost Estimate, H.R. 4173, Dodd-Frank Wall Street Reform and Consumer Protection Act, at 4 (June 28, 2010), available at http://www.cbo.gov/ftpdocs/115xx/doc11596/hr4173.pdf (showing virtually no effect on budget revenues or outlays from Title VII of Dodd-Frank).

${ }^{138}$ As noted earlier, a prior version of this article, published a few weeks before the amendment appeared in the Dodd-Frank bill, recommended amending $§ 1256$ to exclude NPCs and CDSs, among other proposed changes to the Code. The author's views on the proper interpretation of the $\S 1256$ amendment are inevitably affected by this chain of events. Readers may draw different conclusions.
} 
the OTC market. The result is that even before Dodd-Frank there were overlaps in products or competing products in both markets. For example, it is possible to take risk positions not only in commodities, interest rates and foreign currency but also in weather and real estate both on commodities exchanges and in the OTC markets. The starkest examples of the overlap are the CME and IDCG swap futures contracts described above, which offer exchange-traded alternatives to OTC interest rate swaps. All of these products existed prior to the enactment of Dodd-Frank. And it can be expected that the commodities exchanges will continue to develop new products. The distinction between "modern" and "historic" products thus does not provide either a clear or a principled line between contracts that are and are not subject to $\S 1256$.

The fifth alternative also offers the promise of simplicity. However, it seems wrong to this observer for several reasons. The first is that if the $\S 1256$ amendment was intended to apply to all Dodd-Frank swaps, it would have been easier to draft it with a cross-reference. The decision instead to enumerate a list implies that some Dodd-Frank swaps were not intended to be covered. The fact that the ordering and wording of the list in the amendment and in the definition are different also suggests a different meaning for the amendment. Lastly, and perhaps most seriously, this approach is the one most likely to cause derivatives that were thought to be section 1256 contracts prior to Dodd-Frank into non-section 1256 contracts. There is no reason to believe that Dodd-Frank was intended to have that effect.

Indeed, the evidence we have indicates the contrary. As quoted earlier, the single sentence of legislative history to the amendment describes it as "a provision to address the recharacterization of income as a result of increased exchange-trading of derivatives contracts by clarifying that section 1256 of the Internal Revenue Code does not apply to certain derivatives contracts transacted on exchanges." The most important word in this sentence is "clarifying." It seems clear that the amendment was intended to ensure that exchange-trading of what is now an OTC contract does not in and of itself cause the contract to become a section 1256 contract. That is, it was intended to freeze the status quo for derivatives not currently traded on exchanges. It also seems clear that the amendment was not intended to change the current law tax treatment of any derivative currently traded on an exchange, as such a change would constitute more than a clarification. Treating the amendment as freezing the status quo is also consistent with what the author understands to have been the deliberately very limited effect that the amendment was intended to have as a result of the Congressional rules governing the process for moving the Dodd-Frank bill through Congress. ${ }^{139}$

If the analysis above is correct, it has a number of implications for derivatives outside the scope of the amendment. First, if it is a "clarification" to provide that an interest rate swap will not become a section 1256 contract if the swap is traded on a regulated market, that

${ }^{139}$ See supra note 90. 
implies that the interest rate swap did not become a regulated futures contract by reason of that trading. That logic in turn confirms that the term "regulated futures contract" should be given a very limited meaning, as argued earlier based on the prior history of $\S 1256$.

A second important implication has to do with the effect under current law of clearing a derivative through a regulated clearinghouse. If it is a "clarification" to provide that trading CDSs does not cause them to become section 1256 contracts, it seems likely that CDSs do not today constitute section 1256 contracts. After all, if cleared CDSs were section 1256 contracts today, then there would be no reason to include them in the amendment. Thus, the mere fact that a CDS is cleared through a regulated clearinghouse - even one like the CME clearinghouse whose rules are integrally connected to the rules of an exchange-should not cause it to become a section 1256 contract.

Having extracted this much from the single operative sentence of the $\S 1256$ amendment and the single sentence of legislative history, let us return to some of the conundra we considered earlier in the article. The first was the potential disparities in the tax rules applicable to an interest rate swap, and IDCG interest rate swap futures contract and a CME futures contract. The second was the treatment of various instruments in a dealer's interest rate swap book. A third interesting question is how the $\S 1256$ amendment affects energy swaps.

The IDCG contract is both a futures contract and an interest rate swap, since no rule tells us that the two are mutually inconsistent. ${ }^{140}$ The pre-Dodd-Frank status quo is uncertain, since while the contract is a futures contract it is not a contract of the kind Congress envisioned when $\S 1256$ was enacted. Indeed, as noted above, the IDCG swap futures contract illustrates that the issues raised by the migration of OTC contracts into regulated clearinghouses and onto exchanges is not solely the result of Dodd-Frank. These issues also arise because of the initiatives taken by commodities exchanges to expand the scope of their products. That is, the status quo pre-Dodd Frank was a moving rather than static object, and thus not easy to freeze.

Neither statutory language nor legislative history definitively answer the question of how an IDCG swap futures contract should be treated. On balance, this author would come to the conclusion that the $\S$ 1256 amendment's statement that an interest rate swap does not constitute a section 1256 contract should be read to override the rules otherwise applicable to futures contracts, at least in a case like this one where the

${ }^{140}$ This is a slight overstatement. As Bill Paul has commented to me several times, the definition of NPC in Treasury Regulation $\S 1.446-3$ excludes a futures contract. If that priority rule applied more generally, the sprinkling of CFTC pixie dust over a contract to make it a futures contract could mean that such a contract fell outside the scope of the $\S$ 1256 amendment, at least if one believes that that amendment is intended primarily to cover NPCs. While acknowledging the technical point, the author does not believe that an obscure regulatory rule intended to ensure that only one set of timing rules applied to a particular contract should be viewed as informing Congress's judgment as to which of those rules should take priority. 
futures contract is not of a kind envisioned by Congress. That conclusion is based on the history of interpreting $\S 1256$ narrowly, the similarly restrictive intent of the $\S 1256$ amendment, the lack of any rules in $\S 1256$ for contracts with periodic payments, and the desirability of having consistent rules for all interest rate swaps. Given the uncertainty of this or any other conclusion with respect to IDCG interest rate swap futures contracts, this contract is a prime example of the need for regulatory guidance.

If one concludes that the IDCG contract is not a section 1256 contract, one might wonder also about the CME swap futures contract. If the $\S 1256$ amendment covers NPCs and agreements that are similar because they are linked economically to NPCs, even the CME swap futures contract might not qualify as a section 1256 contract.

Turning to the hypothetical dealer book consisting of interest rate swaps, long and short positions in Treasuries, Treasury futures and options thereon, CME swap futures, ICDG swap futures, forward rate agreement and swaptions, it turns out that certainty is similarly elusive. If the forward rate agreement were cleared and/or traded on a regulated market, without more, it would appear to be outside the scope of the $\S 1256$ amendment except under one of the broader readings, because it is not an enumerated contract and also not an NPC. However, if an RFC is limited to contracts that constitute futures contracts, a cleared/traded forward rate agreement would also not come within any of the definitions of a section 1256 contract. If we change the facts and assume that it trades as a forward rate agreement futures contract, then it would be hard to see how the contract could be anything other than a section 1256 contract.

The swaption raises a different technical issue. If traded on a regulated exchange, on its face it would appear to constitute a "non-equity option," a type of section 1256 contract. The legislative history of that definition does not indicate any particular Congressional interest in limiting the term "non-equity option" to any specified class of non-equity options, so the history of $\S 1256$ does not provide a basis for excluding it from that definition. A swaption also is not an NPC. Thus, in order to conclude that a swaption traded on a regulated exchange would not constitute a section 1256 contract, it would be necessary to conclude both that it is a "similar agreement" within the meaning of the $\S 1256$ amendment and that in that case the amendment overrides the definition of non-equity option. This goes beyond the argument made above, that the amendment is intended to address unclear situations and clarify them in favor of non- $\$ 1256$ treatment. Here too, regulatory guidance would be welcome.

Finally, turning to energy swaps, the author confesses some trepidation, as the energy derivatives market is a highly specialized one that the author ventures into only from time to time. Accordingly, rather than trying to answer any questions, this discussion will simply point out some relevant considerations. First, in the case of energy swaps that are exchanged for futures contracts, it is hard to see why the Dodd-Frank $\S$ 1256 amendment would have any effect, at least as those contracts are structured today - that is, with a single bullet payment rather than with a 
payment stream like that of a NPC. The only interpretation of the amendment that could change what the author understands to be the current law treatment of such futures contracts as section 1256 contracts is the broadest one, because energy swaps are included in the Dodd-Frank definition of swap. As noted earlier, however, that definition excludes a contract of sale of a commodity for future delivery. Moreover, if pre-DoddFrank law was fairly clear that energy futures acquired in exchange for an energy swap were section 1256 contracts, then it would seem to go beyond the scope of the amendment to change that.

The treatment of energy swaps that are cleared by a regulated clearinghouse but not exchanged for futures contracts is much less certain. The arguments made above with respect to cleared CDSs suggest that clearing alone does not cause a contract to become a section 1256 contract. CDSs are however specifically enumerated in the $\S 1256$ amendment. The argument may become more tenuous for other contracts. A potentially contrary argument would be that a contract that looks and smells like a futures contract, but for the fact that it does not trade as one, ought to be subject to the same rules as futures contracts. This argument also has its pitfalls. For example, the "fixed" leg of the IDCG's interest rate swap futures contracts is not actually a fixed amount. Instead, it is based on futures prices for a contract with a specified maturity, such as one month or three months. Tying the tax treatment of a derivative to whether it has payment terms linked to futures thus does not seem likely to reduce the amount of confusion over how to classify derivatives that share some characteristics of both the OTC and exchange-traded markets.

In short, any attempt to make sense of the distinction between section 1256 contracts and non-section 1256 contracts seems to be doomed to failure if the goals are to adopt rules that are principled, simple to apply and avoid whipsaw and arbitrage. If one scales back the goals by conceding that it will be impossible to write rules that treat all similar contracts in the same way, so that whipsaw and arbitrage will have to be addressed through some means apart from drawing that line, it may be possible to construct rule that are faithful to the history and, to the extent determinable, policy of the rules of $\S 1256$ along the following lines:

Rule 1: NPCs and CDSs do not constitute section 1256 contracts.

Rule 2: Subject to Rule 1 (meaning that Rule 1 trumps where both Rules could apply), futures contracts do constitute section 1256 contracts.

Rule 3: Options on Rule 1 contracts are not section 1256 contracts; options on Rule 2 contracts are section 1256 contracts.

Rule 4: Other types of contracts (not specifically treated as section 1256 contracts pre-Dodd-Frank) generally are not section 1256 contracts. One might want to modify this to provide that contracts of a kind eligible to be exchanged for Rule 2 contracts and that are cleared by a regulated clearinghouse should be taxed as section 1256 contracts. 
If these rules applied, IDCG interest rate swap futures, forward rate agreements (if not futures contracts), and swaptions would not be section 1256 contracts; CME swap futures would be section 1256 contracts; and energy swaps not exchanged for futures contracts either would or would not constitute section 1256 contracts depending on how Rule 4 was applied.

\section{INITIAL PAYMENTS.}

This Part IV now turns to the other principal issue that is the subject of this article, namely the possibility that the upfront payment on a swap might be treated as a loan for U.S. federal income tax purposes, with the result that payments of interest are deemed to be made between the parties. As discussed in Section II.C, above, it appears likely that there will often be upfront payments, or deemed upfront payments, under cleared swaps for a number of different reasons. An obvious one is that in the case of a swap such as a CDS that provides for coupon payments at the standardized level rather than the market quoted level, there will always be an upfront payment in order to bring the aggregate payments under the swap back to a market level. Other potential causes of an upfront payment, or deemed upfront payment, are closing out cleared swaps, transfers of existing OTC swaps into a clearinghouse, and transfers of existing cleared swaps if an FCM defaults.

As described in Section I.B.1, above, under Treasury Regulation $\S$ 1.446-3(g)(4), a "significant" nonperiodic payment on a notional principal contract is recharacterized for U.S. federal income tax purposes as a deemed loan from the party making the payment to the recipient that is paid back in installments over the life of the contract. In the case of most OTC swaps, these rules are (fairly) clear and have not been problematic for dayto-day business transactions, because it was rare for an upfront payment on interest rate swaps, foreign currency swaps or most other common types of swaps to be paid, or if so, for it to breach the "significance" threshold, whatever that may be. Consequently, taxpayers have not developed the internal systems that would be necessary to monitor whether a deemed loan arises and instead have dealt with the issue on a case-by-case basis.

In the case of cleared swaps, not only is it more likely that upfront payments will be made on a swap, there are also a number of aspects of clearing that raise additional technical questions about when and whether a deemed loan arises, and if so what its terms are. Existing law does not, of course, address those issues. Section IV.A discusses whether an upfront payment on a cleared swap is in fact a "payment" for U.S. federal income tax purposes, and if so, to whom it should be considered paid. Section IV.B discusses a number of issues having to do with when a deemed loan arises on a cleared swap and if so what its terms are. Section IV.C then discusses a number of additional issues that come in to play for cleared CDS. In the course of discussion, this Part IV also makes a number of suggestions for areas in which guidance would be useful.

As this discussion will demonstrate, there are many uncertainties as to whether a deemed loan arises under current law and if so, what its terms are. Since taxpayers must file annual tax returns, whether taxpayers that enter into cleared swaps with upfront payments must treat them as giving 
rise to deemed loans and the determination of how much interest is deemed paid when are not abstract issues. More specifically, deemed loan/interest treatment implicates information reporting rules; withholding tax rules; a variety of rules dealing with interest expense, such as the foreign tax credit rules, Treasury Regulation $\S 1.882-5$, addressing the allocation of interest expense by foreign banks and other foreign persons doing business in the United States in branch form, and the unrelated business taxable income rules for tax-exempt organizations; the $\S 475$ prohibition on marking one's own debt to market; and for some taxpayers that enter into off-market swaps, like standardized CDS, with their affiliates, potentially $\S 956$. In the view of this author, in view of the fact that taxpayers have found themselves in this uncertain new world as a result of an extraordinary and rapid reshaping of the financial markets, and pursuant to changes in non-tax law and regulatory mandates, it would be an appropriate exercise of discretion on the part of the government to announce that it will not, except in cases of abuse or cases that clearly fall within existing law, require taxpayers to treat an upfront payment on a cleared swap as a deemed loan for U.S. federal income tax purposes until guidance is issued that resolves these uncertainties.

\section{A. Payment Issues}

Before turning to more technical issues, it is worth stopping to consider whether as a matter of economic substance the upfront payment is in fact a "payment" at all for U.S. federal income tax purposes. While this article does not attempt to assess how the Danielson doctrine would apply, that question may not be determinative because taxpayers may be held to their form, if adverse to them. ${ }^{141}$ But even if taxpayers are held to their form here, this question is still worth asking, because it may affect the equities involved in how the government approaches the technical questions discussed below, and because it also is highly relevant to the $\S$ 956 issue mentioned above. The fact that in this case taxpayers have not chosen the form in the usual sense, but rather it is the result of guidance, albeit non-binding to date, from regulators also may affect the equities.

As described in Section II.C, an upfront payment on a swap due from Party A to Party B is immediately and automatically reversed as a cash flow matter by a transfer of cash variation margin in the same or a very similar amount from Party B to Party A. This is not the result of some tax-driven structured arrangement or the result of combining two unrelated or loosely related transactions. Rather, it is inherent in the economics of the transaction and in the fundamentals of the structure developed by the industry in response to regulatory imperatives in order to reduce and manage risk. The amounts are the same because one is intended to offset the other as a credit risk matter. In other contexts, one would not doubt that a circular flow of cash, envisioned by the parties and required by the legal

${ }^{141}$ See Comm'r v. Danielson, 378 F.2d 771 (3d Cir. 1967). The Danielson case generally stands for the proposition that taxpayers will be held to the form they have chosen, absent proof that a different treatment is more appropriate. The level of proof required varies in different Circuits. 
documents, would be ignored for U.S. federal income tax purposes, even if it were respected for some other purposes such as a foreign tax regime.

This is not a typical (if there is such a thing) circular flow of cash, however. The initial variation margin is a posting of collateral, which ordinarily is not treated as a contractual payment. Rather, it is a temporary transfer of assets from one party to another that is provided solely for credit support reasons and is expected to be reversed during the course of the transaction. It is economically a loan. Thus, if one treated an upfront payment as giving rise to a deemed loan from Party A to Party B, and the variation margin as a loan in an equivalent amount from Party B to Party A, the question would be whether, in the absence of abuse, these offsetting loans between the same parties, made at the same time and as integral parts of the same transaction, should be respected as such or should be netted against each other. Another way to put the question is whether a 100 percent cash collateralized loan gives rise to indebtedness for U.S. federal income tax purposes, in view of the fact that there has been no extension of credit.

One relevant consideration might be that if the two flows of cash were disregarded for tax purposes, the swap would in the first instance appear to be off-market. For example, if the market quoted level for an interest rate swap is 6 percent, but the parties enter into an interest rate swap with a 5 percent coupon, and Party A consequently pays a $\$ 4,210,000$ upfront payment to Party B and receives initial variation margin from Party $\mathrm{B}$ in the same amount, disregarding the two cash flows of $\$ 4,210,000$ leaves an interest rate swap whose terms provide for off-market coupon payments of 5 percent. However, that swap is only apparently off-market, because there is another cash flow that has not yet been taken into account. The variation margin provided by Party B will be marked to market on a daily basis going forward, and will be paid back to Party B over time. These daily margin payments are "real," in the sense that over time they will cause Party A to pay the economic equivalent of $\$ 4,210,000$ to Party B. Economically speaking, therefore, the periodic payments that Party A makes to Party B would seem to be the equivalent of a coupon that is partly fixed and partly floating, with the "floating amount" determined by reference to changes in the value of an interest rate swap and potentially either positive or negative on any particular day. This would be an unusual animal, but the concept of using objective financial information to determine the amount of a periodic swap payment is not new. ${ }^{142}$ On the other hand, there may be taxpayers who would not view the transformation of a simple 6 percent vs. LIBOR interest rate swap into an instrument with a fixed 5 percent coupon and a variable market-based coupon as an improvement over respecting the form of the cash flows.

Treating the daily margin cash flows in this manner may be a bridge too far. It is one thing to take the view that, at least for some

${ }^{142}$ See Treas. Reg. § 1.446-3(c)(4)(ii) (1994) (defining objective financial information as "any current, objectively determinable financial or economic information that is not within the control of any of the parties to the contract and is not unique to one of the parties' circumstances"). 
purposes, offsetting flows of cash should be disregarded. It is a very different thing to take the view that every transfer of margin with respect to a cleared swap should be treated as a payment under the swap. Since margin transfers will be made daily, reflecting incremental changes in value of the swap, an approach of that kind would effectively mean that the swap would be marked to market for U.S. federal income tax purposes. While there may be some sympathy for that result - after all, the taxpayer in fact has additional cash in its hands, or has paid out additional cash, and the extent to which swap payments and margin payments are netted by a clearinghouse is more far-reaching than in the OTC context - treating a cleared interest rate swap as subject to an effective mark-to-market regime because of margin cash flows seems clearly contrary to Congress's intent in enacting the amendment to $\S 1256$, which was intended to ensure that interest rate swaps and other swaps covered by the amendment continue to be taxed as they were in the OTC market. As a general matter, therefore, for a variety of reasons it seems appropriate to treat the upfront payment as "real" for tax purposes.

Notwithstanding that point, the argument that the upfront payment should be netted to zero or something close to it is particularly compelling when one considers the possible application of $\S 956$. In the example above, if one assumes that Party A is a CFC and Party B is a U.S. affiliate, it can hardly be argued that the CFC has made any net assets available to the U.S. affiliate.

Section 956 generally provides that an investment in "United States property" by a controlled foreign corporation may give rise to an inclusion by its U.S. shareholder under subpart $\mathrm{F}$ if the CFC has earnings and profits that have not yet been included in the shareholder's income. "United States property" for this purpose generally includes any obligation of a United States person, with exceptions for obligations of unrelated parties. Less technically, § 956 gives rise to a potential deemed dividend from a CFC if the CFC lends money, or is deemed to make a loan, to a related U.S. person. Accordingly, if a CFC makes an upfront payment on a swap to a U.S. affiliate there is a potential for a $\S 956$ inclusion. One possible avenue for concluding that there is no investment in United States property could be to conclude that even if a "payment" from the CFC to its U.S. affiliate has taken place, there is no "obligation" of a United States person within the meaning of $\S 956$ because the U.S. affiliate has already transferred a like amount of cash back to the CFC. ${ }^{143}$

Another possible path to that conclusion would be to look to the statutory exceptions to the term "United States property." Section 956 expressly provides two exceptions for transactions in which it is customary to provide collateral. Section 956(c)(2)(J) provides in relevant part that United States property does not include an obligation of a U.S. person to the extent that the principal amount of the obligation does not exceed the fair market value of readily marketable securities posted or received as

${ }^{143}$ The term "obligation" is not defined in the statute. Temp. Treas. Reg. $§ 1.956-$ $2 \mathrm{~T}(\mathrm{~d})(2)$ (2008) defines it to include any form of indebtedness. 
collateral for the obligation in the ordinary course of its business by a United States or foreign person which is a dealer in securities. Thus, if the CFC made an upfront payment to a U.S. affiliate of $\$ 4,210,000$ while the affiliate in turn provided variation margin in the form of readily marketable securities with a value of $\$ 4,210,000$, and one of the parties was a dealer in securities acting in the ordinary course of its business, there would be no United States property for $\S 956$ purposes. A rational tax regime would not provide a worse result if the variation margin is in a form - cash - that completely offsets the obligation in the first place.

Now let us reverse the facts, and assume that the U.S. affiliate makes a $\$ 4,210,000$ upfront payment on an interest rate swap to the CFC, and on the same day the CFC provides $\$ 4,210,000$ variation margin to the affiliate. Section 956(c)(2)(I) provides in relevant part that United States property does not include "deposits of cash made or received on commercial terms in the ordinary course of a United States or foreign person's business as a dealer in securities. . . ., but only to the extent that such deposits are made or received as collateral or margin for (i) a. . . .notional principal contract [or] options contract." It should be clear in this case, without regard to the netting argument, that there is no United States property.

The next question to consider is who should be treated as the recipient of an upfront payment.

As described in Section II.A.1, in practice a derivatives clearinghouse faces its clearing members. As a result, when Party A and Party B submit a swap negotiated in the OTC market to be cleared, each of Party A and Party B will act through a clearing member, usually an FCM. The flow of payments thus will be from Party A to its clearing member to the clearinghouse, and then from the clearinghouse to Party B's clearing member to Party B, and vice versa.

Economically both the clearinghouse and the clearing member are conduits, albeit ones with important legal and economic roles, so that one possible way to treat the transaction for tax purposes would be as if payments were being made from Party A to Party B. That possibility must almost immediately be rejected as a general matter, at least in the absence of abuse, because once the clearinghouse steps in between Parties A and B their economic fates are no longer linked. For example, Party B could the next day enter into an offsetting transaction with Party $C$, in which case the clearinghouse would close out both of Party B's swaps and leave Party A and Party $\mathrm{C}$ as the remaining counterparties. It would be both impossible and meaningless to try to match up the Parties A, B, C etc. on an on-going basis.

Since the status of the clearinghouse as the counterparty to all transactions has very significant economic consequences, the logical answer to the question posed above is to treat each party as making payments to and receiving payments from the clearinghouse. There is a hitch here too, though, which is that some in clearinghouse arrangements 
the clearing members act as agents but in others the clearing members act as principals, for legal purposes. ${ }^{144}$ The real distinction between these legal statuses is not clear to this author; in practice all clearing members appear to perform some agent-like functions (i.e., passing through payments and margin) and some principal-like functions (i.e., providing credit support to the clearinghouse, being the face to customers). Obviously it would be preferable for tax purposes to treat clearing members either always as principals or always as agents. Such guidance as there is suggests that clearing members should be treated as agents, but that guidance is neither clear nor definitive. ${ }^{145}$ Treating a clearing member as a mere intermediary would be consistent, however, with $\S 1256$, which implicitly treats taxpayers that transact in futures contracts as directly entering into contracts that trade on a futures exchange - i.e., ignoring the fact that the futures clearinghouse is dealing legally with an FCM rather than the customer -rather than treating them as entering into an off-exchange contract with a FCM.

The remainder of the discussion below assumes that an upfront payment on a cleared swap is treated for U.S. federal income tax purposes as a cognizable payment that is made by one party to the swap to a clearinghouse, and by the clearinghouse to the other party to the swap. The remaining discussion also ignores the payment of variation margin, except where specifically stated.

\section{B. Deemed Loan Issues}

As has been adverted to earlier in the article, there are a number of technical and practical issues that require clarification in order to determine when a deemed loan arises as a result of an upfront payment, and what the payment terms of the deemed loan are. They are (i) when an upfront payment is treated as "significant," because ordinarily only a "significant" nonperiodic payment is treated as giving rise to a deemed loan, (ii) how to distinguish between swaps that are subject to the deemed loan rules and other derivatives that are not, and (iii) how, or whether, to take into account the special characteristics of cleared swaps.

1. "Significance". Treasury regulation $\S 1.446-3$ does not define the term "significant." Rather, it illustrates the meaning of the term through two examples, which describe the cash flows on a particular swap and then state that the upfront payment is or is not significant.

Both examples concern a five-year interest rate swap entered into when the market rate for such a swap is 10 percent vs. LIBOR. In the first example, Party G agrees to pay 11 percent rather than 10 percent annually. Since Party $G$ is paying more than the market rate, Party $H$ makes an upfront payment to Party $\mathrm{G}$ equal to the present value of 1 percent over 5 years. ${ }^{146}$ This payment is not "significant." In the second example, Party

\footnotetext{
${ }^{144}$ See supra note 52.

${ }^{145}$ See supra note 132 and accompanying text.

146 Treas. Reg. § 1.446-3(g)(6), Example 2 (1994).
} 
$M$ agrees to pay 6 percent rather than 10 percent annually. Since Party $M$ is paying less than the market rate, Party $\mathrm{M}$ also makes an upfront payment to Party $\mathrm{N}$ equal to the present value of 4 percent over 5 years. ${ }^{147}$ This payment is "significant."

Consequently, current law answers the question of whether an upfront payment that is either 10 percent or less than the present value of the at-market fixed leg payments on the swap, or 40 percent or more than the present value of the at-market fixed leg payments on the swap, is "significant," but it provides no guidance for any upfront payment between those two levels. For example, in the case of the interest rate swap that pays 5 percent vs. LIBOR when the market rate is 6 percent vs. LIBOR, the upfront payment is equal to the present value of $1 / 6$, or about 17 percent, of the at-market payments on the fixed leg of the swap. Taxpayers should not have to guess whether that payment gives rise to a deemed loan. It is in the government's interest to clarify that question, to ensure that taxpayers take consistent positions.

2. Distinguishing Between "Swaps.". The deemed loan rules described above apply only to NPCs that are subject to Treasury regulation $\S 1.446-3$. Actually, they apply only to a subset of such NPCs, namely NPCs that qualify as "swaps," as NPCs include caps and floors that are not subject to the deemed loan rule. As anyone familiar with derivatives knows, drawing distinctions between different kinds of derivatives is not always easy. Accordingly, the boundary between derivatives that are and are not subject to these rules is hazy.

Resolving where that boundary lies is a task beyond what it is reasonable to either discuss in this article or expect the government to provide guidance on as a general matter. It would be comforting, however, if guidance provided that the Service would not challenge a reasonable determination made by the taxpayer for purposes of applying the rules listed at the beginning of this Part IV when an upfront payment is made under a cleared swap.

3. Special Attributes of Cleared Swaps. The deemed loan rules assume a fairly static universe. That is, they treat an upfront payment on an interest rate swap as if it will economically be paid back over the contractual life of the swap. This is not quite accurate, since there is a special rule that says in the case of a swap subject to extension or termination one looks to the reasonably expected term of the swap rather than the stated maturity. ${ }^{148}$ But for a swap with no stated extension or termination provisions the loan is treated as payable over the stated term of the swap. While swaps can be and are closed out early, for a swap entered into in the OTC market that seems like a reasonable, and the only practical, basis for determining the term of the deemed loan.

In the case of cleared swaps, particularly for taxpayers that regularly enter into and close out swaps in high numbers, that approach is

\footnotetext{
${ }^{147}$ Treas. Reg. $\S 1.446-3(\mathrm{~g})(6)$, Example 3 (1994).

${ }^{148}$ Treas. Reg. § 1.446-3(f)(3) (1994).
} 
not so reasonable. Under current market practice, this point is particularly relevant to CDS, but the more general issue is relevant for other types of swaps as well.

As described in Section II.A.2, above, long and short positions in cleared CDS are netted on a daily basis. To take an example, assume a dealer on day 1 sells protection under the CDS described in Example 1 in connection with a customer transaction, and receives the $\$ 244,000$ upfront payment. On the next day, the dealer buys protection under an identical CDS in connection with a second customer transaction. Because the market's perception of the creditworthiness of the reference entity has changed, the dealer pays a $\$ 250,000$ upfront payment. The clearinghouse will net the two transactions, with the result that the dealer has no outstanding CDS, and has paid $\$ 6,000$ on a net basis. (If in the second transaction the dealer paid $\$ 240,000$, the transactions would also net, but the dealer would have paid $\$ 4,000$ on a net basis.)

Since dealers routinely enter into many transactions, and the clearinghouses net positions on a daily or more frequent basis, the result is that it is impossible to determine for what period of time any upfront payment actually will relate to. Indeed, the one thing one can probably be reasonably sure about is that whatever the analysis might be on day 1 , it will be modified by the next day's transaction. Similarly, in the case of dealers who operate in such a manner that one affiliate enters into transactions with certain customers but a different affiliate is the one that faces the clearinghouse, so that the first affiliate routinely enters into multiple CDS with the other to hedge its position, upfront payments made and received on different days also will regularly net as an economic matter and may net as a legal matter. Hedge funds or other active market participants in the swap market also are likely to transact in a manner that results in netting of outstanding contracts on a regular basis.

A possible response to these facts would be to shrug. After all, it is not uncommon for issuers of debt to redeem it early, whether voluntarily or pursuant to the terms of the debt instrument. Moreover, it is not so easy to see what other rule should be adopted. Even if one concluded that an upfront payment for a taxpayer of this kind is really a short-term debt instrument, that would not answer the question of how to determine the amount of interest deemed to accrue on that debt instrument.

Alternatively, one might conclude that in this setting it is not appropriate to impute a loan or to impute interest, at least for taxpayers of the kind described above. That raises the more general question of why it is appropriate to do so for NPCs in the first place. If it is correct that the principal reason for the deemed loan construct is to prevent related parties from avoiding withholding tax on interest, a more narrowly targeted rule could serve that purpose without raising the many questions identified above.

C. Additional Issues for CDS.

1. Do the Deemed Loan Rules Apply? As noted above, the deemed loan rules apply only to NPCs that qualify as "swaps," 
and it is unclear whether a CDS is properly treated as an NPC, an option, or possibly some other kind of miscellaneous derivative financial instrument. For this reason if no other, therefore, the proper treatment of cleared CDS with upfront payments is more difficult than for other cleared swaps. As it happens, the question of whether one specific type of CDS should be treated as an NPC or as an option for U.S. federal income tax purposes has been raised in litigation in bankruptcy court, under circumstances that not only make the answer to that question a do-or-die matter for the taxpayer in question but also may have very significant financial consequences for its counterparties.

The bankrupt taxpayer is Ambac Financial Group, Inc., a "monoline" insurer. Like other U.S. monolines, Ambac's core business was historically to provide financial guarantee insurance to investors in municipal bonds. During the heyday of mortgage securitizations, however, Ambac began to write CDS on mortgage-backed securities. That expansion of its business proved ill-fated, and Ambac engaged first in a number of out-of-court settlements with its CDS counterparties and ultimately sought bankruptcy protection.

According to Ambac's financial statements, Ambac's court filings and published news reports, ${ }^{149}$ one of Ambac's most important assets is a $\$ 700$ million refund that it has received as a result of losses on a type of CDS contract known as a "pay as you go" (or PAYGO) CDS. Ambac began to write (non-PAYGO) CDS in 1999, through a non-insurance subsidiary. Ambac treated these CDS as options for tax purposes, and that treatment was reviewed and approved by the IRS through 2004. As a result, Ambac treated CDS premiums received as giving rise to income (presumably capital gain) when the contract was terminated or expired. In 2005 Ambac began to write PAYGO CDS, which it also treated as options for tax purposes. In 2007, Ambac began to experience losses on its PAYGO CDS. In 2008, Ambac adopted the position that PAYGO CDS were properly characterized not as options but instead as NPCs, and began to take losses (but not income) on those CDS on a current basis in a manner consistent with its recognition of those losses for insurance regulatory purposes. Ambac then applied for tentative carryback adjustments based on these net operating losses, and to date has received about $\$ 700$ million in refunds.

In late October of 2010, Ambac was contacted by the IRS for information about its change of position on the characterization on the

\footnotetext{
${ }^{149}$ The following description is based on those sources, in particular AMBAC FinANCIAL GROUP, InC. 2008 ANNUAL REPORT 157-62 (Income Tax note to Ambac's 2008 financial statements), available at http://www.ambac.com/pdfs/87730_ambac10K.PDF; Complaint for Injunctive Relief and Declaratory Judgment Determining Amount of Tax Relief, Ambac Financial Group, Inc. v. United States, Adversary Proceeding 10- , (U.S. Bankruptcy Court, S.D.N.Y.) (Nov. 9, 2010); Jonathan Stempel, Ambac sues U.S. and says IRS may ruin bankruptcy, REUTERS, Nov. 9, 2010, available at http://www.reuters.com/article/idUSTRE6A75EW20101109; Erik Holm and Eric Morath, Ambac Files for Chapter 11, WALl StReEt Journal, Nov. 9, 2010, available at http://online.wsj.com/article/0,,SB10001424052748703514904575602911478916800,00.ht $\mathrm{ml}$.
} 
PAYGO CDS. The IRS also informed Ambac that it was questioning the propriety of the tax refunds and was investigating whether to seek to recoup the tax refunds. Ambac then realized that under the rules applicable to tentative carryback adjustments, the IRS could summarily assess a deficiency, without notice, and impose a levy and attachment on Ambac's assets. Ambac concluded that the effect of such a levy and attachment would be to destroy or seriously jeopardize its ability to reorganize. Ambac therefore accelerated its bankruptcy filing to early November 2010, and is seeking court orders that would allow it to keep the refunds, among other matters. Thus, it is possible that the Ambac litigation will provide the first formal insight into the U.S. federal income tax characterization of at least one type of CDS, although there are also other issues in the litigation that if resolved adversely to Ambac would mean that that issue will not be addressed.

Ambac presumably believed that it had a sound basis for originally treating the PAYGO CDS as options. The fact that the IRS had approved option treatment for its other CDS no doubt played a role in that regard. When Ambac decided to treat PAYGO CDS as NPCs in 2008, however, it did so on the basis of an opinion from one of the "Big Four" accounting firms, KPMG. The Ambac history thus vividly illustrates the uncertain tax status of CDS.

In the absence of a ruling based on principles that apply to CDS generally, uncertainty as to the tax characterization of CDS, and therefore whether the deemed loan rules apply, seems like to continue for some time. That question may be informed by the difficulty of determining what the terms of any such deemed loan would be.

2. If There is a Loan, What are its Terms? The difficulty in determining the terms of a deemed loan arising from an upfront payment on a cleared CDS can be illustrated by turning back to the three examples described in Section II.C.2(c), above. Each of them involved a CDS where the market quoted level differed by 75 basis points from the standardized coupon. However, the upfront payment on each of them was a different amount--\$244,000 for Example 1, \$335,000 for Example 2, and $\$ 377,000$ for Example 3. If one now tries to convert the upfront payment back into a stream of payments on a deemed loan for tax purposes, it is difficult to conclude that each of those three different upfront payments should be treated as the equivalent of an annuity or installment loan consisting of the same stream of 75 basis point to maturity. That is, it would be surprising to conclude that if $\$ 244,000$ represents the present value of a stream of 75 basis points for 5 years, $\$ 335,000$ also represents the present value of that same stream of payments. As described in the discussion of these examples earlier, the explanation for this discrepancy is that the market does not assume an equal likelihood that the notional stream of 75 basis points would be made for the entire tenor of the CDS.

A possible way to deal with this inconvenient fact would be to reconvert each upfront payment into a stream of $X$ (not 75) basis points over the maximum life of the CDS, in an amount that would differ for each example because each of them reflects the present value of a different 
stream of payments. Remember, however, that the regulations that treat an upfront payment as a deemed loan also restate the terms of the related swap so that they have market terms. That would not be the case if the deemed loan payments were treated as, hypothetically, 50 basis points for Example 1, 60 basis points for Example 2 and 65 basis points for Example 3.

Moreover, treating each of these upfront payments as representing a stream of 75 basis points would have the merit of a rule anchored to the real market pricing for these CDS. If one therefore assumed that the best answer is to reverse engineer what the market has done, and to treat the upfront payment as repaid in 75 basis point increments over some period of time, new questions arise that would also have to be addressed in any such guidance. Since the upfront payments are in different amounts, would each case result in a stream of 75 basis point deemed payments for a different period of time? Or would each of them be treated as giving rise to deemed 75 basis points payments for the full tenor of the CDS?

Let us assume that the upfront payment in Example $1(\$ 244,000)$ would be treated as equivalent to an annuity paying 75 basis point coupons for 3 years, the upfront payment in Example $2(\$ 335,000)$ would be treated as equivalent to a similar annuity but for 4 years, and the upfront payment in Example $3(\$ 377,000)$ would be treated as equivalent to a similar annuity but for 4.5 years. What happens if the CDS in Example 1 survives for more than 3 years? Does the deemed annuity continue? Or is the CDS treated as reissued at year 3 ?

Some support for this approach-same payment amount, over different periods - can be found in the NPC timing regulations, because they provide that for purposes of recognizing a nonperiodic payment over the term of an NPC, the term of an NPC that is subject to termination is the reasonably expected term of the contract. ${ }^{150}$ On the other hand, the deemed loan rule provides that the deemed at-market swap must provide for level payments, which would not be the case if the swap in Example 1 remained in existence for more than 3 years unless the swap were treated as reissued at year 3. This approach does not seem like the likely right answer.

Now let us consider the alternative, under which the annuity is deemed to be payable in all three examples over the full five-year term of the CDS. We know that there is uncertainty about whether the annuity will in fact be paid over the entire term, with the highest risk in Example 1. Given the uncertainty as to whether the "lender" will be "repaid" in full, does the deemed loan give rise to contingent payment debt subject to Treasury Regulation § 1.1275-4 (one fervently hopes not)? More significantly, is this debt at all? It can be compared to a credit-linked note, with a payout of zero if the credit event arises. Or it could be compared to an interest-only obligation (an "IO") on a prepayable debt instrument, where the trigger for terminating payments is not repayment of debt but a credit event.

${ }^{150}$ Treas. Reg. § 1.446-3(f)(3) (1994). The regulation does not specify who determines what the reasonably expected term is, leading to the possibility that different parties to an NPC will take different positions. 
There are, as it happens, some tax rules for IOs. For example, IOs issued under the REMIC rules are statutorily treated as debt, like other regular interests in the REMIC. ${ }^{151}$ IOs can also arise pursuant to the bond stripping rules of $\S 1286$. Most IOs under current market practice probably provide for payments based on pools of prepayable debt instruments, and thus either explicitly or by analogy can be handled to at least some extent under the rules of $\S 1272(a)(6)$. That would not be the case for an annuity deemed to arise under a CDS. Moreover, the rules for taxing IOs are not themselves a model of clarity, as evidenced by a request by the Service in 2004 for comments from taxpayers on a variety of issues. ${ }^{152}$ The request states in its introduction that "REMIC IOs present novel and difficult questions in the application of tax rules that were designed primarily to account for instruments that qualify as debt under traditional tax principles." Similarly, the rules for contingent payment debt instruments reserve on the question of how to treat most timing contingencies. ${ }^{153}$

In short, while it is quite possible to come up with a scheme under which an upfront payment is reconverted back into an annuity of some kind, and to devise a method for determining what portion of the annuity payments constitute principal and what portion constitute interest, there are at present no rules that do so. Equally significantly for taxpayers that might hazard the attempt, there are no real analogies, or at least none with tax treatment that is certain, to which the taxpayer might look to take comfort that its invented method clearly reflects income. In the absence of any guidance from the government on even the most basic of questions on the taxation of CDS, and acknowledging that these issues are not easy ones to resolve, it is hard to believe any court would hold taxpayers accountable for not divining what those rules should be, in the absence of some obviously abusive transaction.

That is not to say that the government is without power to write rules requiring any one of the alternatives discussed above, or perhaps another one. Such rules presumably would be issued over the usual measured timeframe, first in proposed form and then in final form with a delayed effective date to allow taxpayers to modify their computer systems and get their paperwork in order. That is very different, however, from the question of whether current law requires such an approach.

3. What About the Proposed Swap Regulations? An article published earlier this year has pointed out another uncertainty about how to treat an upfront payment on a CDS, having to do with the possible application of the proposed regulations dealing with swaps with contingent nonperiodic payments that are described above in Section I.B.1. ${ }^{154}$ As the article explains in some detail, if CDS are subject to those rules, and if the effect of such treatment were to require the protection seller to impute an

${ }^{151}$ I.R.C. $\S 860 \mathrm{~B}(\mathrm{a})$ (2010) (REMIC regular interest taxed as debt); I.R.C. $\S$

$860 \mathrm{G}(\mathrm{a})(1)(\mathrm{B})(\mathrm{ii})$ (2010) (providing authority to treat IOs as REMIC regular interests).

${ }_{152}^{15}$ I.R.S. Announcement 2004-75, 2004-2 C.B. 580.

${ }^{153}$ Treas. Reg. § 1.1275-4(b)(9)(iii) (2004).

${ }^{154}$ See Alan B. Munro, Revisiting Tax Considerations Regarding Credit Default Swaps, 1 Derivatives \& Fin. Instruments, Jan.-Feb. 2010, at 9. 
expense as a result of the possibility that the protection seller would have to make a settlement payment at some point in the future, the amount of the upfront payment for tax purposes might differ from the cash amount. Returning to the example of a CDS in which Party B as protection seller receives an upfront payment of $\$ 335,000$, if these rules applied, Party $B$ would be required to accrue some expense in respect to the contingent future settlement payment. Depending on how that expense is allocated, either the upfront payment might be treated as less than $\$ 335,000$ or the deemed at-market swap might be treated as paying less to Party B than would otherwise be the case. Either of these would complicate the effort to determine how to reconvert the upfront payment into an annuity.

Note further that the proposed regulations would apply only if a cash settlement payment were treated as a nonperiodic payment and not a termination payment, which is not clear. A termination payment is defined generally as a payment to assign or extinguish an NPC. Proposed regulations make clear (sensibly), however, that a periodic payment that happens to be paid at the maturity of an NPC is not a termination payment. ${ }^{155}$ It is also evident from the proposed regulations that a contingent nonperiodic payment made at the maturity of an NPC such as an equity swap is not treated as a termination payment. A termination payment is not, therefore, just any payment that happens to be made at the point when the taxpayer happens to terminate its interest in an NPC. Rather, the concept seems to be that a termination payment is an unscheduled payment not provided for in the terms of the NPC.

It has become common, however, for equity swaps to provide express terms under which a counterparty may terminate the swap early. Since dealers typically permit their customers to terminate swaps early in any event, the purpose of this provision is primarily to set out the terms under which the early termination payment will be calculated. Market practice is to treat these payments as termination payments, which seems right. Coming back to CDS, then, how should one treat an unscheduled settlement payment that $i$ provided for in the terms of the CDS? It seems closer to a termination payment than a nonperiodic payment, but the answer is not clear.

${ }^{155}$ Prop. Treas. Reg. § 1.1234A-1(b), 69 Fed. Reg. 8886, 8898 (Feb. 26, 2004). 


\section{Clearing an At-Market Interest Rate Swap}

Market rate is $6 \%$ vs LIBOR

Step 1 Negotiation of bilateral OTC swap on $\$ 100 \mathrm{~m}$ notional principal amount

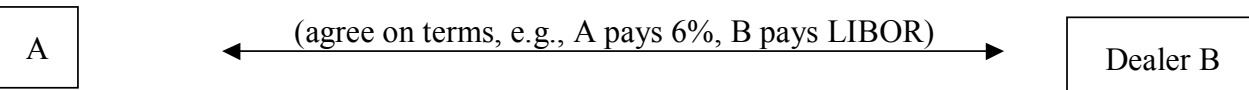

Step 2 Novation to Clearinghouse

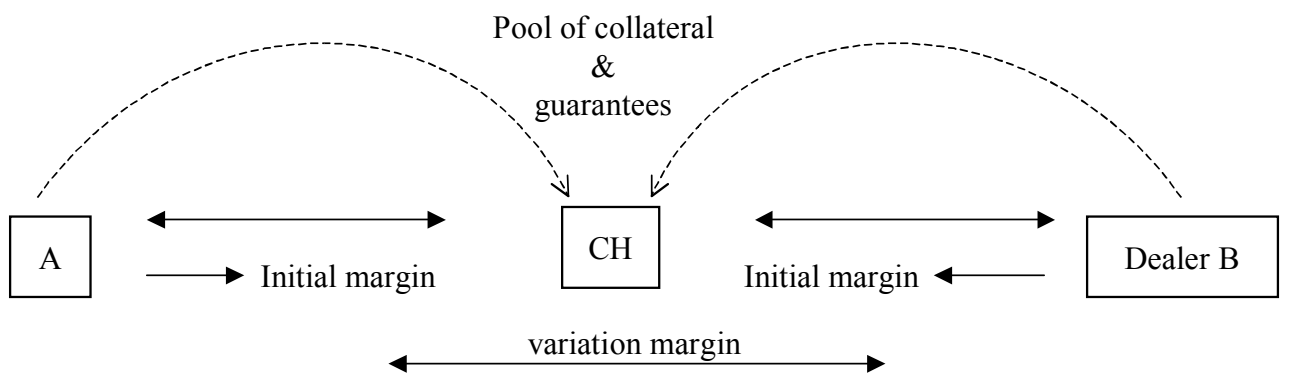




\section{Clearing an Off-Market Interest Rate Swap}

Market rate is $6 \%$ vs LIBOR

Step 1 Negotiation of bilateral OTC swap on \$100m notional principal amount

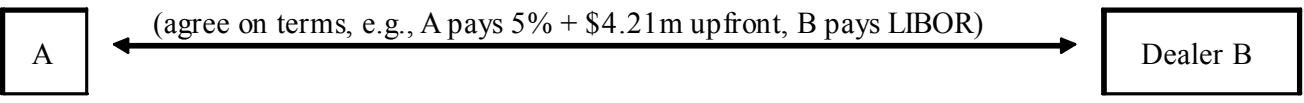

Step 2 Novation to Clearinghouse
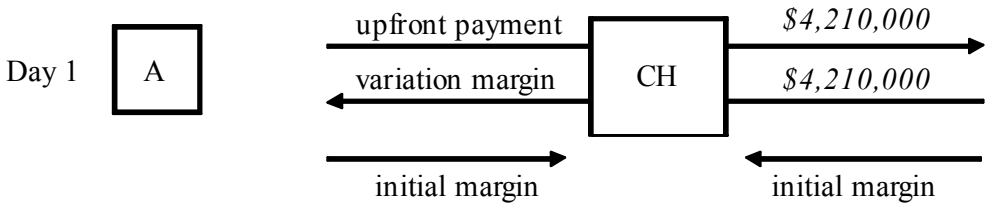

Dealer B
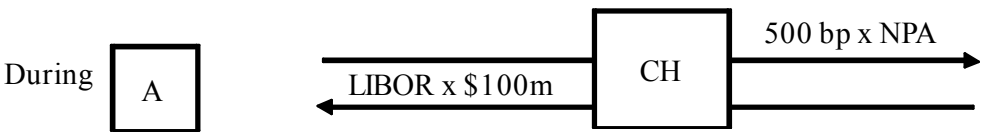

Dealer B 


\section{CDS Clearing}

Step 1 Negotiation of bilateral OTC CDS

PB

$\mathrm{A}$

$\stackrel{\text { (agree on terms, e.g., A pays } 175 \mathrm{bp} \text { ) }}{\longleftrightarrow}$

PS

Dealer B

Step 2 Novation to Clearinghouse

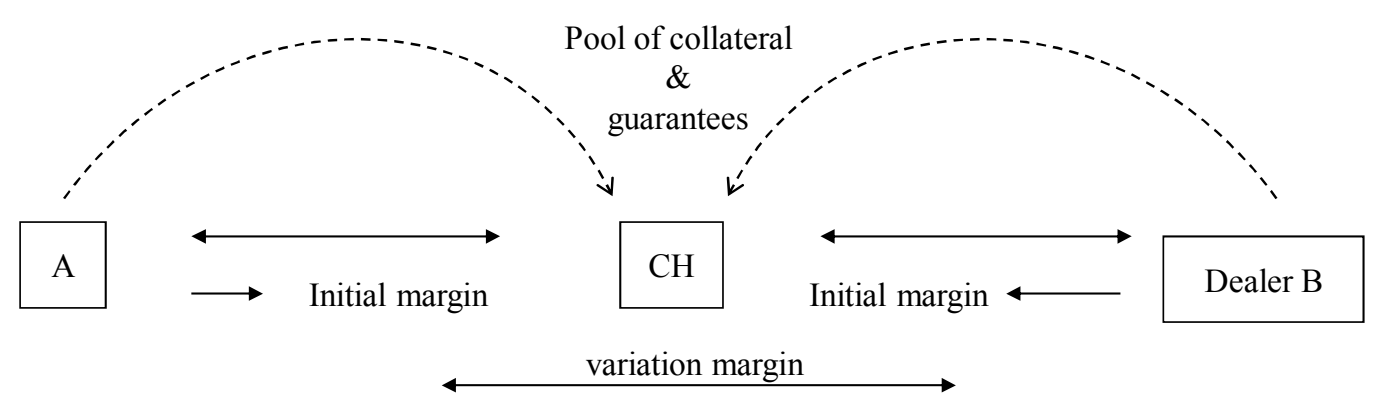




\section{CDS Coupon Standardization}

Example 1 (market level 575 bp; standard coupon 500 bp)
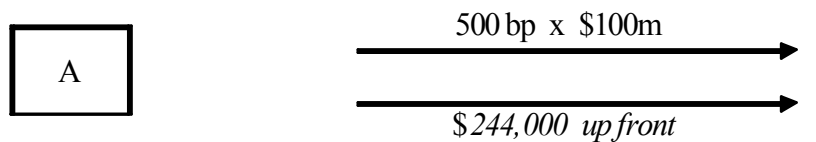

Dealer B

$\underline{\text { Example } 2}$ (market level 175 bp; standard coupon 100 bp)
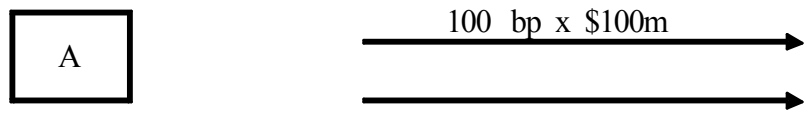

$\$ 335,000$ up front

Dealer B

Example 3 (market level 25 bp; standard coupon 100 bp)

A

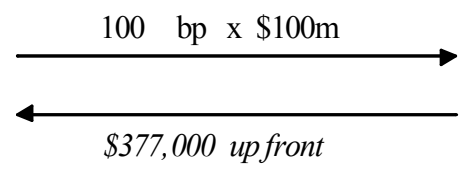

Dealer B 


\section{CDS Clearing - Putting It Together}

Market level 575 bp; standard coupon 500 bp; \$100m NPA
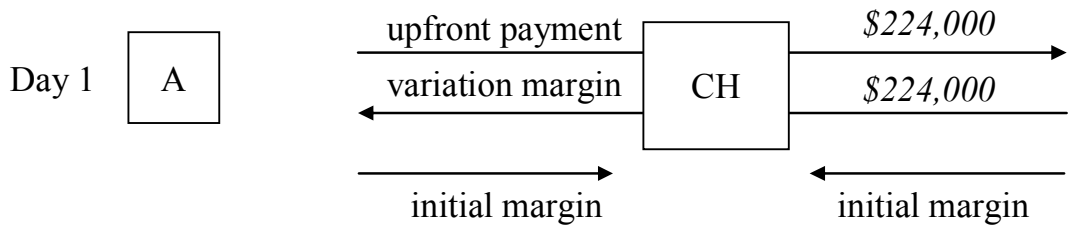

Dealer B
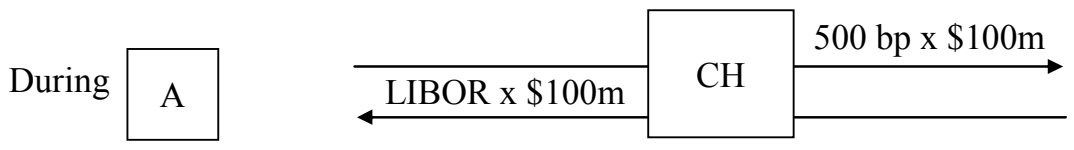

Dealer B 